\title{
Effects of diameter and cross-sectional partitioning on active noise control in round ducts
}

Jeremy Michael Slagley

West Virginia University

Follow this and additional works at: https://researchrepository.wvu.edu/etd

\section{Recommended Citation}

Slagley, Jeremy Michael, "Effects of diameter and cross-sectional partitioning on active noise control in round ducts" (2006). Graduate Theses, Dissertations, and Problem Reports. 2422.

https://researchrepository.wvu.edu/etd/2422

This Dissertation is protected by copyright and/or related rights. It has been brought to you by the The Research Repository @ WVU with permission from the rights-holder(s). You are free to use this Dissertation in any way that is permitted by the copyright and related rights legislation that applies to your use. For other uses you must obtain permission from the rights-holder(s) directly, unless additional rights are indicated by a Creative Commons license in the record and/ or on the work itself. This Dissertation has been accepted for inclusion in WVU Graduate Theses, Dissertations, and Problem Reports collection by an authorized administrator of The Research Repository @ WVU.

For more information, please contact researchrepository@mail.wvu.edu. 


\title{
EFFECTS OF DIAMETER AND CROSS-SECTIONAL PARTITIONING ON ACTIVE NOISE CONTROL IN ROUND DUCTS
}

\author{
by \\ Jeremy Michael Slagley \\ Dissertation submitted to the College of Engineering and Mineral Resources \\ at West Virginia University \\ in partial fulfillment of the requirements \\ for the degree of \\ Doctor of Philosophy \\ in \\ Occupational Safety and Health
}

Approved by

Stephen E. Guffey, PhD, Committee Chairperson

Warren R. Myers, PhD

Wafik H. Iskander, PhD

Gary L. Winn, PhD

Efrem R. Reeves, PhD

Department of Industrial and Management Systems Engineering

Morgantown, West Virginia

2006

Keywords: Active Noise Control, Ducts, Axial Vane Splitters, Cross-sectional Partitioning

Disclaimer: "The views expressed in this dissertation are those of the author and do not necessarily reflect the official policy or position of the Air Force, the Department of Defense or the U.S. Government." 
Abstract

\section{EFFECTS OF DIAMETER AND CROSS-SECTIONAL PARTITIONING ON ACTIVE NOISE CONTROL IN ROUND DUCTS}

\section{by Jeremy M. Slagley}

Active noise control (ANC) is particularly useful in hard-walled ducts where plane waves propagate. Higher order mode waves are much more difficult to control. Basic acoustic principles dictate that the cut-on frequency at which higher order modes will first begin to eclipse simple plane waves in a duct will be determined by the cross-sectional diameter of the duct. The lowest frequency for higher order modes will increase as duct diameter decreases. Therefore, the range of frequencies where plane waves dominate will be greater and effective control using ANC better as duct diameter decreases. The result is that somewhat higher frequencies can be controlled with ANC for smaller diameters. To test those suppositions, a commercially-available ANC system was used to reduce random noise in round ducts having five different diameters. Results showed that insertion loss (IL) ranged from 5 to $30 \mathrm{~dB}$ in frequencies ranging from $40-1000 \mathrm{~Hz}$, and varied inversely with size as expected. The same tests were conducted on a rectangular duct with one cross-sectional dimension fixed and one varied at seven different sizes. Results showed similar IL from 5 to $30 \mathrm{~dB}$ that varied inversely with size. If smaller diameters have broader frequency ranges that can be controlled with ANC, perhaps one could extend the frequency range for a large cross-section by partitioning it into smaller cross-sections. This hypothesis was tested by two methods of cross-sectional partitioning. Partitioning was achieved in one design by inserting a smaller duct inside a large duct. In a second design, a cross-shaped partition was inserted inside the large duct. ANC IL results were 1.7 to $2 \mathrm{~dB}$ better for the large duct partitioned by a smaller inner duct than the large duct alone ( $p=0.0146$ for low frequency and $p=0.0333$ for high frequency). ANC insertion loss was $5.8 \mathrm{~dB}$ better for the large duct partitioned by a cross-shaped splitter at high frequencies than the large duct alone $(\mathrm{p}=0.0003)$. However, the cross-shaped partition system was $5.6 \mathrm{~dB}$ less effective at low frequencies than the large duct ANC IL alone $(\mathrm{p}<0.0001)$. 


\section{DEDICATION}

The author wishes to dedicate this work to his father, Charles A. Slagley, Jr., who passed away after a short struggle with cancer on 16 Jan 2005. He was an educator and inspiration to many, selected as Illinois Secondary School Principal of the Year for 2003. This work is also dedicated to the author's fifth child, Rosemary Claire, who was born in August, 2004. She reminded us all of the joys of life in this valley of tears. Her "Buka" got to hold her before he died. 


\section{ACKNOWLEDGMENTS}

The author wishes to acknowledge some of the many people and organizations who contributed to or facilitated the work herein. Firstly, I acknowledge my utter dependence on Almighty God. I am also eternally indebted to His Mom, the Blessed Virgin Mary, the Theotokos. Secondly, I thank my patient wife and five children (and another due July 2006). I am also indebted to my country in whose service I have remained almost seventeen years, and the generous scholarship from the US Air Force which has allowed me to pursue this academic degree and the research here. Here at West Virginia University, Dr. Steve Guffey's enormous talent and kindly sharing of both professional and personal time and thoughts have served to mold me into a better candidate. Indeed the entire staff of the university and especially the members of my committee have helped my development enormously. The friendship and assistance of many fellow graduate students including Amit Hegde, Ahmed ElSotouhy, Sumeeth Sivanagere, and Vivek Balasubramanian has been uplifting. I would also like to gratefully acknowledge NIOSH Grant 1-R01-OH07732 and a scholarship from the National Hearing Conservation Association which helped finance this research. Lastly, in pursuing the aims of the NIOSH grant, I appreciate the assistance and cooperation of the local Mine Safety and Health Administration (MSHA) district, several MSHA and NIOSH offices, two unnamed coal mining companies, and Dr. Yi Luo of the Department of Mining Engineering. 


\section{TABLE OF CONTENTS}

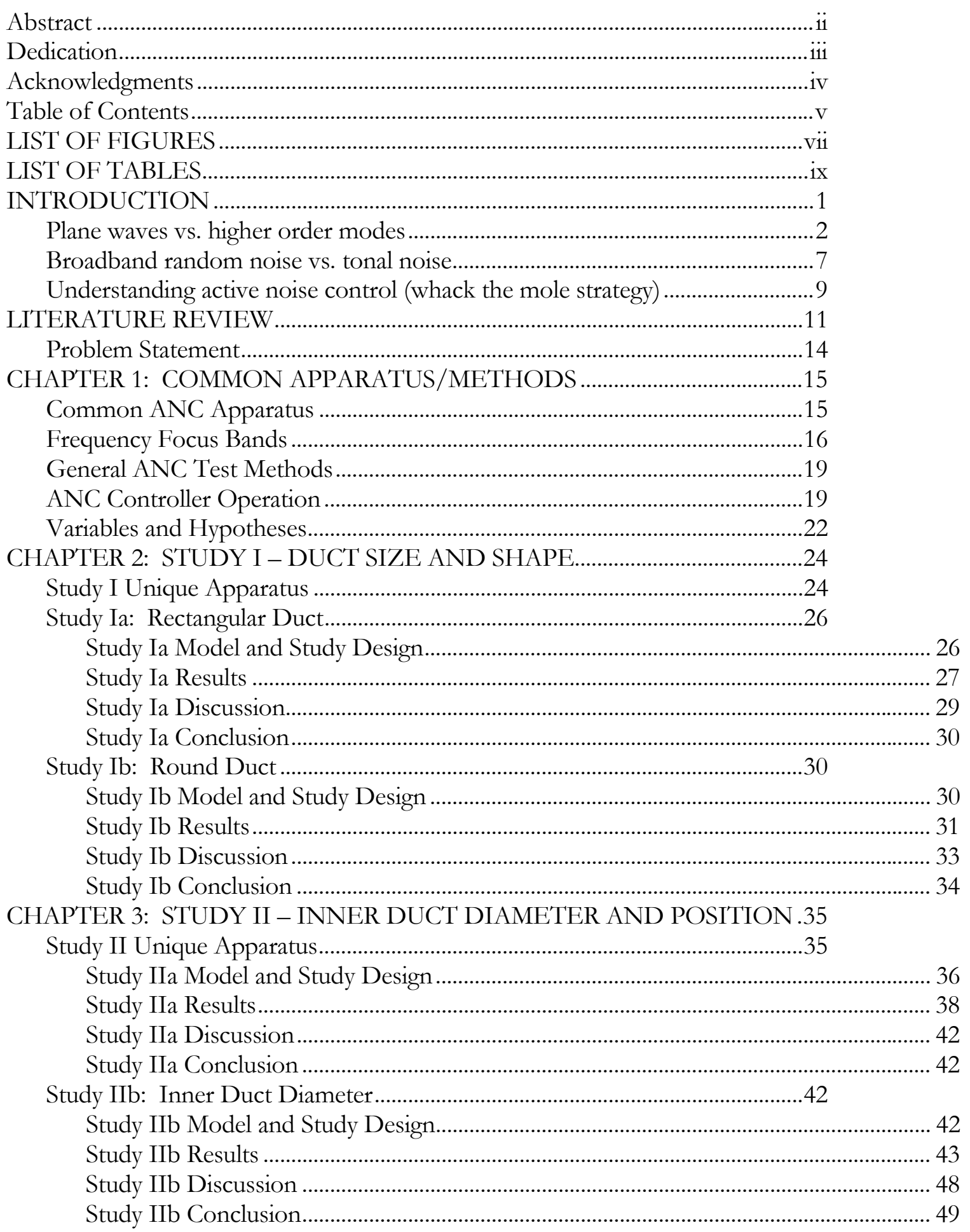


CHAPTER 4: STUDY III - SIMULTANEOUS DUAL-DUCT OPERATION50

Study III Unique Apparatus ..................................................................................50

Study IIIa: Simultaneous Dual-duct Operation.....................................................53

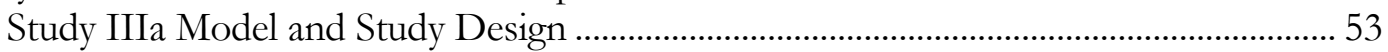

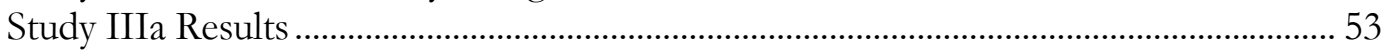

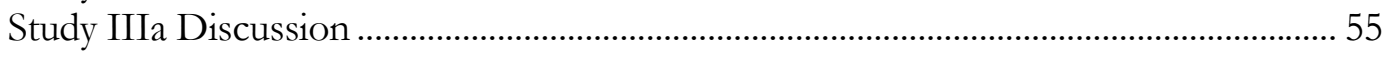

Study IIIa Conclusion ....................................................................................................... 57

Study IIIb: Simultaneous Dual-duct Operation with Reduced Hardware .....57

Study IIIb Model and Study Design ............................................................................. 57

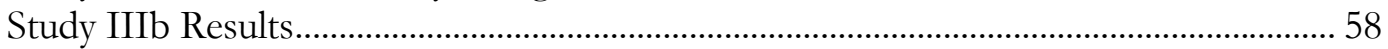

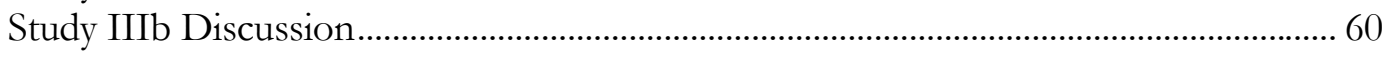

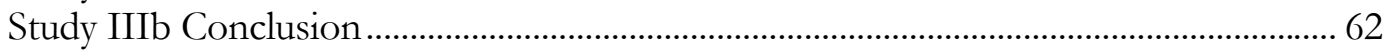

CHAPTER 5: STUDY IV - CROSS-SHAPED SPLITTER .............................63

Study IV Unique Apparatus ...................................................................................63

Study IV Model and Study Design......................................................................64

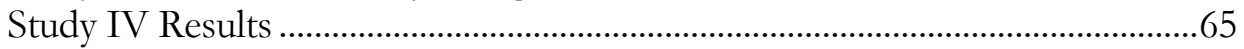

Study IV Discussion .......................................................................................68

Study IV Conclusion...........................................................................................6

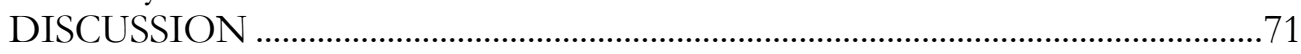

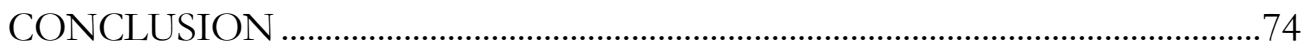

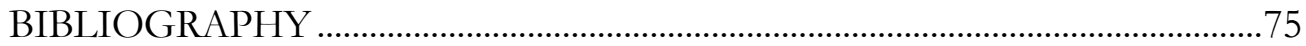




\section{LIST OF FIGURES}

Figure 1. Round duct plane wave vs. higher order mode regions...................................................

Figure 2. Rectangular duct plane wave vs. higher order mode regions.............................................5

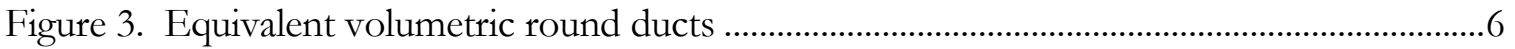

Figure 4. Cross-sectional partitioning schemes for round ducts ...................................................

Figure 5. Effects of bandwidth on active noise control insertion loss ..........................................8

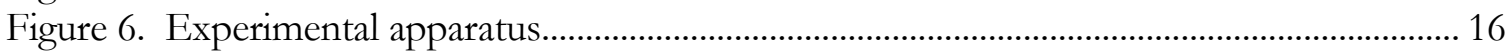

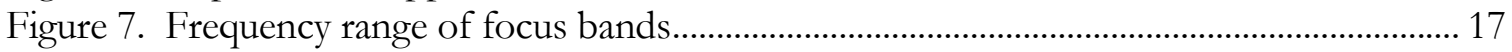

Figure 8. Comparison of IL results presentation methods ........................................................... 18

Figure 9. Example of good transfer function model weights signal............................................... 21

Figure 10. Study Ia Apparatus, Cross-sectional view of rectangular duct apparatus................... 25

Figure 11. Study Ia Apparatus, Side view of microphone mounting methods ........................... 25

Figure 12. Study Ia Results, $\mathrm{IL}_{\max }$ by rectangular cross-sectional width ........................................ 27

Figure 13. Study Ib Results, $\mathrm{IL}_{\max }$ by round duct diameter ............................................................ 32

Figure 14. Study IIa Apparatus, End view of concentric vs. tangent inner duct position ........ 36

Figure 15. Study IIb Apparatus, Inner duct diameter apparatus ................................................... 36

Figure 16. Study IIa Results, $\mathrm{IL}_{\max }$ by inner duct position and diameter ........................................ 39

Figure 17. Study IIa Results, low frequency residuals vs predicted values for inner duct position and diameter study ................................................................................................... 40

Figure 18. Study IIa Results, high frequency residuals vs. predicted values for inner duct

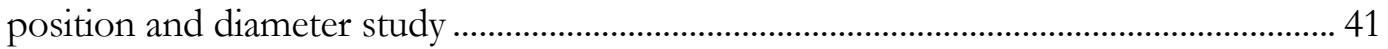

Figure 19. Study IIb Results, $\mathrm{IL}_{\max }$ by inner duct diameter ............................................................... 44

Figure 20. Study IIb Results, Low frequency inner duct diameter data treatment means comparisons with sketches of treatment conditions ............................................................... 46

Figure 21. Study IIb Results, High frequency inner duct diameter data treatment means

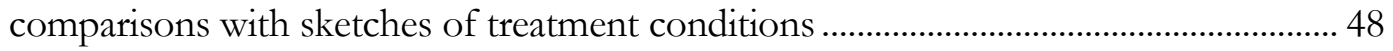

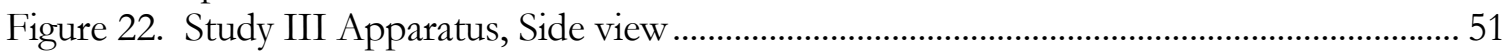

Figure 23. Study III Apparatus, end view of apparatus with control speakers............................. 52

Figure 24. Study IIIa Results, Low frequency comparison of $\mathrm{IL}_{\max }$ by treatment (Dual 12 inch full hardware system vs. 18 inch single system)............................................................. 54

Figure 25. Study IIIa Results, High frequency comparison of $\mathrm{IL}_{\max }$ by treatment (Dual 12 inch full hardware system vs. 18 inch single system)................................................................... 55

Figure 26. Study IIIa Results, ANC insertion loss by 1/3 octave bands (Dual 12 inch full hardware system vs. 18 inch single system) .......................................................................... 56

Figure 27. Study IIIb Results, Low frequency comparison of $\mathrm{IL}_{\max }$ by treatment (Dual 12 inch reduced hardware system vs. 18 inch single system) ………………………….................. 59

Figure 28. Study IIIb Results, High frequency comparison of $\mathrm{IL}_{\max }$ by treatment (Dual 12 inch reduced hardware system vs. 18 inch single system) ........................................................ 60

Figure 29. Study IIIb Results, ANC insertion loss by $1 / 3$ octave bands (Dual 12 inch reduced

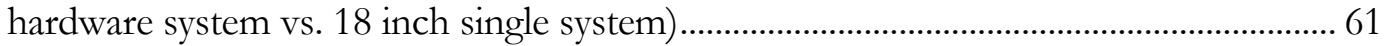

Figure 30. Study IV Apparatus, End view of comparison treatments ............................................ 64

Figure 31. Study IV Results, Low frequency comparison of $\mathrm{IL}_{\max }$ by treatment (Single

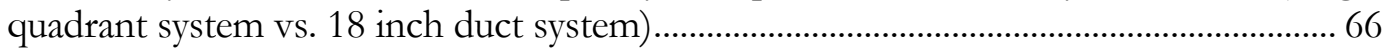


Figure 32. Study IV Results, High frequency comparison of $\mathrm{IL}_{\max }$ by treatment (Single

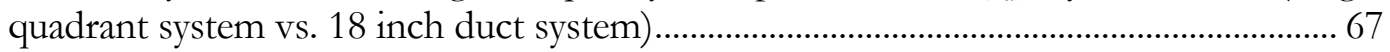

Figure 33. Study IV Results, ANC insertion loss by $1 / 3$ octave bands (Single quadrant system vs. 18 inch duct system) 


\section{LIST OF TABLES}

Table 1. Range of frequencies used to "focus" ANC controller................................................... 16

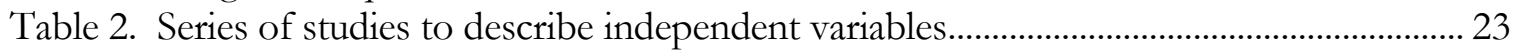

Table 3. Second higher order mode cut-on frequency by cross-sectional width ......................... 29

Table 4. Estimated first higher order mode cut-on frequencies and maximum plane wave dominant frequencies by duct diameter ............................................................................. 34

Table 5. Study IIa Results, p-values for inner duct position and diameter ANOVA tests ....... 42

Table 6. Study IIb Results, Multiple comparison groups of inner duct diameter treatment means for low frequency ANC insertion loss data ............................................................... 45

Table 7. Study IIb Results, Multiple comparison groups of inner duct diameter treatment means for high frequency ANC insertion loss data................................................................. 47

Table 8. p-values and summary results from all studies to describe independent variables ..... 71

Table 9. Number of ducts needed to equal the cross-sectional area of an 18 inch diameter duct 73 


\section{INTRODUCTION}

Noise is a ubiquitous occupational and environmental hazard. While personal protective equipment (hearing protection) can control the hazard, some researchers indicate that there are strong workplace cultural factors that preclude their proper use (Royster and Royster, 2000; Patel et al., 2001). It is therefore more effective to devise engineering controls for noise hazards. Engineering controls for noise can be divided into active and passive methods. Passive methods reduce noise by either transmission loss through dense materials or by absorption of reflected waves, or both. Passive controls are more practical for frequencies at or above $1000 \mathrm{~Hz}$ (Driscoll and Royster, 2000).

Active methods use an out-of-phase countering signal to reduce the offending noise. The actual active noise control (ANC) insertion loss (IL) was initially presumed to be through destructive interference of the primary source wave with the secondary out-of-phase control wave. However, it may also be that the primary wave is cancelled by its own reflection from the change in impedance, or resistance to flow, directly in front of the secondary control speaker. The impedance change comes from the speaker itself causing pressure fluctuations as it vibrates. When an acoustic wave encounters any pressure change, such as at the end of a duct or a change in diameter, part of the wave reflects. Additionally, reduction of the primary wave may be a result of the secondary source "unloading" the primary noise source by changing its radiation impedance, consequently reducing the overall sound power output (Snyder and Hansen, 1989; Snyder and Tanaka, 1993).

In any event, ANC works better at frequencies below $500 \mathrm{~Hz}$ (Hansen 2001) than for higher frequencies. This is due to the longer wavelengths of low frequency noise, which makes them more predictable for ANC control, as will be discussed later. Compared to passive controls, ANC also has the attractive feature of being less bulky and offering less additional resistance to air flow in duct applications. However, unlike passive controls, for which dimensions are not necessarily important to effectiveness, the success of ANC methods is dependent on the physical dimensions of the space in which noise is to be controlled. ANC is easiest to apply and generally produces the greatest degree of noise reduction in closed channels of limited cross-section (Hansen, 2001). These conditions are present in ducts, so it is not surprising that most examples of successful ANC applications are in noisy ducts 
(Gordon and Vining, 1992; Pelton et al., 1994; Driscoll and Royster, 2000; Hansen, 2001). A very common field application is reducing noise escaping from exhaust stacks, especially for cases where the main goal is to reduce fan noise contributions to community noise (Gordon and Vining, 1992). It is also used for cases where the goal is to reduce HVAC system noise to increase comfort of building occupants (Pelton et al., 1994). The effectiveness of ANC applications depends heavily on (a) the ability to sample a sound wave at one point and predict what it will be at a later location, and (b) the bandwidth, or how many target frequencies are included in the range. The ability to predict waves depends on the type of wave, while the bandwidth is dependent on the noise source.

\section{Plane waves vs. higher order modes}

The reason for the relative effectiveness of ANC methods inside ducts can be better appreciated with an understanding of the different types of sound waves inside a duct. Noise inside a duct is physically limited in its direction of propagation. Waves can either travel straight down the duct (plane waves) or bounce back and forth between the walls (higher order modes) (Eriksson, 1980; Kino, 1987; Norton and Karczub, 2003). The cross-sectional dimensions of the duct determine where in the frequency spectrum the plane waves will be the dominant contributor to the overall noise, and where the shorter wavelength, higher order modes will become the dominant noise contributor.

Plane waves have a uniform pressure distribution over the cross-section of the duct and propagate down the center of the duct for wavelengths at least twice the cross-sectional diameter of the duct (Bies and Hansen, 2003). Using ANC methods, these plane waves can be analyzed at one location in the duct and countered at some distance away in the same duct with high accuracy (and thus high effectiveness) since their frequency spectra do not change rapidly as they move down the duct.

High frequency sound waves behave quite differently from low frequency sounds with wavelengths long enough to become plane waves. Instead of moving longitudinally in the duct, they bounce back and forth between the duct walls and set up waves corresponding to "higher order modes." A higher order mode is an integer value of reflections representing waves that are repeatedly traveling the same pathway as they reflect between the duct walls. 
The boundary or "cut-on" frequency $\left(f_{\text {co }}\right)$ at which higher order modes begin in round ducts can be estimated using Equation 1 (Bies and Hansen, 2003):

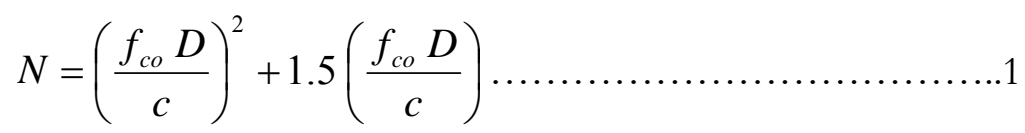

Where:

$N=$ integer mode number

$f_{c o}=$ cut on frequency $(\mathrm{Hz})$

$D=$ duct diameter $(\mathrm{ft})$

$c=$ speed of sound in air (fps)

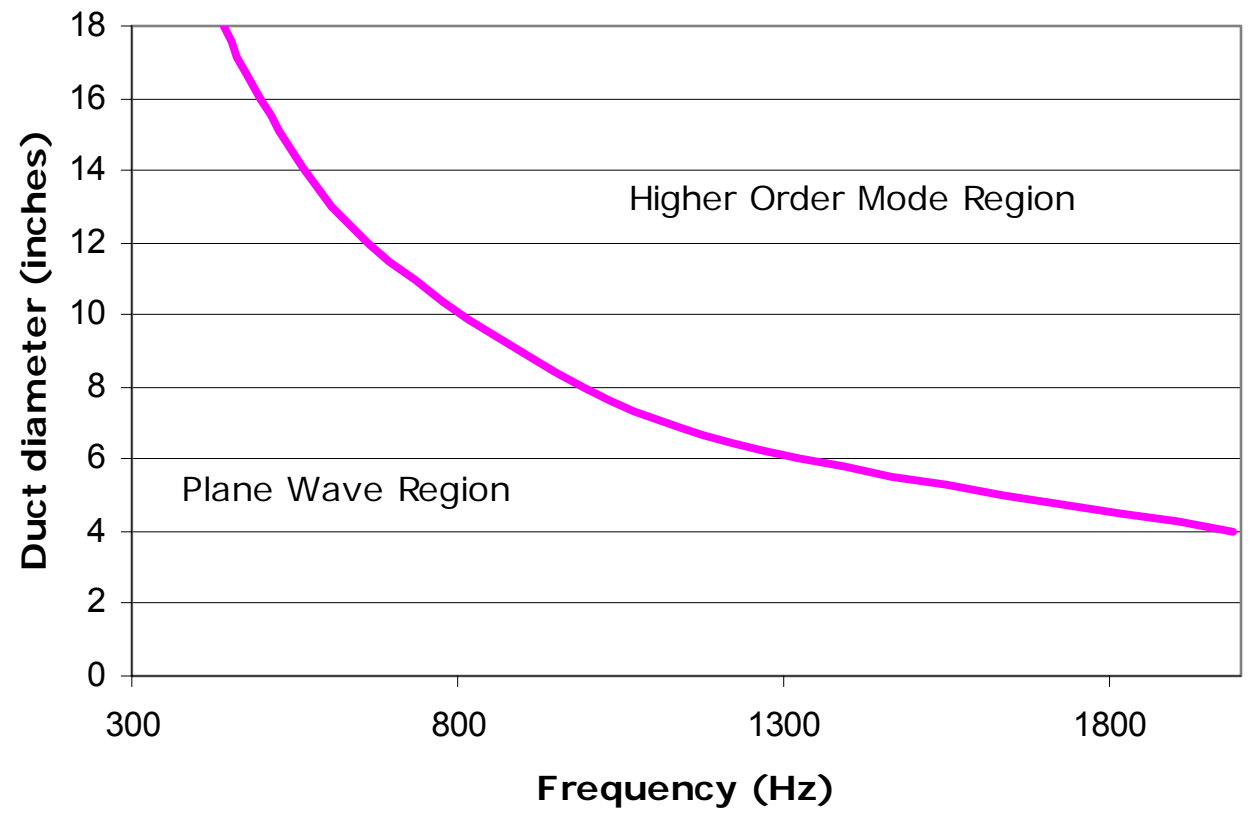

Figure 1. Round duct plane wave vs. higher order mode regions

As can be inferred from Equation 1 and is plotted in Figure 1, the frequency for a given mode number is inversely related to the duct diameter $(D)$. This suggests that modes become increasingly important at larger diameters. As one continues up the frequency spectrum for a given diameter, higher order modes will increasingly dominate the noise content. The dominant frequency below which plane waves will still dominate the higher 
order modes $\left(f_{d}\right)$ can be estimated for round ducts by Equation 2 (Eriksson, 1980; Bies and Hansen, 2003; Norton and Karczub, 2003):

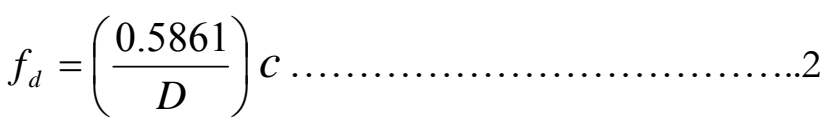

Where:

$$
\begin{aligned}
& f_{d}=\text { dominant frequency }(\mathrm{Hz}) \\
& D=\operatorname{duct} \text { diameter }(\mathrm{ft}) \\
& c=\text { speed of sound in air }(\mathrm{fps})
\end{aligned}
$$

For rectangular ducts, the cut-on frequency can be estimated from Equation 3 (Norton and Karczub, 2003):

$$
f_{c o}=\left(\frac{c}{2 \pi}\right)\left[\left(\frac{m \pi}{a}\right)^{2}+\left(\frac{n \pi}{b}\right)^{2}\right]^{1 / 2} \ldots \ldots \ldots \ldots \ldots . . .3
$$

Where:

$$
\begin{aligned}
& f_{c o}=\text { cut on frequency }(\mathrm{Hz}) \\
& c=\text { speed of sound in air }(\mathrm{fps}) \\
& a=\text { width of duct in } x \text { direction } \\
& b=\text { width of duct in } y \text { direction } \\
& m=\text { number of pressure nodal lines in } x \text { direction } \\
& n=\text { number of pressure nodal lines in } y \text { direction }
\end{aligned}
$$

As Equation 3 implies, the plane wave and higher order mode frequency regions depend on both the vertical and horizontal cross-sectional dimensions. If one of the dimensions were held constant, then there would be different cut on frequencies for the first, second, third, etc. modes based on the other cross-sectional dimension. However, the first higher order mode may depend only on the constant dimension if it were larger than the other dimension. Figure 2 displays a plot for a constant vertical dimension of $61 \mathrm{~cm}$ and a varied horizontal dimension of less than $61 \mathrm{~cm}$. 


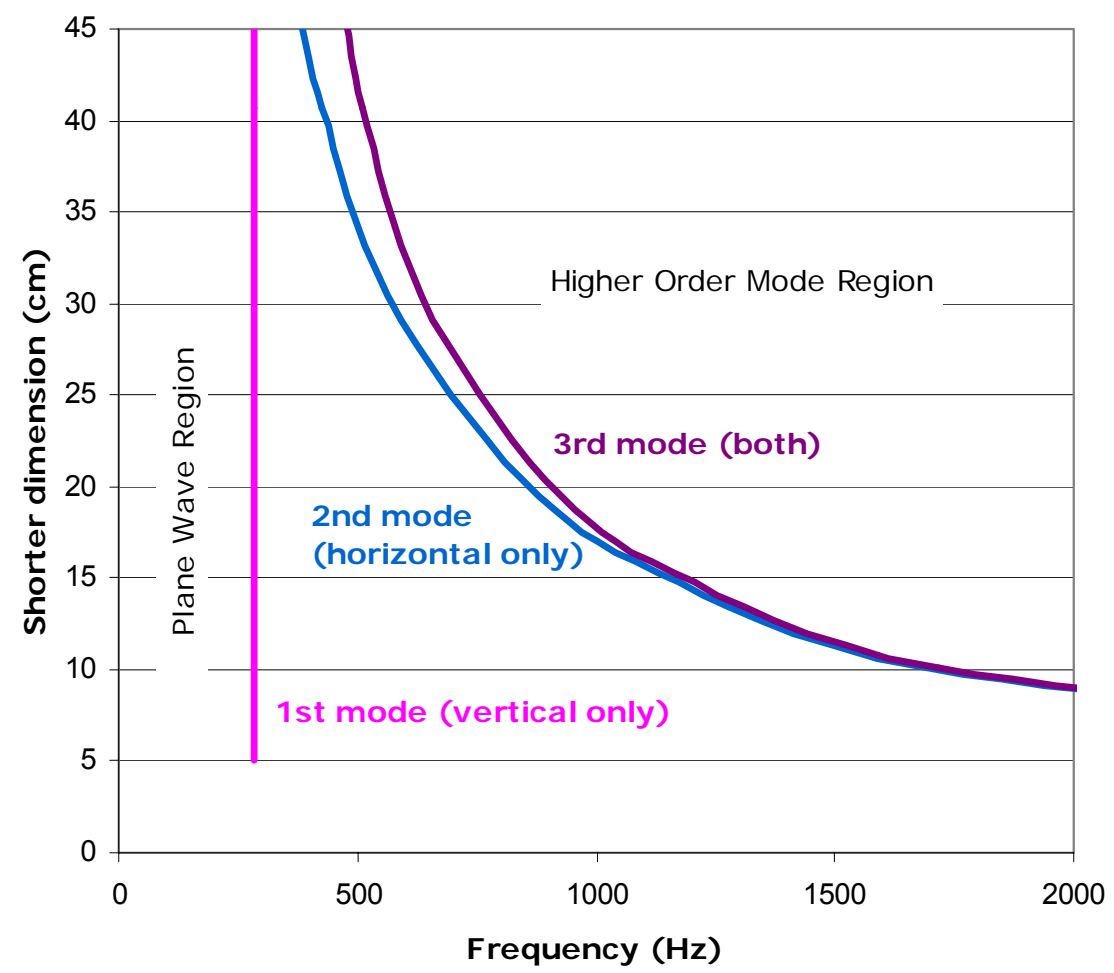

Figure 2. Rectangular duct plane wave vs. higher order mode regions

For a given shorter horizontal dimension, the first lowest frequency mode would be due to the constant larger vertical dimension, then the second mode due to the horizontal only, then the third due to both dimensions. The degree to which the rectangular duct higher order modes contribute to and potentially dominate the noise spectrum is unknown.

Since higher order mode waves bounce back and forth in the duct space as the wave front moves down the duct, the frequency content of the wavefront is difficult to predict at a distant position. Therefore, $\mathrm{ANC}$ is much easier to employ against plane waves than higher order modes. Also, since higher order mode cut-on frequencies are inversely related to the cross-sectional dimensions of the duct, smaller ducts have a larger frequency range that is dominated by plane waves and can be more readily controlled by ANC methods. Hence, one could reasonably expect that values of IL achieved at a given frequency at one diameter will fall with larger diameters or rectangular dimensions as planar waves become progressively less 
important than higher order modes. This is widely assumed to be true by ANC practitioners (Bies and Hansen, 2003), but the author was unable to find any published literature relating duct diameters and ANC performance.

Plane waves are simple to control because the movement of the wave down the duct can be easily predicted from the length of the duct and the speed of sound. Higher order modes are erratic and therefore difficult to predict and control. As a result many sensors (such as microphones) and control speakers are needed to sample and counter higher order modes (Mazanikov et al., 1977; Eriksson et al., 1989; Zander and Hansen, 1992; Pelton et al., 1994). Therefore, if the frequencies involved are largely limited to those producing plane waves, ANC is more likely to produce substantial insertion losses.

Two methods used to reduce duct dimensions without reducing total cross-sectional area are (1) using many smaller ducts for the same volumetric flow as in Figure 3 or (2) using axial vane splitters for cross-sectional partitioning as in Figure 4. It is not always practical to substitute several smaller diameter ducts for a larger one since the pressure due to air flow is proportional to diameter to the 4.5 power (Guffey and Hickey, 1983). While splitters have been used to increase surface area of acoustically absorptive material in ducts for some time (Cullum, 1949; Beranek, 1960), there is only one study applying them to active noise control (Eghtesadi et al, 1986). As is discussed next, another primary consideration in applying active noise control is the width of the frequency bands. The amount of insertion loss is limited by the size of the target frequency range. ANC systems can be optimized for only a narrow range of frequencies at a time (Hansen, 2001).

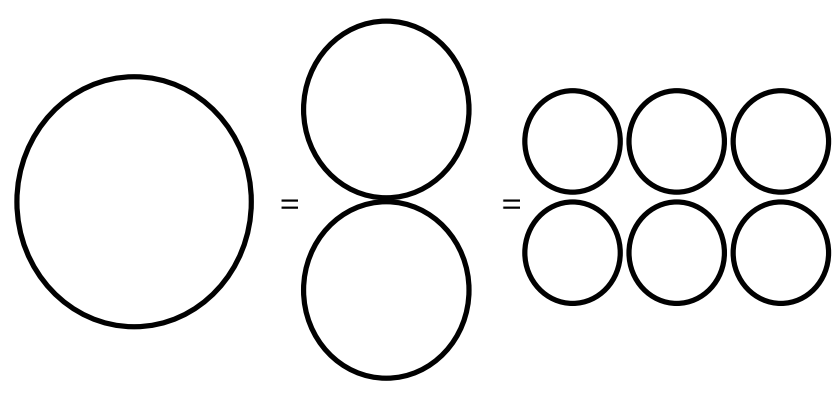

Figure 3. Equivalent volumetric round ducts 

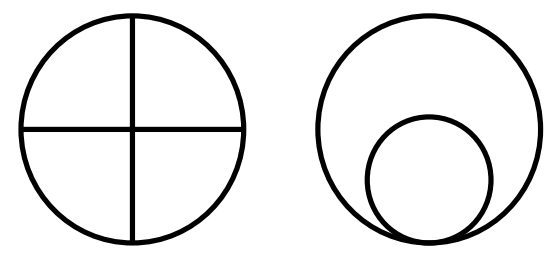

Figure 4. Cross-sectional partitioning schemes for round ducts

\section{Broadband random noise vs. tonal noise}

Noise problems in the occupational and environmental health $(\mathrm{OEH})$ field are typically broadband (i.e., a broad range of frequencies) and are seldom narrow band ("tonal"). "Pure tones" (single frequency) are rare. Noises in OEH practice also typically are "random" in that amplitudes at each frequency fluctuate separately without following a cyclical or other pattern. Tonal noise tends to vary non-randomly, and pure tones may be quasi-constant. Hence, while the bandwidth of typical noises may be constant, the amplitude of the frequencies inside the band changes constantly. A commonly-encountered source of narrow band noise comes from the repetitive passage of fan blades as a fan wheel rotates. Because of the repetitive, easily predicted nature of pure tones, ANC is extremely effective in reducing them, even the higher order modes. In applying ANC to actual industrial duct noise problems, Bies and Hansen (2003) report that:

"Typical results achieved are 15-20 dB over two octaves of random noise and 20-30 dB for tonal noise. Typical frequencies which are controlled range from $40 \mathrm{~Hz}$ to $400 \mathrm{~Hz}$."

Figure 5 gives a visual representation of potential ANC insertion losses for different bandwidths taken from the words of Bies and Hansen (2003) above. Note that the actual effectiveness at some frequencies is different from that reported by Bies and Hansen (2003). For a given broadband noise, each ANC system uses an algorithm to determine the most important (i.e., highest amplitude) frequencies. The smaller the range of frequencies and the fewer individual frequencies of concern, the more accurately the ANC system can predict and counter those frequencies. Even if insertion loss is desired across a wide range of frequencies, 
it is generally most effective to focus on a single two-octave band within the range where ANC has the potential to be effective. If the ANC system can handle several channels independently, the adjacent two-octave bands can be controlled by a separate channel.

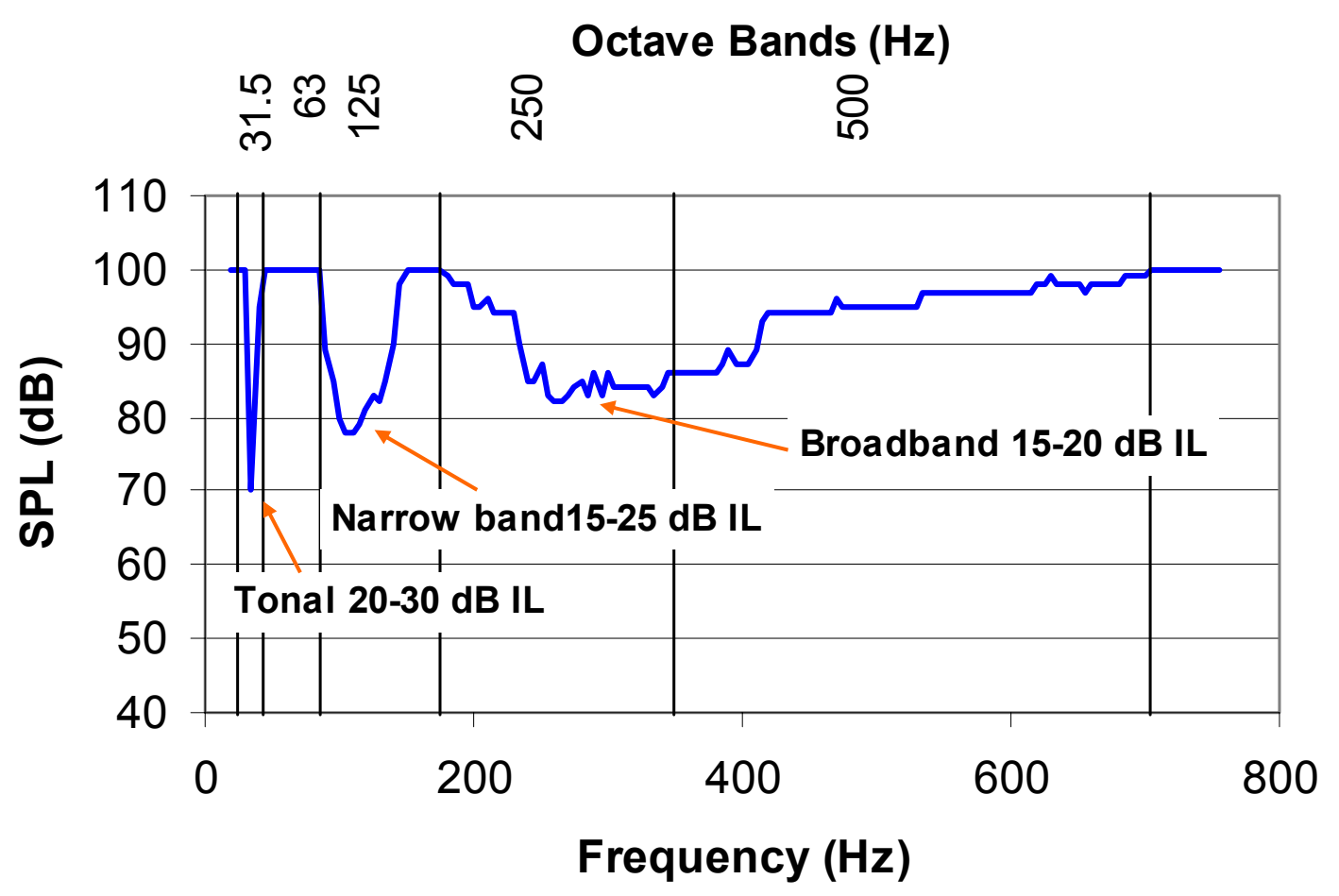

Figure 5. Effects of bandwidth on active noise control insertion loss

Since broadband random noise is much more often encountered than tonal or narrow bands, this study focused on control of broadband random noise only. Also, since duct materials differ in density and transmission loss, durability, vibration transfer, and other important properties, a single common duct material was used. The author could find nothing published to address material specifically. There should be an effect of material due to vibration transfer and transmission loss, but it should be dwarfed by the effect of diameter at frequencies beyond the plane wave dominant frequency $\left(f_{d}\right)$ for that cross-sectional duct dimension. It is not clear whether the results for one material can be applied accurately to other materials. 


\section{Understanding active noise control (whack the mole strategy)}

Using an ANC device requires a control strategy. The basic problem is that ANC is most effective against the relatively low frequency plane waves but has some effect at higher frequencies. In addition, $\mathrm{ANC}$ is most effective if tuned to a relatively narrow band of frequencies. Hence, if the source noise is narrow band, due to plane waves, and below $400 \mathrm{~Hz}$, ANC can be applied with a high degree of success. Indeed, 20-30 dB reductions for pure tones is commonplace (Bies and Hansen, 2003).

If the noise source is broadband and extends past $400 \mathrm{~Hz}$, then deciding which frequencies to tune for becomes important and much more complicated. "Aiming" at the single highest peak is not necessarily the best strategy, especially when one considers the bias against low frequency noise due to A-weighting. Furthermore, the ANC will have some degree of usefulness beyond the narrow range one aims for, and the effectiveness over the broad range for a given focus depends on which frequencies are dominated by plane waves and which by higher order mode waves. Hence, the optimum focus generally can be known only by observing the results of trial attempts. It is also possible to have more than one focal range by using additional controllers. Most ANC devices are custom-made for the particular noise situation and often have several controllers. "Off-the-shelf" controllers like the one used in this study are typically set up for just one digital signal processor for the controller. Additional expense and a higher degree of understanding are required to use two or more controllers. The width of the frequency band to control limits the amount of insertion loss achievable. The limitation is a result of the frequency weighting algorithms used by the controller.

ANC devices use algorithms to determine weighting schemes for which frequencies to focus on. They can be adaptive, so that the weights are constantly updated as the noise changes. Since frequency spectra of noise can change due to heat build-up in machines, wear and tear, etc., the adaptive nature of ANC devices makes them particularly attractive. However, computational speeds limit the number of weights and the degree of accuracy that can be applied over a given frequency range. If the frequency range is broad (greater than two octaves), then the number of weights may be spread thinly and be less effective in controlling the noise.

A descriptive analogy may be useful to illustrate the limits and applications of ANC technology. Many people have played the parlor game, "Whack the Mole." In it, the player is 
given a padded club and stands before a table with many holes. Small statues of moles (small rodents responsible for yard damage) randomly pop up from the holes and remain above the table surface for a short period of time. The player must see the mole pop up and whack it with sufficient force from the padded club to make it fall down inside the table again. Moles can pop up several at a time, and proficient players are challenged with more moles popping up for shorter durations. If there are many moles at a time, the player may not whack each mole with sufficient force. Also, if a player focuses on an area of the table with a high frequency of mole appearance, he may miss a mole on the other end of the table.

In ANC applications, the controller determines where the noise amplitudes are the highest and assigns weights to those frequencies so that it checks them more often. The more frequencies to check, the less likely it will counter with sufficient amplitude and precision to reduce the noise at those frequencies. If the noise is narrow band, then there are fewer frequencies to counter. If the noise is a pure tone, then the ANC can counter it without much chance of error. However, if the noise is broadband (greater than or equal to two octaves), then there are many frequencies to check. In "Whack the Mole," one obvious remedy is to call one's friends over and give them all clubs, then assign them certain areas of the table to watch for moles. The fewer holes per person to watch, the more likely good mole control is to be achieved. Likewise, the ANC can have multiple channels, each assigned to "watch over" a portion of the frequency range. Alternatively, in "Whack the Mole" as in ANC, one can choose to focus on the most target rich area and ignore the rest.

Hence, to control noise that covers more than 2 octaves with an ANC device having a single controller, a practitioner could employ "focus bands" to determine which frequency ranges to attack (see Table 1 for the focus bands for this study). The steps are:

1) first perform frequency analysis to the narrowest degree possible $(1 / 3$ octaves or narrow band) and determine the representative frequency spectrum of concern (Where are the moles coming from?)

2) considering A-weighting contours, determine the frequency range (or ranges for a multi-modal distribution) that should be reduced. (Which ones should I concentrate on whacking?) 
This method of "noise-whacking" was employed in the current study in order to determine how well ANC could work across the frequency spectrum with ideal hardware.

\section{LITERATURE REVIEW}

Within acoustics, the field of active noise control (ANC) has an impressive range of literature. Gordon and Vining's review of the field (1992) indicated the enormous output of researchers in ANC. With an estimated 2,000 researchers in the field, there are over 100 scientific papers per year on ANC topics ranging from modeling to stability to energy conservation. The very interesting nature of ANC and the promise of low frequency noise control make it attractive to researchers. As explained previously, ANC in ducts offers quick, dramatic results and ready application in industry.

While ANC has been applied with limited success in 3-dimensional spaces, such as a tractor cab by Gulyas et al. (2002), there is much more published on nominally 1-dimensional spaces such as ducts. The shape of the duct is not a major concern in the literature, although there are differences in the mode calculations between rectangular and round ducts. It appears that researchers happen to use the duct that is available or more suited for the main objective of the research. For instance, Boudreau et al. (2000) used round ducts, but their intent was to look at the non-uniform pressure distributions in round ducts and sample with microphone arrays then use multiple control channels to gain better ANC of pure tone noise. Many researchers have used rectangular ducts. Egaña et al. (2003) and Pelton et al. (1994) used rectangular ducts because they were trying to control noise that happened to be in rectangular ducts. Liu and Fung (2002) as well as Yuan (2003) used rectangular ducts, but their focus was to improve robustness of the ANC systems through better software calculation procedures. Eghtesadi et al. (1986) used rectangular ducts in studying energy conservation in heating, ventilating, and air conditioning (HVAC) systems because those systems usually employ large rectangular ducts. Eriksson et al. (1989) also used rectangular HVAC ducts to study higher order mode controls because very large ducts were available, not because they are usually rectangular.

Plane wave ANC is the thrust of most of the research of ANC in ducts. Plane waves are easier to control and much of the duct research specifically mentions that the experimental design was set to focus on plane waves only. Among others, this was the approach of 
Eghtesadi et al. (1986), Egana et al. (2003), La Fontaine and Shephard (1991), Okamoto et al. (1994), Zimmer et al. (2003), and Wu et al. (1996). Higher order modes are more difficult to control but not impossible. Mazanikow et al. (1977) used a waveguide in 1970's Russia to get 15-20 decibels (dB) reduction in tonal noise. Eriksson et al. (1989) and Zander and Hansen (1992) developed higher order mode control more recently. These developments helped Pelton's team (1994) devise a successful intervention in a new Florida office building using active control of higher order mode noise. Walker's research (2001) on the actual higher order mode pressure distribution inside round ducts is an example of the on-going effort to improve higher order mode control. For widespread application, however, plane wave ANC is still more popular, since higher order mode control requires successively more microphones, control speakers, and controller complexity for each higher mode.

Besides recognizing that plane waves are easier to control, many researchers also mention axial vane splitters as a method to prevent higher order modes from dominating plane waves at higher frequencies. Eghesadi et al. (1986) actually split an HVAC duct to reduce higher order mode concerns. Egaña et al. (1989) used an HVAC duct from a train car that was already split by design. Eriksson et al. (1989) focused on higher order mode control, but mentioned that axial splitters would be a common method to prevent higher order mode propagation. Earlier mention of axial vane splitters by Cullum (1949) and Beranek (1960) was solely to facilitate passive noise controls by increasing the absorptive surface area inside the duct.

The physical hardware of the various test apparatuses has also been a concern. While most ANC systems are custom-built by the researchers, several in use are commerciallyavailable systems. Eriksson and Allie (1988) used the Nelson Digisonix dX-30 system in an article that was more of an advertisement for the product. Okamoto et al. (1994) used the Activox controller. Slagley and Guffey (2006) and the current study used the EZ-ANC II controller (Causal Systems, Inc., Adelaide, Australia), since it is the only commercial ANC system currently available.

The sensors and actuators (i.e., microphones and speakers) of the physical system are also cause for concern. Some sensors must be directional to prevent feedback from the control actuators. Swinbanks (1973) developed and tested a method to tease out the directionality of a sound signal using multiple microphones as a dipole. Directionality is 
important to prevent feedback for an ANC system. Poole and Leventhall (1976) used Swinbanks' dipole to achieve a $50 \mathrm{~dB}$ insertion loss of tonal noise at $150 \mathrm{~Hz}$. Zhou and Shi (1991) used an L-formed duct instead of the dipole to reduce feedback and increase performance of ANC in ducts. Okamoto et al. (1994) altered the housing of the control speaker to make it a resonator and thereby reduced the needed volume velocity (amount of available sound power) of the control speaker. The builders of the EZ-ANC II system discussed the physical issues that make a problem amenable to ANC solution, as well as offering basic guidance (Snyder and Hansen, 1989; Snyder, 2001). Also, Hansen (2001) gives extensive guidance on sensors and actuators in his book.

The modeling and calculations of the system software is just as important as the physical hardware, and there is a wide range of research on software topics. Several researchers developed different modeling methods for ANC in ducts. Tanaka et al. (1992) used modeling of ANC of tonal and broadband noise in ducts to confirm their proposed boundary control method. Wu et al. (1996) used a time-domain rather than the typical frequency-domain algorithm for control and found better global control. Zimmer et al. (2003) used an improved model of finite and infinite round ducts for ANC application. Very recently, Chen et al. (2005) preconditioned the least mean square (LMS) data entering the multi-channel filtered-x LMS algorithm to improve multiple channel ANC results. The current study's controller employed a filtered-x LMS algorithm, since it is incorporated into the product.

Occupationally-focused signal conditioning was done by Kuo and Tsai (1993) to make the system focus on the frequency range of concern for human hearing. They did this using a filtered-e algorithm. Sommerfeldt and Samuels (2001) implemented Kuo and Tsai's idea into their research using loudness levels (phons) as their measure of effectiveness.

System stability and robustness have been researched as well. Liu and Fung (2002) increased system stability and robustness via a new filter method. Yuan (2003) used a new feedback signal computation to improve robustness and stability in duct ANC. Kim and Park (1999) also increased system robustness through estimation of driving frequencies for multitonal noise. By modeling based on several signals, they increased the signal to noise ratio of the overall system for better stability. 
In spite of the volumes of ANC research, some fundamental questions remain unanswered. While there are equations for estimating the frequency ranges of plane wave and higher order mode dominance in round and rectangular ducts, there have been no empirical studies to confirm the efficacy of the equations. Given that so many researchers state the importance of limiting ANC in ducts to plane wave control, it is rather important to better understand the limits and degree of ANC success with regard to plane waves. Since the duct cross section is the only determining variable besides shape, it would be useful to research the ANC performance on plane waves in round and rectangular ducts of varying cross-sectional dimensions. Information gained would aid in the design of strategies to use cross-sectional partitioning by axial vane splitters in large ducts to extend the frequency range of plane wave dominance and improve ANC of broadband noise in large ducts. After reviewing the literature, no diameter effects studies or cross-sectional partitioning strategy studies were found except Eghtesadi et al.'s (1986) study on energy conservation. The data obtained from such experiments would aid in devising simple ANC solutions for large duct broadband noise problems so often encountered in industry.

\section{Problem Statement}

The research presented here attempts to extend the usefulness of ANC in large ducts by exploring the effects of cross-sectional dimensions and partitioning on ANC insertion loss in large ducts. The initial information gathered from cross-sectional dimension studies in both rectangular and round ducts was used to help design cross-sectional partitioning experiments that focused only on round ducts. 


\section{CHAPTER 1: COMMON APPARATUS/METHODS}

\section{Common ANC Apparatus}

The active noise control test device was common throughout all studies and is discussed in this section. The apparatus difference between the studies was in the different ducts used. The unique apparatuses for each study are presented in the individual chapters pertaining to those studies.

The simple active noise control (ANC) system sketched in Figure 6 was used for the experiments described here. The components consisted of a source speaker attached tightly to one end of the various ducts with a directional reference microphone next to the source speaker in the tube. The $1 / 4$ " array microphone (PCB Piezotronics, Depew, NY) was made directional by inserting it into a $1 / 2$ ” I.D. four foot long X5305 microporous tube (Porex, Atlanta, GA). A directional reference microphone preferentially senses the source speaker wave impinging at the tip and was necessary to prevent feedback from the control speaker noise broadcast at the other end of the duct reaching the reference microphone.

The source speaker signal was random broadband white noise generated by a signal generator on an OR-38 (OROS, Falls Church, VA) real-time analyzer (RTA). The reference microphone signal was fed into the EZ-ANC II active noise controller (Causal Systems, Inc., Adelaide, Australia) which used a "filtered- $x$ " control algorithm to determine the signal generated for the control speaker to counter the noise coming down the duct. Another $1 / 4$ " array microphone (PCB Piezotronics, Depew, NY) was used as the "error" microphone (see Figure 6) to detect the residual sound after control (i.e., the sound not "cancelled" by the downstream speaker). The active noise controller dynamically adjusted the signal sent to the control speaker to minimize the residual sound. For the experiments, the error microphone signal was split off to the real-time analyzer to provide a result reading (with and without $\mathrm{ANC})$. 


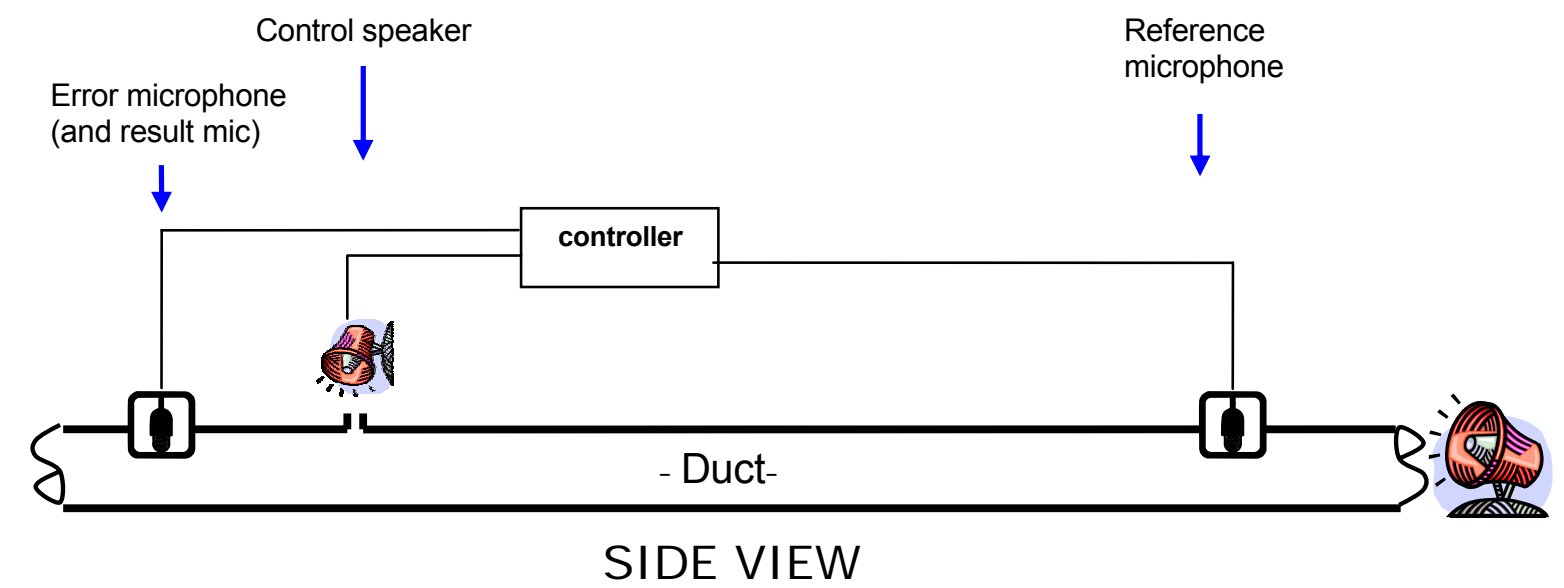

Figure 6. Experimental apparatus

\section{Frequency Focus Bands}

As indicated previously, "focus bands" of frequencies aided in comparing the best ANC achievable for different frequency regions. Focus bands two octaves wide were developed to use in the experiments (Table 1). The focus band encompassing the 500-1000 $\mathrm{Hz}$ bands was split into single octaves because of the difference in octave width at higher frequencies. Figure 7 provides a visual representation of the width of the frequency focus bands.

Table 1. Range of frequencies used to "focus" ANC controller

\begin{tabular}{ccc}
\hline Focus Bands & Octave bands included & Frequency range \\
\hline 1 & 31.5 and $63 \mathrm{~Hz}$ & $25-90 \mathrm{~Hz}$ \\
2 & 125 and $250 \mathrm{~Hz}$ & $90-355 \mathrm{~Hz}$ \\
3 & 500 and $1 \mathrm{k} \mathrm{Hz}$ & $355-1400 \mathrm{~Hz}$ \\
$3 \mathrm{a}$ & $500 \mathrm{~Hz}$ & $355-710 \mathrm{~Hz}$ \\
$3 \mathrm{~b}$ & $1 \mathrm{k} \mathrm{Hz}$ & $710-1400 \mathrm{~Hz}$ \\
\hline
\end{tabular}




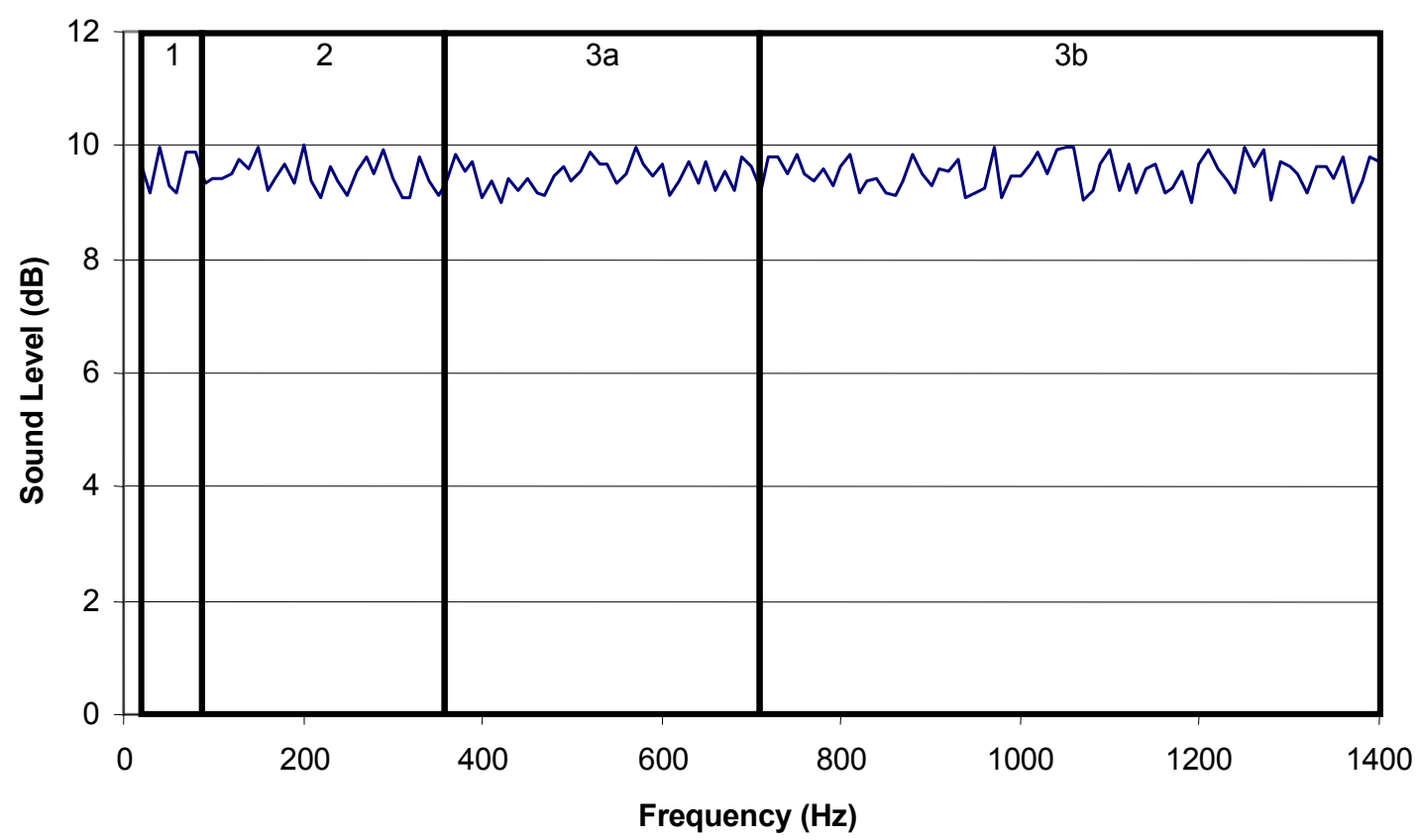

Figure 7. Frequency range of focus bands

A preliminary study was performed using these focus bands to determine the best method of reporting results. Insertion loss estimates from $1 / 3$ octave band readings on various duct sizes were compared between focus bands. For some situations, the IL was larger for a frequency due to a focus band that did not include the frequency than for the focus band that did include the frequency. (e.g., the highest IL for the $500 \mathrm{~Hz} 1 / 3$ octave band may be when using the 125 and $250 \mathrm{~Hz}$ focus bands.) This was due to the inexact nature of sound filters, as well as the bandwidth effect explained in the introduction and illustrated in Figure 5.

Three methods of summarizing IL estimates were investigated in the preliminary study. The first was to compare the IL estimate from all focus bands at each frequency, and take the highest IL estimate. This maximum insertion loss $\left(\mathrm{IL}_{\max }\right)$ method can be supported from the idea that the ANC system would be tuned to reduce the noise of highest concern in practice. The next method (a) was simply to use the IL for each frequency within its focus band using two octave wide bands. Since the bands get wider as frequency increases, a third method (b) was devised that used one octave wide focus bands for the 500 and $1,000 \mathrm{~Hz}$ octave bands. The data are presented in Figure 8 using the three different methods of estimating insertion loss. 


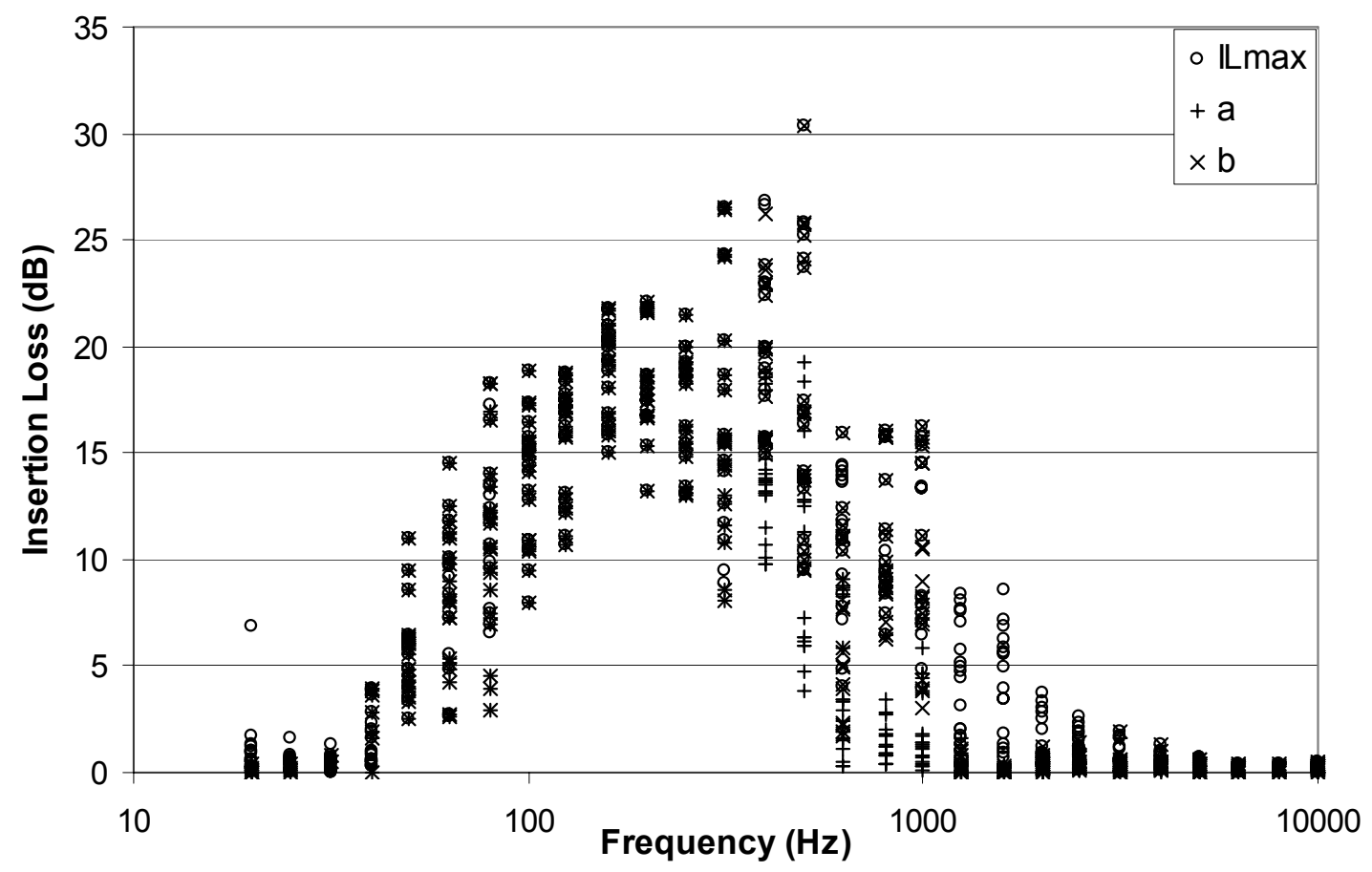

Figure 8. Comparison of IL results presentation methods

The method to determine IL made little difference for frequencies below $400 \mathrm{~Hz}$. Above $400 \mathrm{~Hz}$, method (a) produced lower IL values, presumably due to the fact that the third focus band was a full two octaves wide at 500 and 1,000 Hz. There was no difference between $\mathrm{IL}_{\max }$ and method (b) below $1 \mathrm{k} \mathrm{Hz}$. At higher frequencies method (a) produced negligible IL values and the $\mathrm{IL}_{\max }$ method produced modest $\mathrm{IL}$ values. When used by a practitioner the ANC equipment would be set up for the particular noise spectrum of concern. Therefore, the $\mathrm{IL}_{\max }$ method estimated the best reductions that can be achieved under the most favorable broadband conditions. It also may represent the best that current ANC devices and software can accomplish for broadband noise even with multiple controllers. For those reasons, the $\mathrm{IL}_{\max }$ method was used as the "best achievable result" when presenting results in this investigation.

A further concern was how to best summarize the results. Since the thrust of all the experiments was to determine the difference in ANC IL above a certain frequency where 
higher order modes would begin and compare interventions, a common frequency breakpoint of $280 \mathrm{~Hz}$ was chosen. The $1 / 3$ octave bands of $20-250 \mathrm{~Hz}$ were summed by decibel addition as a low frequency $\mathrm{IL}_{\max }$ value. The $1 / 3$ octave bands of $315-5,000 \mathrm{~Hz}$ were summed as a high

frequency $\mathrm{IL}_{\max }$ value. It should be noted that the high frequency value actually incorporates a range that would be considered "low" or "middle" frequency by practitioners. However, the high frequency value represents the frequency range that is reported as difficult to control by either active or passive controls.

\section{General ANC Test Methods}

The signal generator for the source speaker used a broadband random white noise and a band-pass filter for the frequency ranges two octave bands wide for the 31.5 and $63 \mathrm{~Hz}$ bands, the 125 and $250 \mathrm{~Hz}$ bands, and the 500 and $1000 \mathrm{~Hz}$ bands. The signal was filtered on the single octave bandwidths for the 500 and 1,000 $\mathrm{Hz}$ bands, also, since those bands are much wider than the lower frequency bands. The filters on the active noise controller were also set to give priority to the microphone input signals in the set focus bands.

After filter weights were established to optimize the impulse response of the active noise controller, a two-minute active noise control test was performed to check stability of the system. If the system was stable, a 30 second linear average sample was taken from the error microphone with ANC on, then ANC off. The difference between the "on" and "off" sound levels at a given frequency was the insertion loss (IL) of the ANC for the frequency. Previous experiments showed that a one minute stabilization period was sufficient.

Results were analyzed by comparing the $\mathrm{IL}_{\max }$ values above and below the minimum cut-on frequency of the test set. For instance, the lowest cut-on frequency for the different round duct diameters was determined by the largest duct. The $\mathrm{IL}_{\max }$ values at and below that octave band should be similar between varied diameter ducts and different above that octave band.

\section{ANC Controller Operation}

Once the ducts and physical system were prepared for experimentation (see Figure 6), the signal generator was set to the frequency focus band described in the preceding section. The volume of the source speaker was adjusted to at least $20 \mathrm{~dB}$ above the overall linear sound 
pressure level (SPL) of the background inside the duct at the error microphone position. For instance, once the white noise frequency range of 20-90 Hz was set in the signal generator for the first frequency focus band for a particular run, the error microphone reading was noted with all volume dials turned down completely (but not off). Turning the dials off would have removed the background noise that is present in live speakers. The "background" reading included both the exterior noise in the test room as well as speaker noise. The volume of the source speaker was adjusted to at least $20 \mathrm{~dB}$ above the background SPL. Typical readings for background noise were in the range of $65-72 \mathrm{~dB}$, so that typical source speaker volumes were in the range of 90-95 dB. This allowed room for the ANC to reduce noise and still have the reading be uncontaminated by background noise. The source speaker level was adjusted higher for frequency focus band $2(25-30 \mathrm{~dB}$ above background) because the system performed best in the $80-400 \mathrm{~Hz}$ region and more room was required above background to allow for clean readings of insertion loss levels.

The input and output frequency filters of the controller were set according to Table 1. The frequency filters on the microphone input signals were set so that the controller would be focused on the frequency range broadcast into the ducts and less influenced by higher frequency harmonics or lower frequency subharmonics and background noise.

The input gains to the controller were then adjusted so that the average peak height of the reference and error signals were between 0.2 and 0.3 on the scale from -1.0 to 1.0 volts. This allowed for occasional random peaks that would not be truncated above the scale as well as room below the signal to still be of sufficient size after the ANC controller reduced it. If the error signal were too low to begin with, the ANC control algorithm may reduce it less during the control process.

The next step was crucial to good ANC control. The transfer function (TF) model weights had to look like an impulse, having a steep rise then an oscillating decay back to the midline in order for ANC to work well. A good TF Model is shown in Figure 9. To get the best possible TF Model for the particular run, the controller was set to "ID" and "ANC ON" and the control speaker signal volume raised until the error microphone read $3 \mathrm{~dB}$ above the original noise. (Note that the controller settings represent software options specific to the ANC controller used during these experiments.) This ensured that the control speaker had sufficient power to at least equal the noise from the source speaker at the error microphone 
sample position, since adding two identical noise sources (out of phase) results in a $3 \mathrm{~dB}$ increase in SPL.

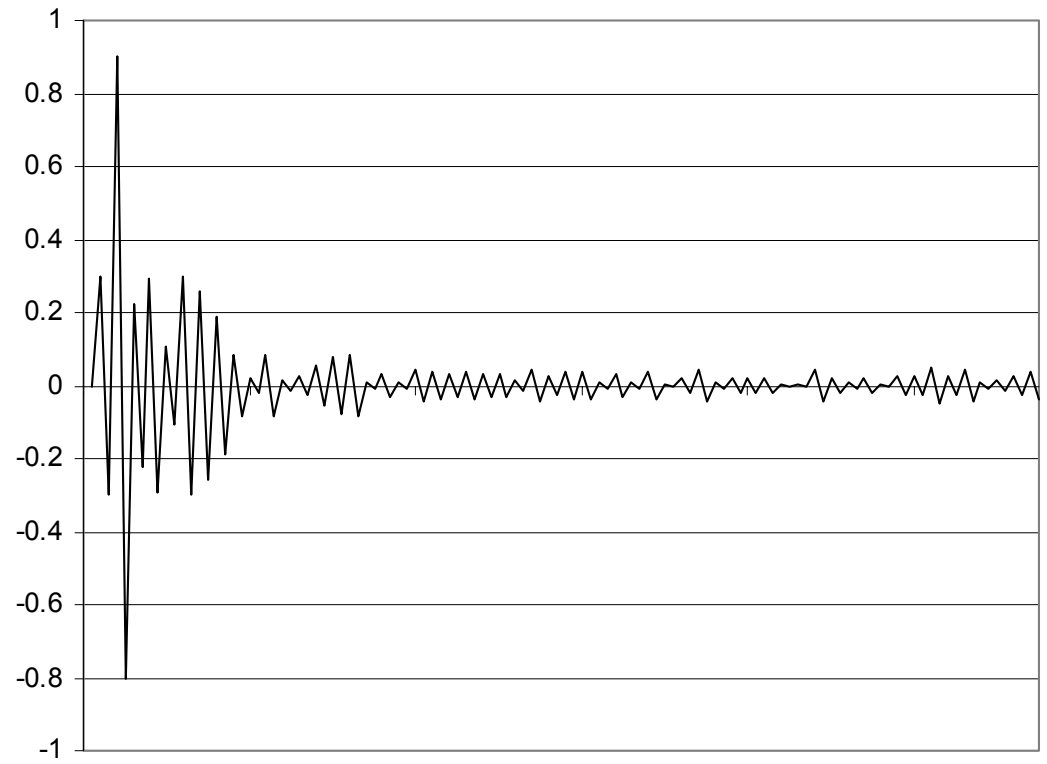

Figure 9. Example of good transfer function model weights signal

The weights were retrieved with the "Fetch Weights" button and the TF Model examined to see whether it resembled an impulse. If the TF Model did not resemble an impulse, then the speaker volumes, input gains, and model weighting length were adjusted to get the TF Model which most resembled an impulse.

The next step began the actual test. The "ID" and "ANC ON" buttons were switched off and the "ALG" and "ANC ON" buttons were then switched on. A stopwatch was used to monitor the controller stability during a two minute test. If the controller did not become unstable (sudden peak tones capable of blowing speakers), then a 30 second linear average was taken with the ANC controller on. The results were recorded using an OR-38 (OROS, Falls Church, VA) real-time analyzer. Those results in 1/3 octave bands were then transferred to a spreadsheet and a 30 second linear average was taken with the ANC controller turned off. Lastly, all speaker volumes were turned completely down and a 30 second average was taken of the background noise. All results were compiled on the spreadsheet. 
At times, especially for high frequency test bands (3, 3a, and 3b) of larger dimension ducts ( $>8$ inches), the controller would become unstable before the two minute stabilization time. If so, the weights were flushed and the TF Model re-weighted. If after repeated attempts, the controller could not be stable for the two minute period, a reading was taken at a shorter time before the controller became unstable, as late in the period as possible. Such occasions were then noted in the data tables. Such instabilities would result in almost no insertion loss and so would not give false positive readings.

Within each study, the order of trial runs was randomized. The test ducts were dismantled in-between runs, so that even testing the same conditions two times in a row would not be simply "repeated measures." Data was evaluated using JMP Intro software (SAS Institute, Inc., Cary, NC).

\section{Variables and Hypotheses}

The two dependent variables monitored were the insertion loss at two different frequency ranges. One-third octave band values, with ANC on, were subtracted from the same bands with ANC off to give a measure of insertion loss for each $1 / 3$ octave band. The maximum insertion loss values among the frequency focus bands were recorded for each $1 / 3$ octave band. The insertion loss values were then summed from $20-250 \mathrm{~Hz}$ as a low frequency $\mathrm{IL}_{\max }$ value, and summed from $315-5000 \mathrm{~Hz}$ as a high frequency $\mathrm{IL}_{\max }$ value. These two values, $\mathrm{IL}_{\max } \leq 250 \mathrm{~Hz}$ and $\mathrm{IL}_{\max } \geq 315 \mathrm{~Hz}$, were the dependent variables.

There are numerous independent variables that affect the $\mathrm{IL}_{\max }$ results for $\mathrm{ANC}$ of random noise in ducts. The independent variables of bandwidth, stabilization time, and software settings on the ANC controller were held constant as described previously in this section. Microphone position was held constant during each individual study. The remaining independent variables were: rectangular dimension, round diameter, inner duct position and diameter for two-duct studies, simultaneous operation of two ducts, simultaneous operation with a reduced hardware configuration, and finally a cross-shaped splitter in a round duct. As these were too many variables to analyze in a single study, a series of studies was devised to address one to two independent variables at a time. The studies with variables, null hypotheses, and test type are listed in Table 2. 
Table 2. Series of studies to describe independent variables

\begin{tabular}{llll}
\hline Study & \multicolumn{1}{c}{ Variable } & \multicolumn{1}{c}{$\mathbf{H}_{\mathbf{0}}$} & \multicolumn{1}{c}{ Test } \\
\hline Ia & $\begin{array}{l}\text { Rectangular } \\
\text { dimension }\end{array}$ & No effect of horizontal dimension & 1-way ANOVA \\
Ib & $\begin{array}{l}\text { Round diameter } \\
\text { IIa }\end{array}$ & Inner duct position & $\begin{array}{l}\text { No effect of diameter } \\
\text { diameter, interaction }\end{array}$ \\
IIb & $\begin{array}{l}\text { Inner duct } \\
\text { diameter }\end{array}$ & No effect of inner duct diameter & 1-way ANOVA \\
IIIa & $\begin{array}{l}\text { Simultaneous } \\
\text { operation }\end{array}$ & $\begin{array}{l}\text { No difference between 18” duct alone } \\
\text { and 2 ducts simultaneously }\end{array}$ & 1-way ANOVA \\
IIIb & $\begin{array}{l}\text { Hardware } \\
\text { combination }\end{array}$ & $\begin{array}{l}\text { No difference between 18” duct alone } \\
\text { and 2 ducts with single reference } \\
\text { microphone }\end{array}$ & t-test \\
IV & $\begin{array}{l}\text { Cross-shaped } \\
\text { splitter }\end{array}$ & $\begin{array}{l}\text { No difference between 18” duct alone } \\
\text { and single quadrant area }\end{array}$ & t-test \\
\hline
\end{tabular}

The series of studies was designed to describe the effects of diameter and crosssectional partitioning on active noise control in round ducts. Each study is treated in a separate chapter to adequately describe the unique apparatus/methods, results, and discussion for each independent variable. 


\section{CHAPTER 2: STUDY I - DUCT SIZE AND SHAPE}

Since the plane wave region can be described in rectangular and round ducts by Equations 1 and 3 as dependent on the cross-sectional dimensions of the duct, a study was needed to ascertain how well these independent variables correlated to the dependent variables of high and low frequency ANC insertion loss. The first study, Ia, was designed to examine the effect of varying a single dimension of a rectangular duct to change the cut-on frequency of the first higher order mode. The second study, Ib, was designed to examine the effect of different round duct diameters used to change the cut-on frequency of the first higher order mode. These effects on the higher order mode cut-on frequency should directly affect the ANC insertion loss that could be achieved.

\section{Study I Unique Apparatus}

Study Ia was performed with a $24 \mathrm{ft}$ long rectangular duct constructed of $3 / 8$ " thick plywood. The duct was constructed of $8 \mathrm{ft}$ lengths connected end to end and sealed with foam. The cross-sectional height of the duct was fixed at $61 \mathrm{~cm}$, while the width was variable from 7 to $55 \mathrm{~cm}$ (Figure 10). One side wall was moveable, with threaded 3/8" steel rods used to fix the side wall at certain widths for the experiments. The reference microphone was suspended by nylon thread in the center of the cross section $1 \mathrm{ft}$ inside the source end of the duct. The error microphone was insulated from vibration inside a foam tube and placed on a wire stand $1 \mathrm{ft}$ inside the far end of the duct, centered in the cross section (see Figure 11). 


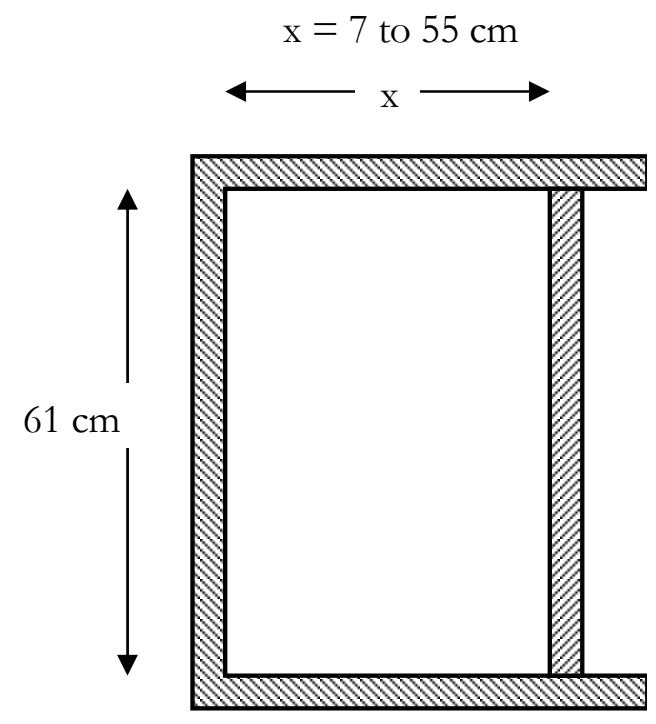

Figure 10. Study Ia Apparatus, Cross-sectional view of rectangular duct apparatus

Error microphone in foam holder on wire stand

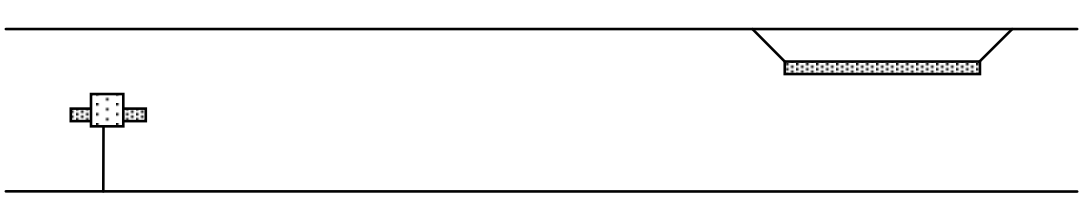

Reference microphone

suspended with nylon thread

Figure 11. Study Ia Apparatus, Side view of microphone mounting methods

Study Ib tested for the effects of diameter in round ducts using tight-fitting laserwelded center-seam galvanized steel duct (Nordfab, Inc., Thomasville, GA) with diameters 4, $6,8,12$, and 18 inches. The ducts were selected based on availability and space constraints.

The ducts were all $5 \mathrm{ft}$ long lengths clamped and tightly sealed at the ends to form a 20 $\mathrm{ft}$ long straight path. The source speaker was joined to one end of the run of ducts, and the control speaker joined to a 4 inch length of duct connected to the straight duct with a $60-90^{\circ}$ junction fitting at a distance of roughly $20 \mathrm{ft}$ from the source speaker at the other end of the 
run of duct. (See Figure 6) Given the $4 \mathrm{ft}$ porous plastic tube needed to make the reference microphone directional, the actual duct length between the reference microphone and the control speaker was actually $16 \mathrm{ft}$. Preliminary testing established that 15 feet was sufficient length to allow travel time for the active noise controller processor to determine a counter signal for the noise as the plane wave traveled down the length of the duct.

\section{Study Ia: Rectangular Duct}

\section{Study Ia Model and Study Design}

Study Ia was designed to test the hypothesis that there was no effect on $\mathrm{IL}_{\max }$ from changing the cross-sectional width of the rectangular duct while holding the height to $61 \mathrm{~cm}$. Seven cross-sectional widths were selected based on equal $8 \mathrm{~cm}$ spacing between the largest and smallest possible widths of the test fixture $(7,15,23,31,39,47$, and $55 \mathrm{~cm})$. A fixed effects model was developed to describe the experiment:

$\mathrm{IL}_{i j}=\mu+\tau_{i}+\varepsilon_{i j}$

Where:

$\mathrm{IL}_{i j}=$ insertion loss in decibels $(\mathrm{dB})$

$\mu=$ average insertion loss for all treatments

$\tau_{i}=$ effect of the $i^{\text {th }}$ cross-sectional width, $i=1,2, \ldots, a$

$\varepsilon_{i j}=$ random error $j=1,2, \ldots, n$

This model was used to test the following hypothesis on the effect of diameter:

$\mathrm{H}_{0}: \tau_{1}=\tau_{2}=\ldots=\tau_{a}=0$

$\mathrm{H}_{1}$ : at least one $\tau_{i} \neq 0$

Stated non-mathematically, the hypothesis was:

$\mathrm{H}_{0}$ : No effect of cross-sectional width (horizontal dimension)

$\mathrm{H}_{1}$ : At least one cross-sectional width effect different from another

The study design employed the one-way analysis of variance (ANOVA) procedure to analyze the seven levels of the single treatment. Power calculations indicated that, given the 
average variability in the preliminary tests $\left(\Sigma \tau_{i}^{2}=194.9\right.$ and $\left.s=6.98 \mathrm{~dB}\right)$, two replicates $(\mathrm{n}=2)$ were required to test the cross-sectional width effect with $a=7$ treatment groups with sufficient power $(\beta \leq 0.20)$ (Montgomery, 2001). The fourteen runs were randomized to prevent any bias from order or time.

Study Ia Results

The results of the rectangular duct study are shown in Figure 12. The $\mathrm{IL}_{\max }$ values in decibels for the two dependent variables (low and high frequency) are plotted against the independent variable of cross-sectional width in centimeters. The open circles represent the low frequency data, and the closed triangles represent the high frequency data. Regression lines were added to the figure to help analyze the data.

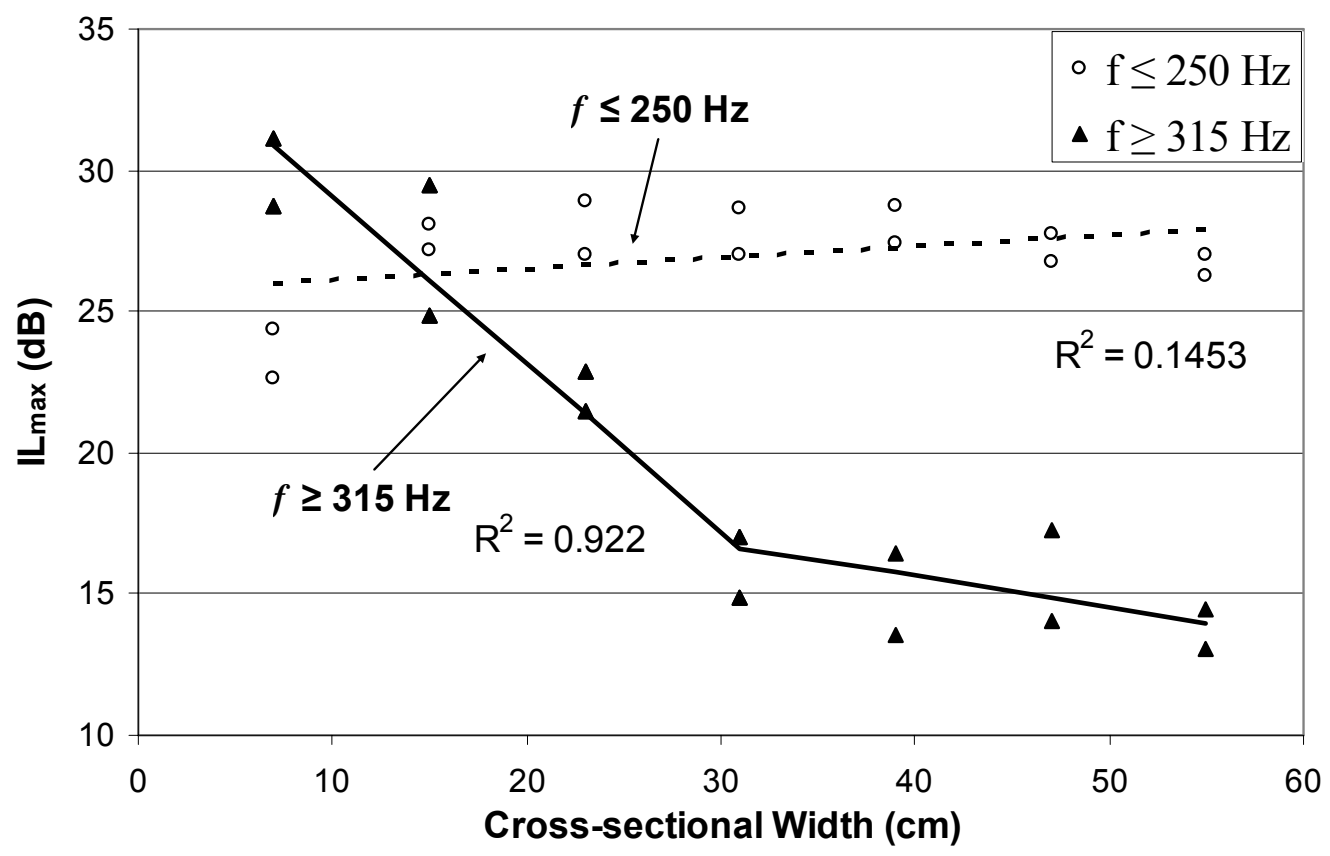

Figure 12. Study Ia Results, $\mathrm{IL}_{\max }$ by rectangular crosssectional width

Low Frequency: For the low frequency data, the best fit line does not describe the data well, with an associated $\mathrm{R}^{2}$ of only 0.1453 . However, it appears that the dependent 
variable does not have a very large effect on the low frequency $\mathrm{IL}_{\max }$ result. In other words, the $\mathrm{IL}_{\max }$ is constant at low frequency with regards to cross-sectional width.

The treatment levels appeared to have unequal variances, so O’Brien's test was conducted on the group variances (actually an ANOVA on the variances from the group means) to determine whether they were sufficiently equal (homoscedasticity). The O'Brien test returned a $\mathrm{p}$-value of $<0.0001$, so that the treatment variances were considered unequal, which nullifies the usual ANOVA results. Therefore Welch's ANOVA procedure (Welch, 1951; Brown and Forsythe, 1974 and 1974a), which is designed for testing group means when variances are unequal, was conducted on the data. Welch's ANOVA uses the reciprocal of the sample variances of the group means to weight the means for the F-test. Welch's ANOVA returned $\mathrm{p}=0.3348$ for the low frequency data. The null hypothesis that there was no effect from the cross-sectional width on the low frequency data could not be rejected at $\alpha=0.05$.

High Frequency: The high frequency data were certainly affected by the crosssectional width. As the width increases, the cut-on frequency of the first higher order mode decreases, so that the overall $\mathrm{IL}_{\max }$ at the higher frequencies should decrease as well. That is reflected in the data in Figure 12. A linear regression line fit to the high frequency data had an $\mathrm{R}^{2}$ of 0.8279 and does describe the data relationship somewhat. An exponential line fit to the data only increased the value of $\mathrm{R}^{2}$ to 0.8401 . However, the high frequency data seem to reach a cut-off point with a change of slope between 23 and $31 \mathrm{~cm}$. Therefore, multivariate regression was used to determine a fit for the data in the case of a breakpoint between two slopes. The regression was fit using Equation 4.

$$
\hat{Y}=b_{0}+b_{1} X_{1}+b_{2}\left(X_{1}-31 \mathrm{~cm}\right) X_{2} \ldots \ldots \ldots \ldots \ldots . . . .4
$$

Where:

$$
\begin{aligned}
& \hat{Y}=\mathrm{IL}_{\max }(\mathrm{dB}) \\
& b_{0}, b_{1} \text {, and } b_{2}=\text { Regression coefficients } \\
& X_{1}=\text { Cross-sectional width of the rectangular duct }(\mathrm{cm}) \\
& X_{2}=1 \text {, when } X_{1}>31 \mathrm{~cm} \text {, otherwise } X_{2}=0
\end{aligned}
$$

The R2 value for the multivariate regression line from Equation 4 was 0.922, which described the data well. The high frequency data also failed O'Brien's tests and were considered heteroscedastic $(p<0.0001)$. Welch's ANOVA returned $p=0.0220$ for the high 
frequency data. The null hypothesis that there was no effect from the cross-sectional width on the low frequency data was rejected for the high frequency data.

\section{Study Ia Discussion}

The results of the rectangular duct study support the logic based on the higher order mode cut-on frequency expressed in Equation 3. For low frequencies, there was no effect of changing the cross-sectional width. For high frequencies, there was a significant effect of changing the cross-sectional width, so that $\mathrm{IL}_{\max }$ decreased with increasing width. There appears to be a limit in the effect somewhere between 23 and $31 \mathrm{~cm}$ as the slope of the data changed from negative to flat.

According to Equation 3 (p. 13), the first higher order mode would depend on the larger cross-sectional height, which was fixed at $61 \mathrm{~cm}$. This mode would appear above 282 $\mathrm{Hz}$. Therefore, there should be no difference in $\mathrm{IL}_{\max }$ below this point regardless of the crosssectional width, as was seen in the data. However, above $282 \mathrm{~Hz}$, the first mode would begin, and the second mode, tied to the cross-sectional width, would begin at different points depending on the width (Table 3 and Figure 2).

Table 3. Second higher order mode cut-on frequency by cross-sectional width

\begin{tabular}{cc}
\hline $\begin{array}{c}\text { Second Higher } \\
\text { Cross-sectional } \\
\text { Width }(\mathrm{cm})\end{array}$ & $\begin{array}{c}\text { Order Mode Cut-on } \\
\text { Frequency }(\mathrm{Hz})\end{array}$ \\
\hline 7 & 2460 \\
15 & 1148 \\
23 & 749 \\
31 & 556 \\
39 & 442 \\
47 & 366 \\
55 & 313 \\
\hline
\end{tabular}

Since the cut-on frequency for the second higher order mode decreases with increasing cross-sectional width, the range of frequencies with only plane waves and the first mode also decreases with increasing width. Therefore, the $\mathrm{IL}_{\max }$ for the high frequency range should be smaller with increasing cross-sectional width, which was seen in the data. 


\section{Study Ia Conclusion}

For the high frequency $\mathrm{IL}_{\max }$ data, there was a 6 to $14 \mathrm{~dB}$ average increase in insertion loss for successively smaller cross-sectional widths $(23,15$, and $7 \mathrm{~cm})$ compared to the $31 \mathrm{~cm}$ treatment. There is a significant effect of cross-sectional width on high frequency $\mathrm{IL}_{\max }$ for rectangular ducts, and the effect follows the logic of the underlying equation.

\section{Study Ib: Round Duct}

This set of experiments attempted to describe the effects of round duct diameter on ANC insertion loss. While the only relevant variable according to Equation 1 is the duct diameter, other potential confounders were nevertheless kept constant. For instance, only steel duct of the same type and manufacturer was used in the study. Tight-fitting laser-welded center seam galvanized steel duct (Nordfab, Inc., Thomasville, GA) of diameters 4, 6, 8, 12, and 18 inches was used. Other materials or manufacturing methods were not incorporated to limit confounding.

\section{Study Ib Model and Study Design}

Study Ib was designed to test the hypothesis that there was no effect on $\mathrm{IL}_{\max }$ from changing the diameter of the round duct. Five different diameters were selected based on available sizes $(4,6,8,12$, and 18 inch). A fixed effects model was developed to describe the experiment:

$$
\mathrm{IL}_{i j}=\mu+\tau_{i}+\varepsilon_{i j}
$$

Where:

$$
\begin{aligned}
& \mathrm{IL}_{i j}=\text { insertion loss in decibels }(\mathrm{dB}) \\
& \mu=\text { average insertion loss for all treatments } \\
& \tau_{i}=\text { effect of the } i^{\text {th }} \text { diameter, } i=1,2, \ldots, a \\
& \varepsilon_{i j}=\text { random error, } j=1,2, \ldots, n
\end{aligned}
$$


This model was used to test the following hypothesis on the effect of diameter:

$$
\begin{aligned}
& \mathrm{H}_{0}: \tau_{1}=\tau_{2}=\ldots=\tau_{a}=0 \\
& \mathrm{H}_{1}: \text { at least one } \tau_{i} \neq 0
\end{aligned}
$$

Stated non-mathematically, the hypothesis was:

$\mathrm{H}_{0}:$ No effect of diameter
$\mathrm{H}_{1}:$ At least one diameter different from another

The study design used to analyze the five levels of a single treatment was the one-way analysis of variance (ANOVA) procedure. Power calculations indicated that, given the average variability in the preliminary tests $\left(\Sigma \tau_{i}^{2}=194.9\right.$ and $\left.s=2.21 \mathrm{~dB}\right)$, three replicates $(\mathrm{n}=3)$ were required to test the diameter effect with $a=5$ treatment groups with sufficient power $(\beta \leq$ 0.20) (Montgomery, 2001). The fifteen runs were randomized to prevent any bias from order or time.

Study Ib Results

The results of the round duct study are shown in Figure 13. The $\mathrm{IL}_{\max }$ values in decibels for the two dependent variables (low and high frequency) are plotted against the independent variable of duct diameter in inches. The open boxes represent the low frequency data, and the closed triangles represent the high frequency data. Linear regression lines were added to the figure to help analyze the data. 


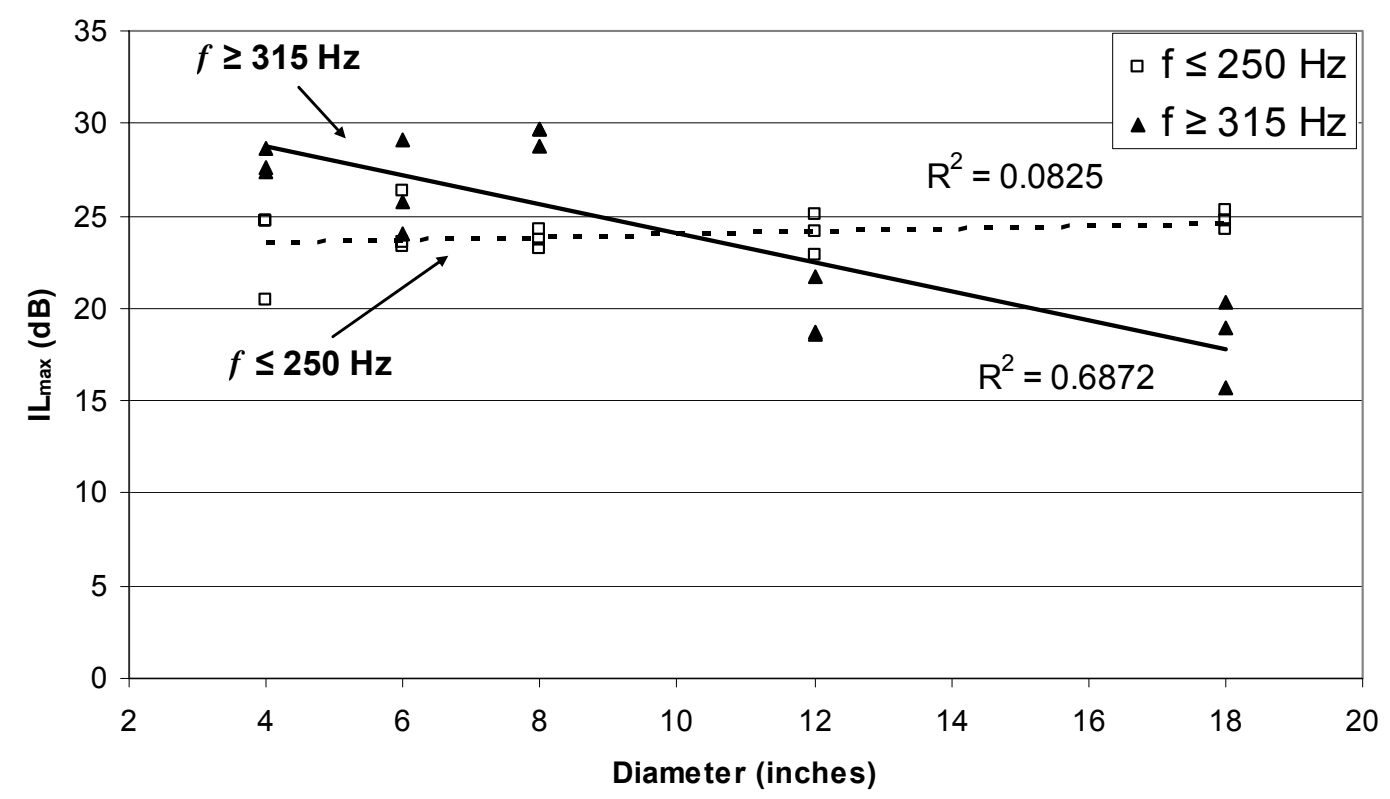

Figure 13. Study Ib Results, $\mathrm{IL}_{\max }$ by round duct diameter

Low Frequency: For the low frequency data, the best fit line does not describe the data well, with an associated $\mathrm{R}^{2}$ of only 0.0825 . However, it appears that the dependent variable does not have a very large effect on the low frequency $\mathrm{IL}_{\max }$ result. Again, the low frequency $\mathrm{IL}_{\max }$ appears constant with regards to diameter.

The treatment levels appeared to have unequal variances, so the O'Brien's test was conducted on the group variances to determine whether they were sufficiently equal (homoscedasticity). The O’Brien test returned a p-value of 0.3893 for the low frequency data set, indicating homoscedasticity, but observation of the data in Figure 13 still indicated possible heteroscedasticity. Also, the Levene's test returned $\mathrm{p}=0.0257$, indicating heteroscedasticity. Thus, although the data appear to have unequal variances, they may be considered adequately homoscedastic. ANOVA tests on the data returned $\mathrm{p}=0.7751$ (no significant effect from diameter). In case of actual heteroscedasticity, Welch's ANOVA was also run on the data to confirm the normal ANOVA results. Welch's ANOVA returned $\mathrm{p}=0.4328$ for the low frequency data with the same conclusions. 
High Frequency: The high frequency data are certainly affected by the diameter. As the diameter increases, the cut-on frequency of the first higher order mode decreases, so that the overall $\mathrm{IL}_{\max }$ at the higher frequencies should decrease as well. That is reflected in the data in Figure 12. A linear regression line fit to the data has an $\mathrm{R}^{2}$ of 0.6872 and does describe the data relationship somewhat.

The high frequency data appear to have unequal variances, since the data at 4 and 8 inches are much more tightly grouped than other treatments. Both the O’Brien and Levene tests on the high frequency data returned acceptable p-values of 0.5052 and 0.1150 , respectively. The ANOVA test gave $\mathrm{p}<0.0001$ for the high frequency data. Further, the model for the high frequency data accounted for $90 \%$ of the variability in the data according to the ANOVA. In case of actual heteroscedasticity, Welch's ANOVA returned $\mathrm{p}=0.0024$ for the high frequency data, which seemed to agree with the normal ANOVA results.

The null hypothesis that there was no effect from the cross-sectional width on the low frequency data could not be rejected at $\alpha=0.05$, while it was rejected for the high frequency data. It is important to recall that the low and high frequency groups are adjacent.

\section{Study Ib Discussion}

The estimated cut-on frequencies for the first higher order modes of the five duct sizes calculated from Equation 1 are presented in Table 4, along with the estimated dominant frequencies below which plane waves will dominate the noise signal, calculated from Equation 2. These frequencies were expected to be the upper boundary for the effective range for the simple ANC system (see Figure 6). As duct diameter increases, the upper boundary of plane wave domination decreases and $\mathrm{IL}_{\max }$ at higher frequencies should correspondingly decrease. 
Table 4. Estimated first higher order mode cut-on frequencies and maximum plane wave dominant frequencies by duct diameter

\begin{tabular}{ccc}
\hline $\begin{array}{c}\text { Diameter } \\
\text { (inches) }\end{array}$ & $\begin{array}{c}\text { Cut-on Frequency } \\
(\mathrm{Hz})\end{array}$ & $\begin{array}{c}\text { Maximum Plane Wave } \\
\text { Dominant Frequency }(\mathrm{Hz})\end{array}$ \\
\hline 4 & 1695 & 1987 \\
6 & 1130 & 1325 \\
8 & 847 & 993 \\
12 & 565 & 662 \\
18 & 377 & 442 \\
\hline
\end{tabular}

The results of the round duct study support the logic based on the higher order mode cut-on frequency Equation 1. For low frequencies below the first higher order mode cut-on frequency of the largest diameter $(377 \mathrm{~Hz})$, there was no effect of changing the diameter. In effect, all diameter systems operated on plane waves for the low frequency $\mathrm{IL}_{\max }$ data. For high frequencies, there was a significant effect of changing the diameter, so that $\mathrm{IL}_{\max }$ decreased with increasing diameter.

\section{Study Ib Conclusion}

For the high frequency $\mathrm{IL}_{\max }$ data, there was a 1.4 to $11.1 \mathrm{~dB}$ average increase in insertion loss for successively smaller diameters (12, 8, 6, and 4 inches) compared to the 18 inch diameter duct. There is a significant effect of diameter on high frequency $\mathrm{IL}_{\max }$ for round ducts that follows the logic of the underlying equation.

There is an advantage to reducing round duct diameter for high frequency ANC insertion loss. A smaller diameter round duct could be used as a cross-sectional partition for a larger round duct by inserting the smaller duct inside the larger. The ANC behavior of the small duct round cross-section was known, but the ANC behavior in the remaining crosssection of the large duct was not known. The next step would be to study the effects on $\mathrm{IL}_{\max }$ of the remaining cross-sectional space inside the large duct. 


\section{CHAPTER 3: STUDY II - INNER DUCT DIAMETER AND POSITION}

\section{Study II Unique Apparatus}

Study II was designed to test the effect on ANC insertion loss efficacy of inserting a smaller diameter round duct inside an 18 inch diameter round duct. A large 18 inch diameter round duct was used as the outer duct. Then different smaller diameter round ducts were inserted into the 18 inch duct to create cross-sectional partitions. The $\mathrm{IL}_{\max }$ was compared between different smaller duct diameters as the treatment group and also to the 18 inch large duct alone using multiple comparison techniques.

The smaller inner ducts were capped at the end facing the source speaker to reduce the sound transmitted down their interior that might radiate back into the outer duct space (see Figure 14). Since Study Ib established the ANC IL of different diameter round ducts, Study II was not concerned with the ANC IL of the smaller inner ducts but of the outer duct space left after the smaller ducts were inserted.

The large outer duct was $20 \mathrm{ft}$ long in four $5 \mathrm{ft}$ sections up to a "tee" as in Figure 6. The tee was also 18 inches in diameter, with a 4 inch diameter perpendicular branch 8 inches long for the control speaker input to the system. The tee was $2 \mathrm{ft}$ long. After the tee, an additional $5 \mathrm{ft}$ length of 18 inch diameter duct was added with acoustic foam at the far end to reduce reflections. All junctions between $5 \mathrm{ft}$ sections were sealed with gasketed clamps. The control speaker was held in place with gravity and a gasket that sealed the air space between the speaker and the 4 inch diameter tee branch. Microphones were suspended 2 inches below the top of the 18 inch duct directed toward the source speaker. The microphones were suspended by nonconductive means (duct tape attached to foam holder) so that duct surface vibration would not transfer to and contaminate the microphone signals (similar to Figure 11).

The inner ducts were similar to the 18 inch duct except they were straight runs of sealed, clamped duct $25 \mathrm{ft}$ long with no tee. The effect of the position of the duct, whether concentric to or sitting at the bottom of the outer duct (tangent), was investigated in the first stage of the study (IIa). The tangent position was achieved by simply placing the inner duct at the bottom of the outer duct. The concentric position was achieved by placing two 18 inch long $3 / 8$ " threaded steel rods in each $5 \mathrm{ft}$ section of inner duct. The inner ducts were held in 
place at the center of the rods by nuts. The inner ducts were then inserted into the 18 inch outer duct and clamped together (see Figure 14).

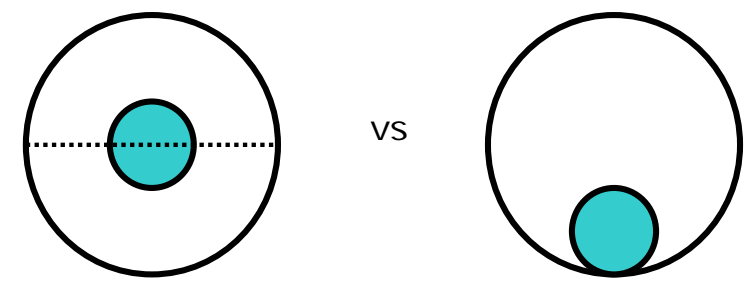

Figure 14. Study IIa Apparatus, End view of concentric vs. tangent inner duct position

The second stage of Study II (IIb) investigated the effect of different diameter inner ducts on the ANC IL in the remaining area of the 18 inch diameter outer duct as shown in Figure 15. The inner ducts were 6 inch, 8 inch, 12 inch, and 16 inch diameter. The empty 18 inch diameter outer duct was also tested as a treatment group with which to compare all other treatments.

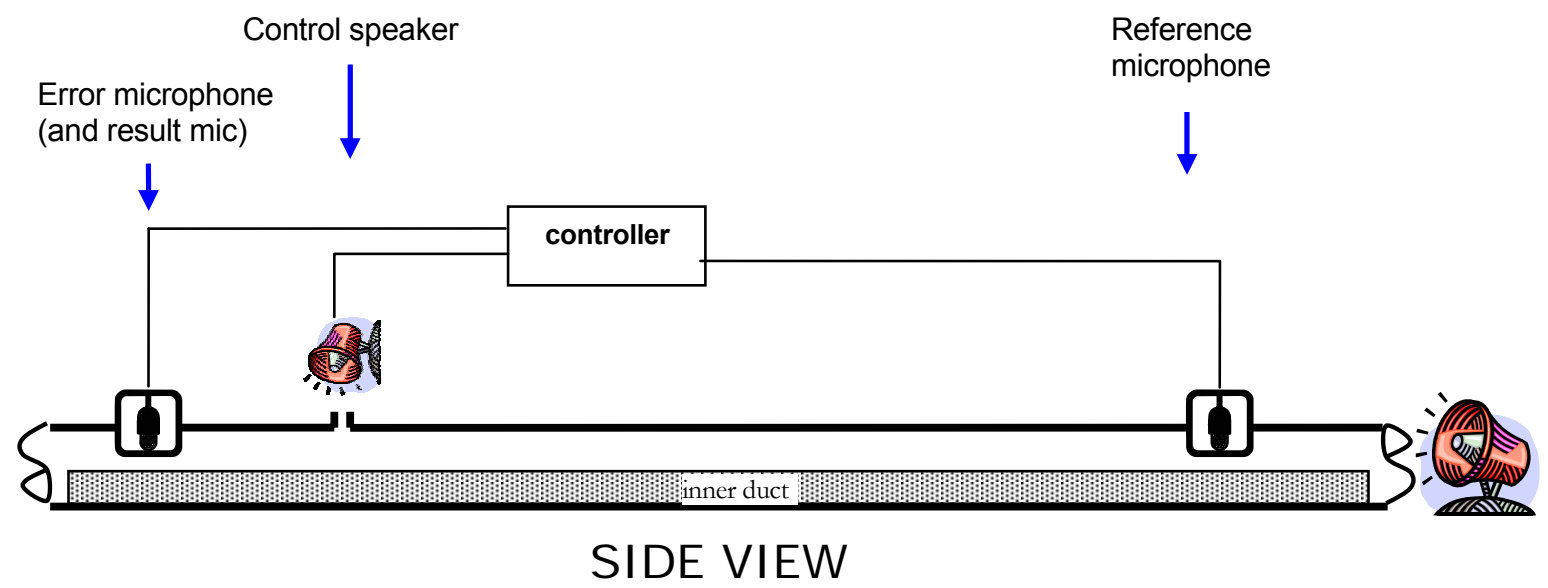

Figure 15. Study IIb Apparatus, Inner duct diameter apparatus

Study II a Model and Study Design

Study IIa was designed to test the hypothesis that there was no effect on $\mathrm{IL}_{\max }$ from the shape of the remaining open space of the large diameter 18 inch outer duct. The 
remaining space was either a ring shape or a crescent depending on whether the inner duct position was concentric or tangent (see Figure 14). Several preliminary runs seemed to indicate that the 6 and 8 inch inner duct diameters gave the most consistent results. For that reason, they were selected as the two comparison groups, allowing exploration of interactive effects of inner duct diameter and position. A factorial experiment was conceived to capture the possible interaction effects of diameter and position. The following fixed effects model was developed to describe the experiment:

$$
\mathrm{IL}_{i j k}=\mu+\tau_{i}+\beta_{j}+(\tau \beta)_{i j}+\varepsilon_{i j k}
$$

Where:

$$
\begin{aligned}
& \mathrm{IL}_{i j k}=\text { insertion loss in decibels }(\mathrm{dB}) \\
& \mu=\text { average insertion loss for all treatments } \\
& \tau_{i}=\text { effect of the } i^{\text {th }} \text { diameter, } i=1,2, \ldots, a \\
& \beta_{j}=\text { effect of the } j^{\text {th }} \text { position, } \mathrm{j}=1,2, \ldots, b \\
& (\tau \beta)_{i j}=\text { effect of the interaction of diameter and position } \\
& \varepsilon_{i j k}=\text { random error, } k=1,2, \ldots, n
\end{aligned}
$$

This model was used to test the following hypotheses on the effects of diameter, position, and their interaction:

Diameter:

$$
\mathrm{H}_{0}: \tau_{1}=\tau_{2}=\ldots=\tau_{a}=0
$$

$\mathrm{H}_{1}$ : at least one $\tau_{i} \neq 0$

Position:

$$
\mathrm{H}_{0}: \beta_{1}=\beta_{2}=\ldots=\beta_{b}=0
$$

$\mathrm{H}_{1}$ : at least one $\beta_{j} \neq 0$

Interaction:

$\mathrm{H}_{0}:(\tau \beta)_{11}=(\tau \beta)_{21}=\ldots=(\tau \beta)_{a b}=0$

$\mathrm{H}_{1}$ : at least one $(\tau \beta)_{i j} \neq 0$ 
Stated non-mathematically, the hypotheses were:

Diameter

$\mathrm{H}_{0}$ : No effect of inner duct diameter (8" vs. 6")

$\mathrm{H}_{1}$ : At least one inner duct diameter different

Position

$\mathrm{H}_{0}$ : No effect of inner duct position (concentric vs. tangent)

$\mathrm{H}_{1}$ : At least one inner duct position different

Diameter x Position interaction

$\mathrm{H}_{0}$ : No effect of inner duct diameter and position interaction

$\mathrm{H}_{1}$ : At least one interaction different

The study design used to analyze two levels of two different treatments was the twoway analysis of variance (ANOVA) procedure. Power calculations indicated that, given the average variability in the preliminary tests $\left(\Sigma \tau_{i}^{2}=5.13, \Sigma \beta_{j}^{2}=1.27, \Sigma(\tau \beta)_{i j}^{2}=26.94\right.$, and $s=$ $0.85 \mathrm{~dB})$, two replicates $(\mathrm{n}=2)$ were required to test the inner duct diameter effect with $a=2$ treatment groups ( 6 and 8 inch), the position effect with $b=2$ treatment groups (concentric vs. tangent), and the interaction of the two effects with sufficient power $(\beta \leq 0.20)$ (Montgomery, 2001). The eight runs were randomized to prevent any bias from order or time.

\section{Study IIa Results}

The results of the inner duct position study are shown in Figure 16. The $\mathrm{IL}_{\max }$ values in decibels for the two dependent variables (low and high frequency) are plotted against the independent variable of inner duct position as a categorical variable. The open boxes represent the 6 inch inner duct diameter data, and the closed triangles represent the 8 inch inner duct diameter data. Low frequency $\mathrm{IL}_{\max }$ results were slightly higher than high frequency, and the two frequency regions are denoted by brackets on the figure. 


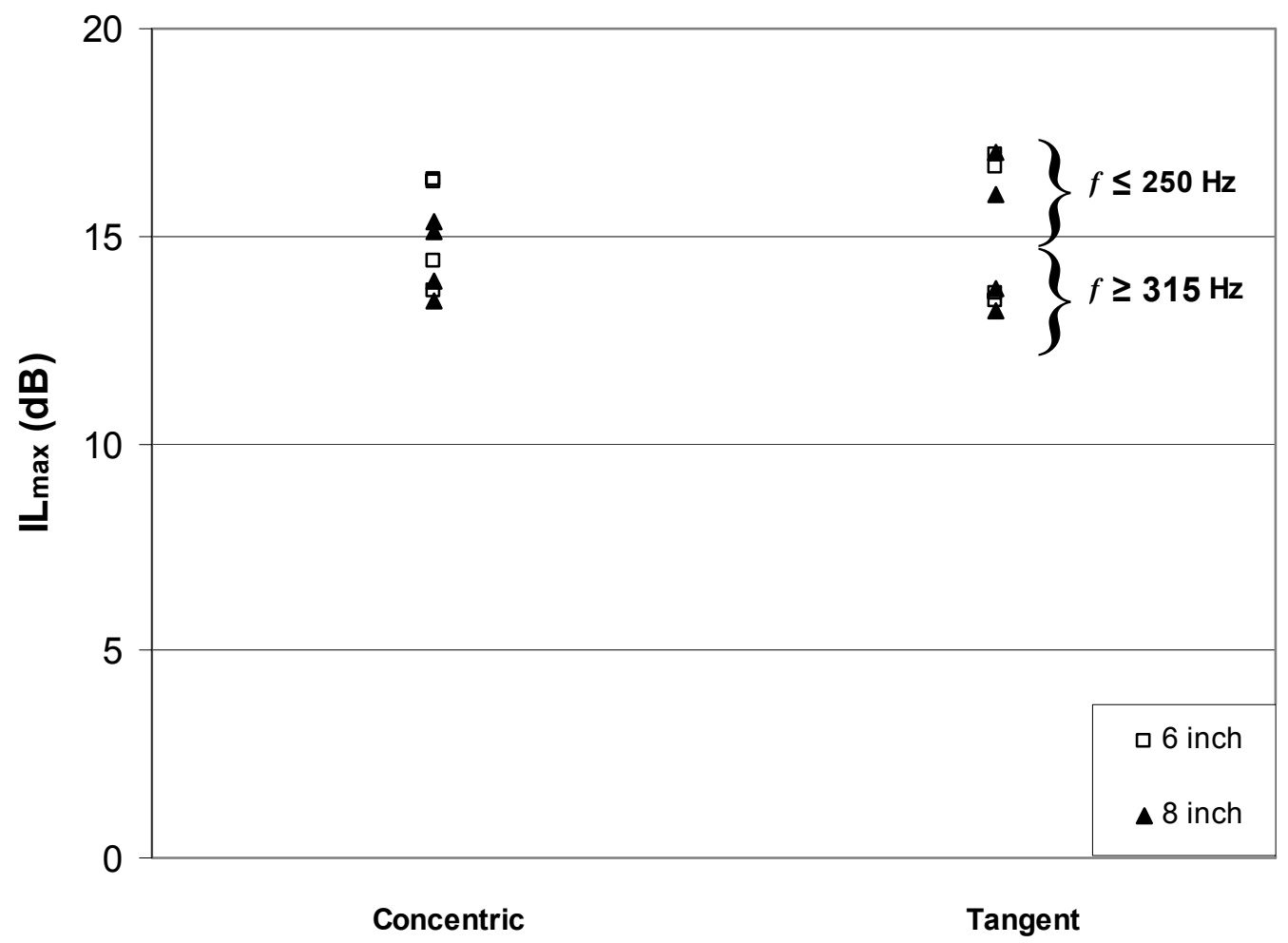

Duct Position

Figure 16. Study IIa Results, $\mathrm{IL}_{\max }$ by inner duct position and diameter

It appears that neither the inner duct position, the inner duct diameter, nor their interaction have large effects on the high frequency $\mathrm{IL}_{\max }$ result. The low frequency data may be affected by the inner duct diameter in the concentric position, but not the tangent position. Therefore, there may be an interaction effect for the low frequency $\mathrm{IL}_{\text {max }}$ data.

The treatment levels appeared to have equal variances. Bartlett's test for homogeneity of variances was performed on the cell variances and returned $\mathrm{p}=0.2484$ for low frequency, and $\mathrm{p}=0.8249$ for high frequency. The result of Bartlett's test was that the variances were homogeneous; however, as there were only two samples per dependent variable combination, the normality of variance distributions could not be adequately checked. Since Bartlett's test is sensitive to departures from normality, further confidence was desired. A plot of the residuals for the low frequency data in Figure 17 seemed to indicate unequal variances. A plot of the 
residuals for the high frequency data in Figure 18 may also indicate unequal variances. Thus, although the data appear to have unequal variances, they may be sufficiently homoscedastic to allow a two-way ANOVA. Three variance-stabilizing transformations were attempted (logarithm, square root, and the inverse) without any better effect.

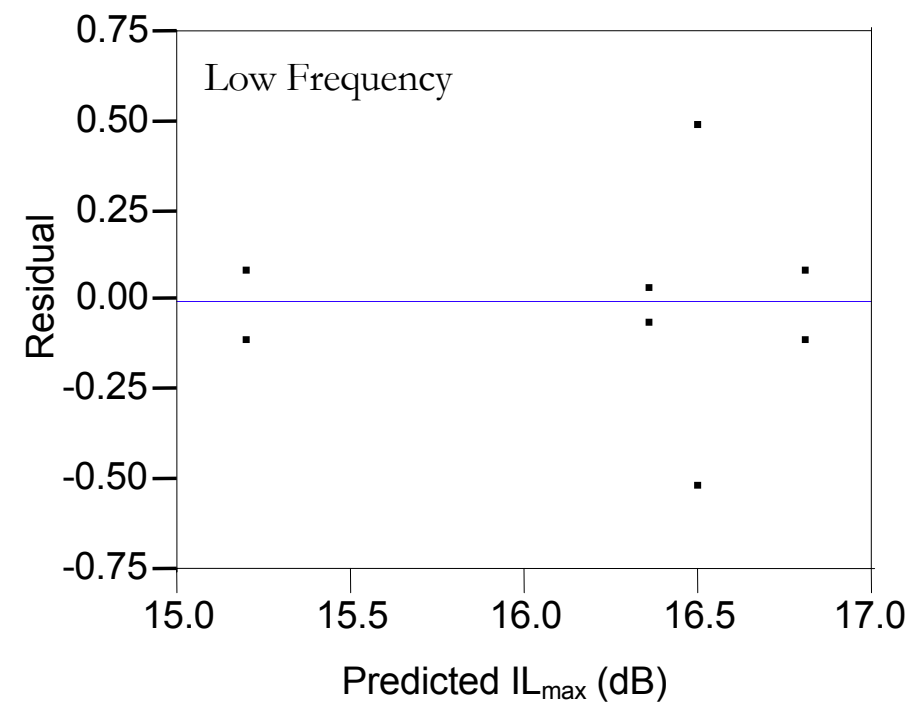

Figure 17. Study IIa Results, low frequency residuals vs predicted values for inner duct position and diameter study 


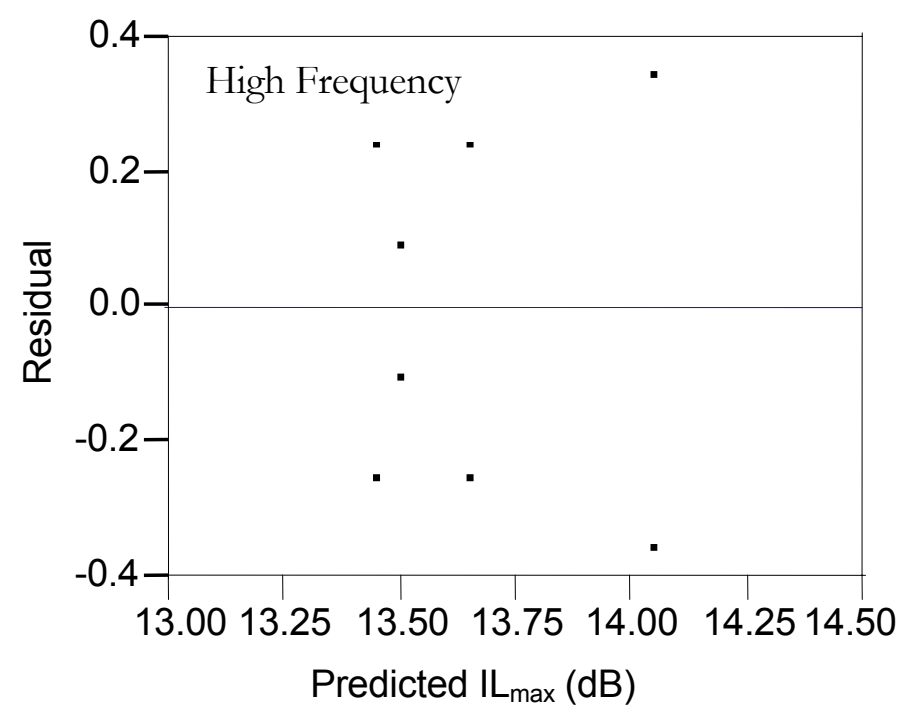

Figure 18. Study IIa Results, high frequency residuals vs. predicted values for inner duct position and diameter study

The results of the various ANOVA tests are listed in Table 5. For the low frequency data, the only significant independent variable in the model according to the two-way ANOVA was the inner duct diameter $(\mathrm{p}=0.0499)$. There were no significant variables for the high frequency data. In case of actual inequality of variances, Welch's ANOVA was also run on the data. However, Welch's was not designed for the two-way ANOVA. The results of Welch's ANOVA on each independent variable separately were that none of the variables were significant in describing the variation of the dependent variables. Therefore Welch's tends to corroborate the two-way ANOVA results.

The null hypotheses that there was no effect from the inner duct diameter on the low frequency data could be rejected at $\alpha=0.05$, if the equality of variances assumption was actually met. All other hypotheses could not be rejected. 
Table 5. Study IIa Results, p-values for inner duct position and diameter ANOVA tests

\begin{tabular}{|c|c|c|c|c|}
\hline \multirow[b]{2}{*}{ Parameter } & \multicolumn{2}{|c|}{ Low Frequency } & \multicolumn{2}{|c|}{ High Frequency } \\
\hline & $\begin{array}{c}\text { 2-way } \\
\text { p-value }\end{array}$ & $\begin{array}{l}\text { 1-way* } \\
\text { p-value }\end{array}$ & $\begin{array}{r}\text { 2-way } \\
\text { p-value }\end{array}$ & $\begin{array}{l}\text { 1-way* } \\
\text { p-value }\end{array}$ \\
\hline Position & 0.2898 & 0.0799 & 0.2001 & 0.1811 \\
\hline Inner Duct Diameter & 0.0499 & 0.1906 & 0.4253 & 0.4354 \\
\hline Position x Diameter & 0.1788 & $\mathrm{n} / \mathrm{a}$ & 0.5283 & $\mathrm{n} / \mathrm{a}$ \\
\hline
\end{tabular}

*Welch's ANOVA procedure

\section{Study IIa Discussion}

As stated previously, the main objective of Study IIa was to determine where to position the inner ducts in subsequent 2-duct studies. Although interpretation of the results was not as straightforward as other studies, the data seem to indicate that there is no significant difference in effect on the independent variables of low and high frequency ANC insertion loss from concentric vs. tangent inner duct position. There does not appear to be a significant effect from the interaction of inner duct diameter and position. Although there may be a significant effect from inner duct diameter, a separate study (IIb) was already planned to assess that difference. Therefore, since the tangent inner duct position was much easier to set up between runs and allows for an easy access for control speakers to the inner ducts for Study III, the tangent position was selected for subsequent studies.

\section{Study IIa Conclusion}

There was no significant difference between tangent and concentric inner duct position for the 6 inch and 8 inch duct diameters for low and high frequency. Since the tangent position was much easier to study, the tangent inner duct position was selected for subsequent studies.

\section{Study IIb: Inner Duct Diameter}

\section{Study IIb Model and Study Design}

Study IIb was designed to test the hypothesis that there was no effect on $\mathrm{IL}_{\max }$ in the remaining crescent-shaped open cross-section of the large diameter 18 inch outer duct from changing the diameter of the inner duct. Tested inner diameters were zero inch (no-inner- 
duct), 6, 8, 12, and 16 inches. Based on Study IIa findings, all inner ducts were positioned tangent to the bottom of the outer duct. Since the only effect being studied was the inner duct diameter effect, a single factor fixed effects model was sufficient for the study design. The statistical model assumed was:

$\mathrm{IL}_{i j}=\mu+\tau_{i}+\varepsilon_{i j}$

Where:

$\mathrm{IL}_{i j}=$ insertion loss in decibels $(\mathrm{dB})$

$\mu=$ average insertion loss for all treatments

$\tau_{i}=$ effect of the $i^{\text {th }}$ inner diameter, $i=1,2, \ldots, a$

$\varepsilon_{i j}=$ random error $j=1,2, \ldots, n$

This model was used to test the following hypothesis on the effect of diameter:

$\mathrm{H}_{0}: \tau_{1}=\tau_{2}=\ldots=\tau_{a}=0$

$\mathrm{H}_{1}$ : at least one $\tau_{i} \neq 0$

Stated non-mathematically, the hypothesis was:

$\mathrm{H}_{0}$ : No effect of inner duct diameter

$\mathrm{H}_{1}$ : At least one inner duct diameter different

Power calculations indicated that, given the average variability in the preliminary tests $\left(\Sigma \tau_{i}^{2}=5.13\right.$ and $\left.s=0.83 \mathrm{~dB}\right)$, three replicates $(\mathrm{n}=3)$ were required to test the inner duct diameter effect with $a=5$ treatment groups $(0,6,8,12$, and 16 inch) with sufficient power $(\beta \leq 0.20)$ (Montgomery, 2001). The fifteen runs were randomized to prevent any bias from order or time.

Study IIb Results

The results by frequency region for all the inner duct diameter are displayed in Figure 19. The $\mathrm{IL}_{\max }$ values in decibels for the two dependent variables (low and high frequency) are plotted against the independent variable of inner duct diameter in inches. The open boxes represent the low frequency data, and the closed triangles represent the high frequency data. Linear regression lines were added to the figure to help visualize the data. 


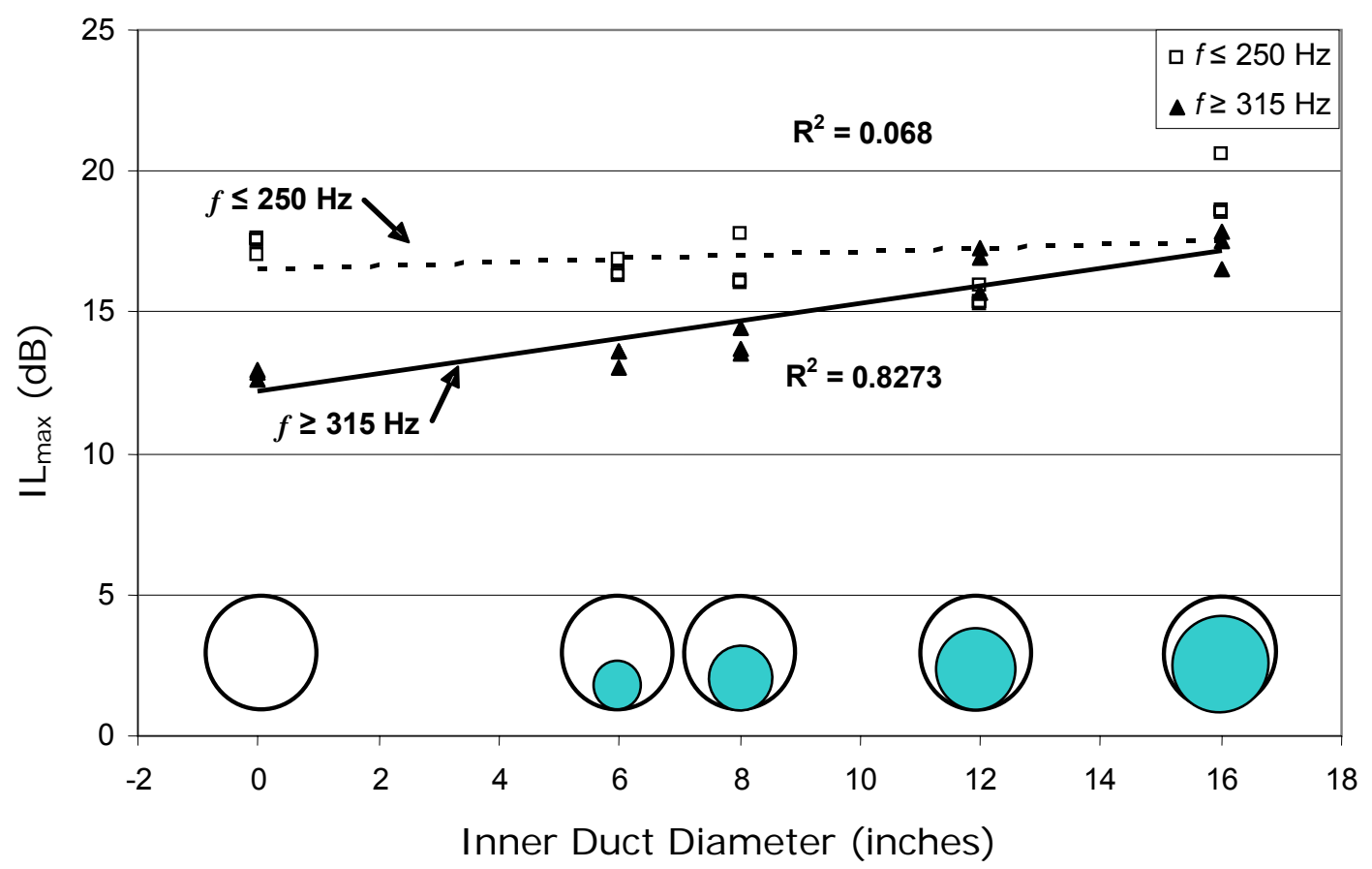

Figure 19. Study IIb Results, IL $L_{\max }$ by inner duct diameter

Low Frequency: For the low frequency data, the best fit line does not describe the data well, with an associated $\mathrm{R}^{2}$ of only 0.068. It appears that the independent variable does not have an effect on the low frequency $\mathrm{IL}_{\max }$ result. In other words, a constant value explains the data well, as was expected.

The treatment levels appeared to have unequal variances, so the O'Brien's test was conducted on the group variances to determine whether they were sufficiently equal (homoscedasticity). The O'Brien test returned a p-value of 0.4002 for the low frequency data set, indicating homoscedasticity, but observation of the data in Figure 19 still indicated possible heteroscedasticity. Also, Levene's test returned $\mathrm{p}=0.0195$, indicating heteroscedasticity. Thus, although the data appear to have unequal variances, they may be considered homoscedastic. ANOVA tests on the data returned $\mathrm{p}=0.0012$ for the low frequency data. Further, the model accounted for $81 \%$ of the sums of squares variability for the low frequency data. In case of actual heteroscedasticity, Welch's ANOVA was also run on the data to confirm the normal 
ANOVA results. Welch's ANOVA returned $\mathrm{p}=0.0157$ for the low frequency data. The null hypothesis was rejected at $\alpha=0.05$ for the low frequency data. There was an effect from the diameter on $\mathrm{IL}_{\max }$.

High Frequency: The high frequency data were certainly affected by the inner duct diameter. As the diameter increases and the open crescent-shaped air space in the outer 18 inch duct decreases, the cut-on frequency of the first higher order mode increases, so that the overall $\mathrm{IL}_{\max }$ at the higher frequencies should increase as well. That was reflected in the data in Figure 19. A linear regression line fit to the high frequency data had an $R^{2}$ of 0.8273 and did describe the data relationship somewhat.

Both the O'Brien and Levene tests for equality of variances on the high frequency data returned acceptable p-values of 0.5447 and 0.1001 , respectively. The ANOVA returned $\mathrm{p}<0.0001$ for the high frequency data. Further, the model accounted for $94 \%$ of the sums of squares variability for the high frequency data. In case of inequality of variances, Welch's ANOVA was run for comparison and returned $\mathrm{p}=0.0020$ for the high frequency data, which agreed with the normal ANOVA results.

Low Frequency Multiple Comparisons: While this analysis concluded that the model was a good description of the data and that the inner diameter was important, the more important question was whether the different treatments were different from the open duct (zero inch inner diameter). The cell means and groups using the Tukey-Kramer Honestly Significant Difference (HSD) multiple comparison technique are listed in Table 6 for the low frequency data.

Table 6. Study IIb Results, Multiple comparison groups of inner duct diameter treatment means for low frequency ANC insertion loss data

\begin{tabular}{lccccc}
\hline Inner Diameter (inch) & 0 & 6 & 8 & 12 & 16 \\
\hline Mean IL (dB) & 17.4 & 16.5 & 16.6 & 15.6 & 19.2 \\
Group A* & $\mathrm{x}$ & & & & $\mathrm{x}$ \\
Group B* & $\mathrm{x}$ & $\mathrm{x}$ & $\mathrm{x}$ & $\mathrm{x}$ & \\
*A = all treatments with similar means & & & & \\
*B = all treatments with similar means & & & &
\end{tabular}


The ANC insertion loss performances of the system with inner duct diameters of 0,6 , 8, and 12 inches were not significantly different from one another (group B). Also, while the 16 inch inner duct diameter system was different from the 6, 8, and 12 inch systems, it was not statistically different from the control treatment of zero inch (group A). These results indicated that for the low frequency region $(20-250 \mathrm{~Hz})$, there was no significant advantage to inserting inner ducts for cross-sectional partitioning inside the 18 inch outer duct. A visual inspection of the data points with the confidence intervals of the treatment means shown as error bars supported the statistical conclusions (Figure 20).

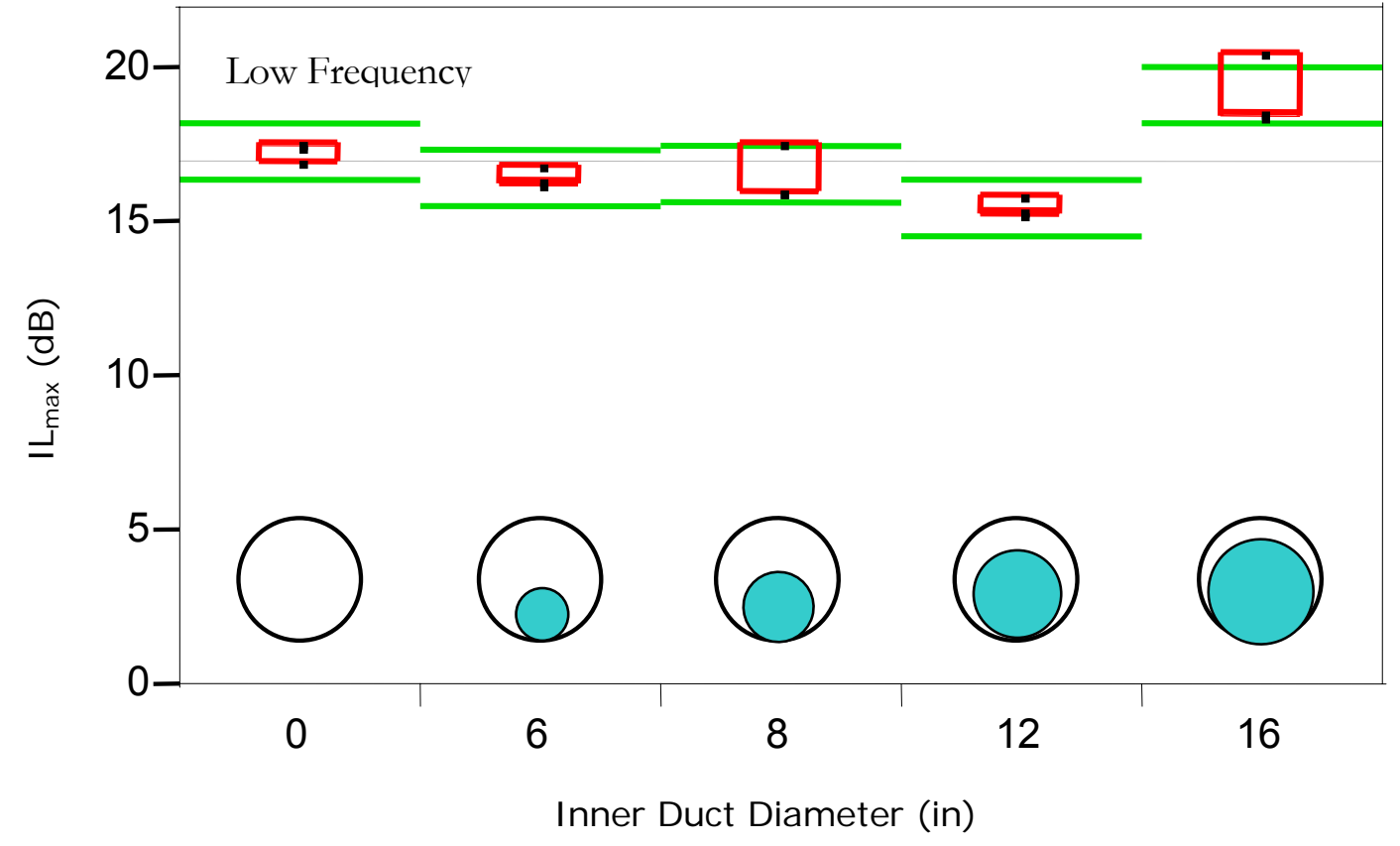

Figure 20. Study IIb Results, Low frequency inner duct diameter data treatment means comparisons with sketches of treatment conditions

High Frequency Multiple Comparisons: For the high frequency data, the analysis concluded that the model was a good description of the data and that the inner diameter was also important, but the more important question was still whether the different treatments were different from the open duct (zero inch inner diameter). The cell means and groups 
using the Tukey-Kramer Honestly Significant Difference (HSD) multiple comparison technique are listed in Table 7 for the high frequency data.

Table 7. Study IIb Results, Multiple comparison groups of inner duct diameter treatment means for high frequency ANC insertion loss data

\begin{tabular}{lccccc}
\hline Inner Diameter (inch) & 0 & 6 & 8 & 12 & 16 \\
\hline Mean IL (dB) & 12.9 & 13.4 & 13.9 & 16.6 & 17.3 \\
Group A* & & & & x & x \\
Group B* & x & x & x & &
\end{tabular}

$* \mathrm{~A}=$ all treatments with similar means

$* \mathrm{~B}=$ all treatments with similar means

The ANC insertion loss performances of the system with inner duct diameters of 0,6 , and 8 inches were not significantly different from one another (group B). The ANC insertion loss of the 12 and 16 inch diameter inner ducts was significantly higher than the other conditions (group A). These results indicated that for the high frequency region $(315-5 \mathrm{k} \mathrm{Hz})$, there was no significant advantage to inserting 6 or 8 inch diameter inner ducts for crosssectional partitioning inside the 18 inch outer duct. However, inserting 12 or 16 inch diameter inner ducts resulted in an average $3.7-4.4 \mathrm{~dB}$ increase in ANC insertion loss above the 18 inch diameter duct alone. 


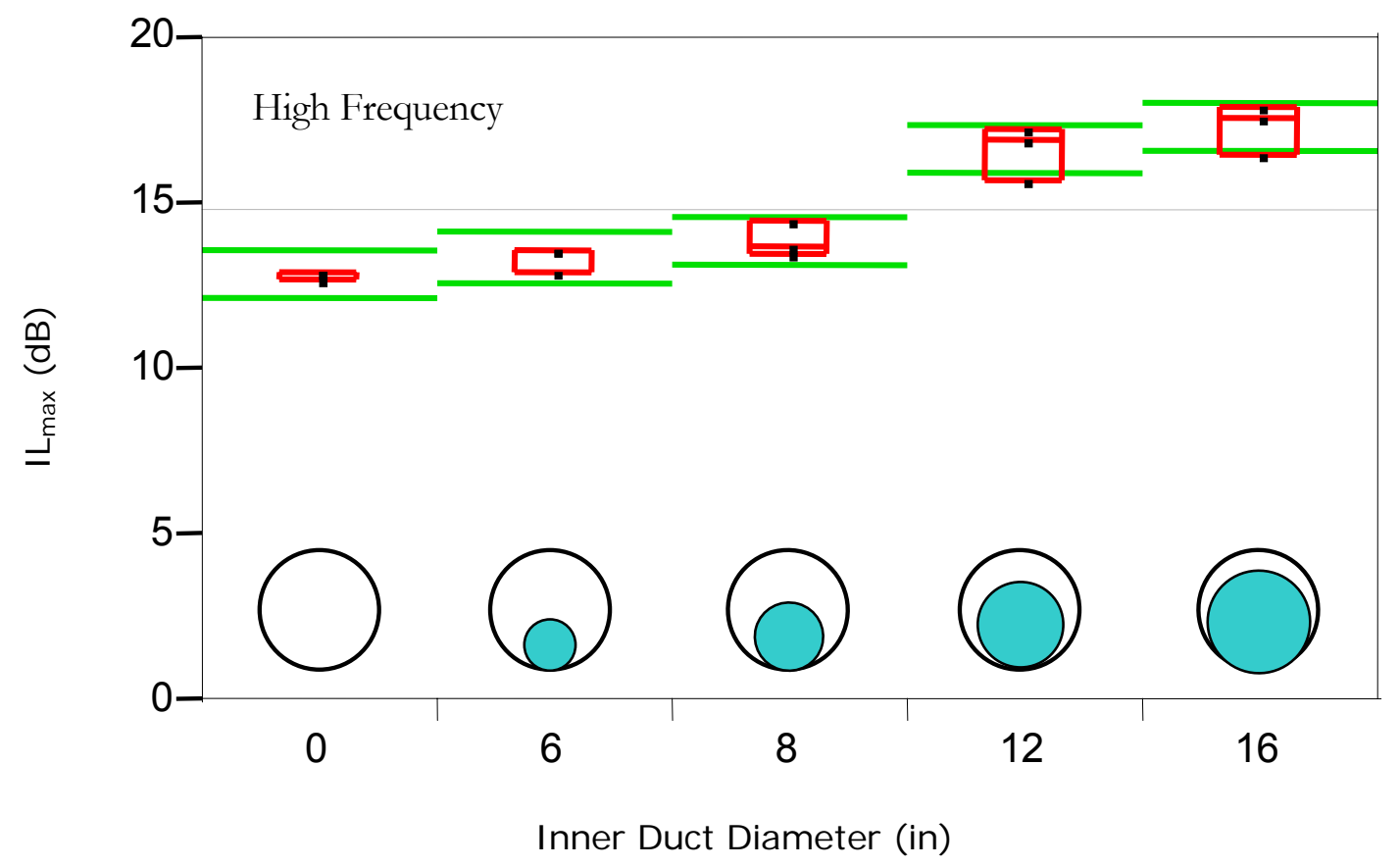

Figure 21. Study IIb Results, High frequency inner duct diameter data treatment means comparisons with sketches of treatment conditions

A visual inspection of the data points with the confidence intervals of the treatment means drawn in as error bars (Figure 21) supported the statistical conclusions that the 12 and 16 inch diameter inner duct treatments resulted in higher ANC insertion loss than the other treatments.

\section{Study IIb Discussion}

The purpose of this second stage of the two duct study (Study IIb) was to determine whether there was a significant effect on ANC insertion loss from the size of the remaining crescent-shaped space inside the 18 inch diameter outer duct when inner ducts of diameters 6 , 8,12 , and 16 inches were inserted as cross-sectional partitions. The inner duct diameter stage of the study indicated that ANC insertion loss in the low frequency region was not significantly affected by inner duct diameter. However, there was a significant increase in ANC insertion loss at higher frequencies when the inner duct diameters were large enough. 


\section{Study IIb Conclusion}

The results of the inner diameter stage of Study II indicated that it would be prudent to test only the 12 and 16 inch diameter inner ducts for Study III. However, since there was very little open space inside the 18 inch outer duct with the 16 inch inner duct inserted so that it may be impractical to implement, the 12 inch inner diameter duct was selected for Study III. 


\section{CHAPTER 4: STUDY III - SIMULTANEOUS DUAL-DUCT OPERATION}

The logical progression in the overall research to examine the effects of cross-sectional partitioning on ANC insertion loss was to make both inner and outer ducts "live" by having ANC activated for both simultaneously. There were two stages to the third study as well; first to run two independent full ANC systems on the two ducts, then to see if the amount of hardware could be reduced on one of the ANC duct systems to reduce costs. In both stages, the cross-sectional partitioned treatment was compared to ANC within the 18 inch outer duct alone.

\section{Study III Unique Apparatus}

Study III used the previously described 18 inch outer duct, with a 12 inch inner duct inserted. Based on the Study II finding that coaxial was no better than the more convenient tangent placement, a 12 inch inner diameter duct was placed tangent to the bottom of the 18 inch outer duct. The inner duct was open to the same source noise and had a separate reference microphone, control speaker, and error microphone (see Figure 22). The 12 inch ANC was run by a separate set of channels on the same active noise controller as the 18 inch outer duct. A 4 inch diameter, 8 inch long piece of duct connected the control speaker to the 12 inch duct through the wall of the 18 inch duct. The control speaker for the 12 inch system was isolated inside a $3.4 \mathrm{ft}^{3}$ plywood box to reduce cross-contamination of noise between the two ducts (see Figure 23). The gaps between the plywood box and the 4 inch diameter control speaker tube, as well as the 18 inch outer duct wall and the 4 inch tube, were packed with acoustic foam and sealed with duct tape to reduce noise cross-contamination. 


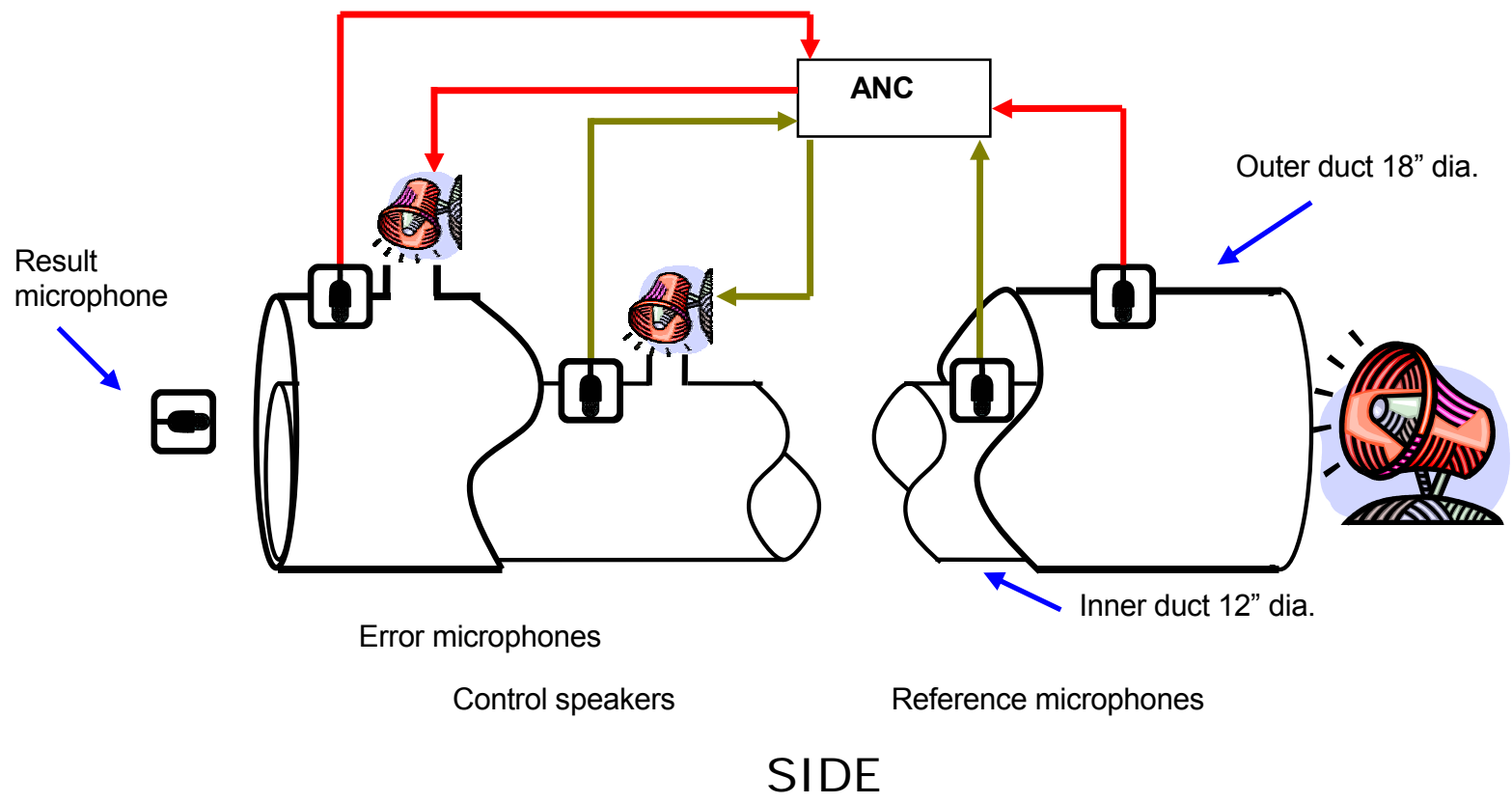

Figure 22. Study III Apparatus, Side view

In order to compare the difference in overall ANC insertion loss with and without the inner duct system in place, a separate result microphone was placed at the center of the end of the 18 inch duct, 4 in past the end (see Figure 22). Both stages of the study compared a simultaneous dual-duct system to a single 18 inch duct system, as in Figure 23. 

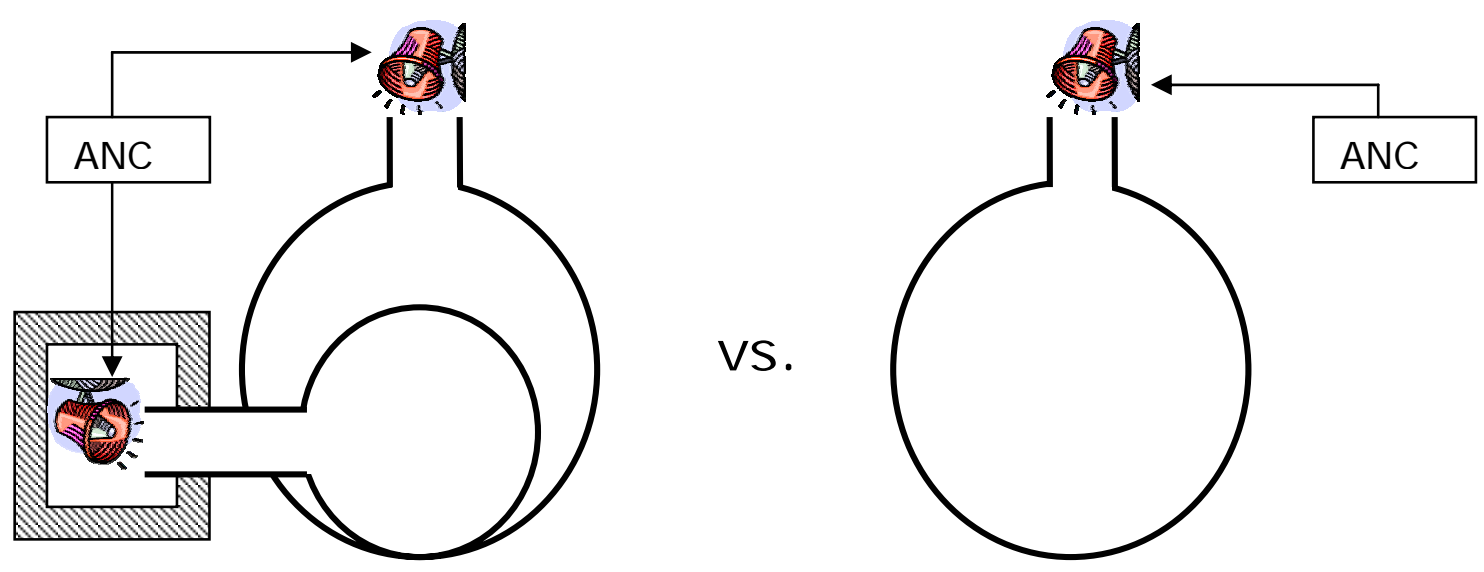

12 " duct inside 18" duct with dual ANC controls
18" duct with single ANC controls

Figure 23. Study III Apparatus, end view of apparatus with control speakers

The second stage of the study (Study IIIb) was to determine whether a reduced hardware system could still return better ANC insertion loss than the 18 inch duct ANC alone. Preliminary studies attempted to eliminate hardware and check the stability of the system. When an error microphone from either the 18 inch or 12 inch system was removed, the system became too unstable to measure within seconds and had to be shut down to protect the speakers. When a single control speaker signal was sent to each control speaker, there was no measurable ANC insertion loss for either system. The only viable hardware reduction scheme was determined to be eliminating the reference microphone from the 18 inch outer duct system and feeding the 12 inch inner duct reference microphone signal to the outer duct control channels and algorithm. 


\section{Study IIIa: Simultaneous Dual-duct Operation}

\section{Study III Model and Study Design}

Study IIIa was designed to test the hypothesis that there was no difference in $\mathrm{IL}_{\max }$ between employing one and two channels for controls. For the latter, one channel controlled the inner duct and the second controlled the gap between the two ducts. The statistical model for this simple comparative experiment was:

$$
\mathrm{IL}_{i j}=\mu_{i}+\varepsilon_{i j}
$$

Where:

$$
\begin{aligned}
& \mathrm{IL}_{i j}=\text { insertion loss in decibels }(\mathrm{dB}) \\
& \mu_{i}=\text { average insertion loss at the } i^{\text {th }} \text { factor level, } i=1,2, \ldots, a \\
& \varepsilon_{i j}=\text { random error, } j=1,2, \ldots, n
\end{aligned}
$$

This model was used to test the following hypothesis on the comparison of the two treatments:

$$
\begin{aligned}
& \mathrm{H}_{0}: \mu_{1}=\mu_{2} \\
& \mathrm{H}_{1}: \mu_{1} \neq \mu_{2}
\end{aligned}
$$

Stated non-mathematically, the hypothesis was:

$\mathrm{H}_{0}$ : No difference between the 18 inch duct system alone and the dual duct system operated simultaneously

$\mathrm{H}_{1}$ : There is a difference

Power calculations indicated that, given the average variability in the preliminary tests $(s=1.72 \mathrm{~dB})$ and the desired detectable difference $(\delta=1.5 \mathrm{~dB})$, four replicates $(\mathrm{n}=4)$ were required to compare the means with $a=2$ treatment groups (single vs. dual) with sufficient power $(\beta \leq 0.20)$ (Montgomery, 2001). The eight runs were randomized to prevent any bias from order or time.

\section{Study IIIa Results}

As with previous results, significant differences were found for the higher but not the lower frequency range. 


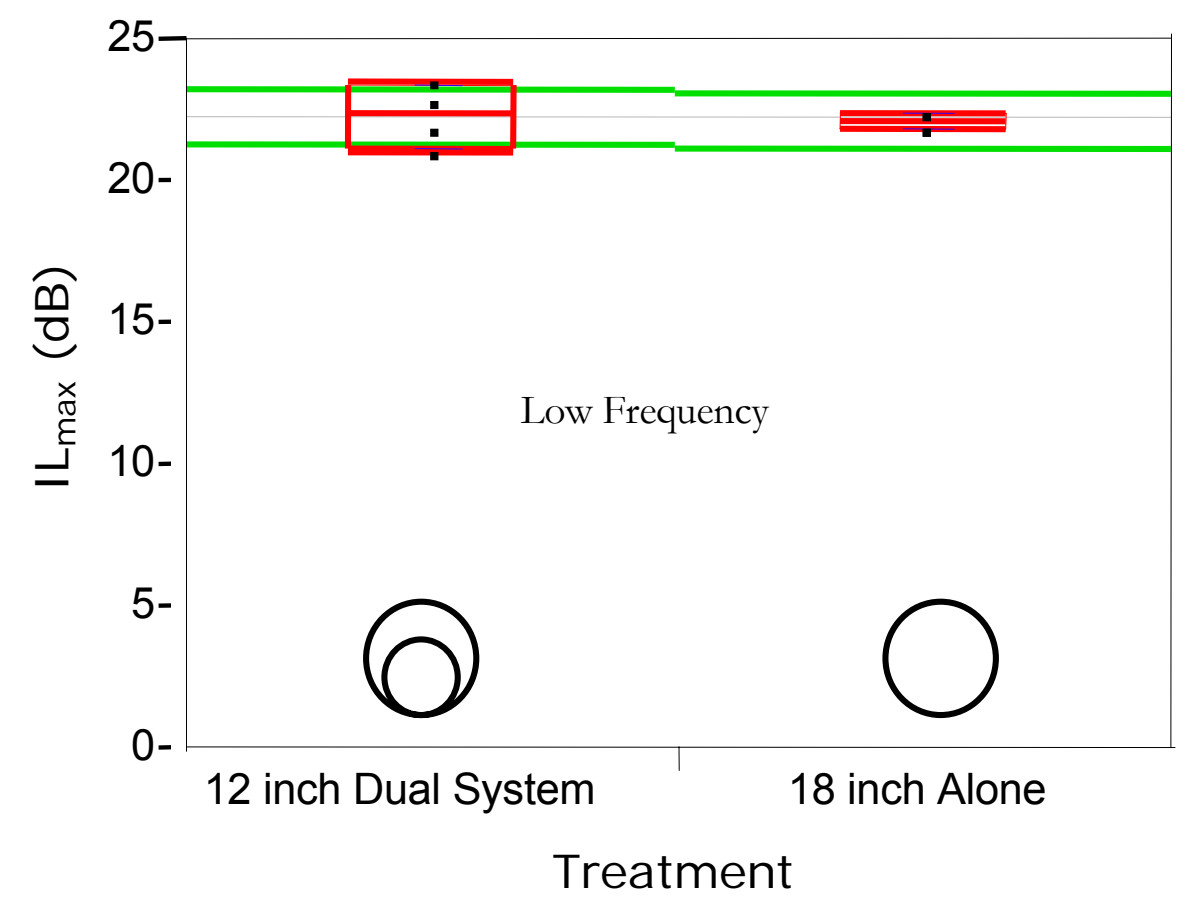

Figure 24. Study IIIa Results, Low frequency comparison of $\mathrm{IL}_{\max }$ by treatment (Dual 12 inch full hardware system vs. 18 inch single system)

Low Frequency: The results for the low frequency $\mathrm{IL}_{\max }$ comparison between the dual system and the single 18 inch system are displayed in Figure 24. An unequal variance t-test indicated that the two treatment groups were not significantly different $(\mathrm{p}=0.3749)$. The graph of the data supported that result, as the variances were very different and the $\mathrm{IL}_{\max }$ values for the two groups overlap. 


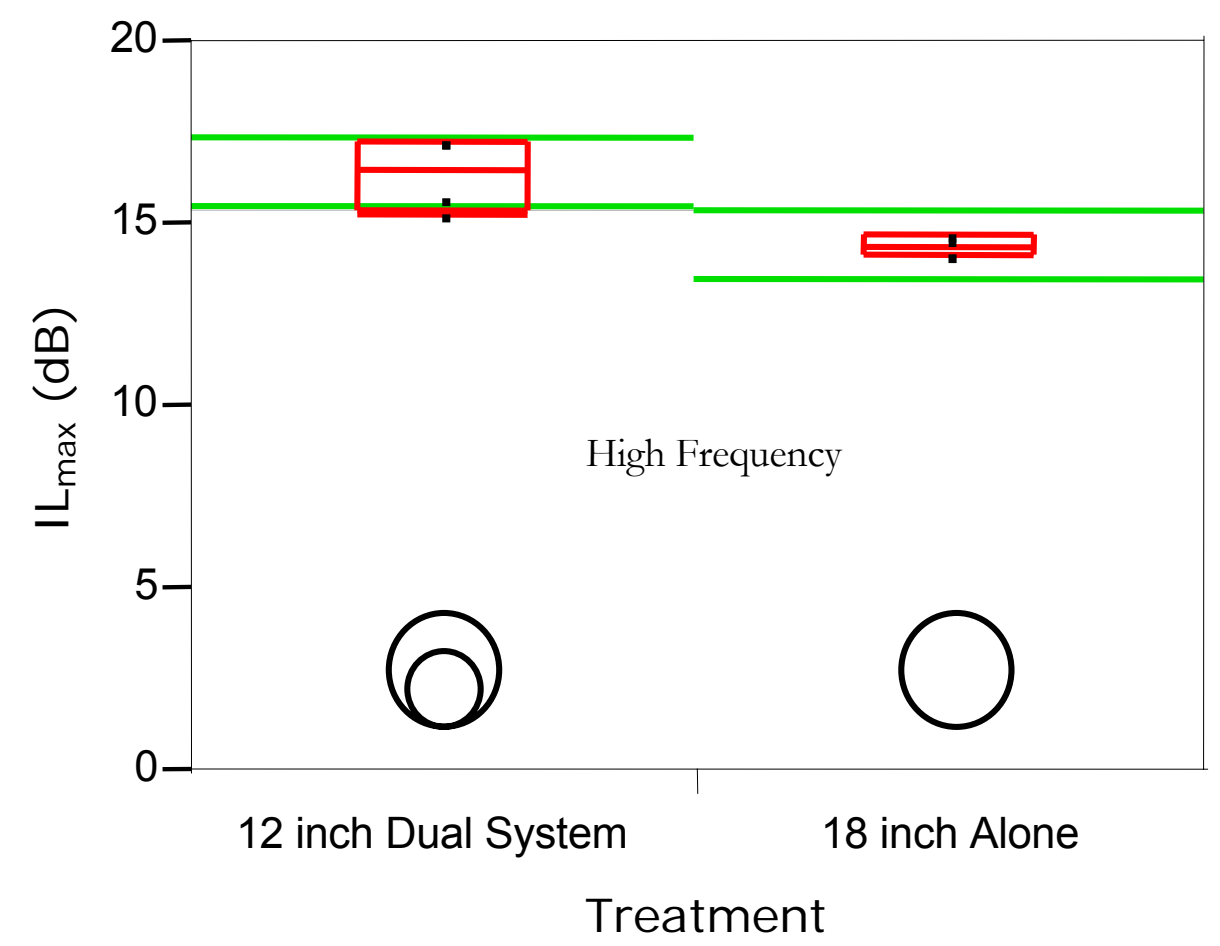

Figure 25. Study IIIa Results, High frequency comparison of IL $\mathrm{L}_{\max }$ by treatment (Dual 12 inch full hardware system vs. 18 inch single system)

High Frequency: The results for the high frequency $\mathrm{IL}_{\max }$ comparison between the dual system and the single 18 inch system are displayed in Figure 25. The data appear to show both different means and strikingly different variances. An unequal variance t-test indicated that the two treatment groups were significantly different $(\mathrm{p}=0.0178)$. The graph of the data supported that result, as the variances were very different but the $\mathrm{IL}_{\max }$ values for the two groups did not overlap anywhere in their ranges.

\section{Study IIIa Discussion}

The dual system achieved $2 \mathrm{~dB}$ better ANC insertion loss over the 18 inch single system on average. While that difference is significant, it is not highly substantial. However, when the 1/3 octave band insertion loss values were plotted in Figure 26, there was a 
substantial difference between the two treatment groups for certain high frequency third octave bands. The dual system data points were denoted by "+" signs, and the 18 inch single system data points were denoted by open squares. The vertical line in the center of the figure marks the division between low and high frequency for the experiments. The mean difference between the groups at the $315 \mathrm{~Hz}$ band is $4 \mathrm{~dB}$. The effect is obscured somewhat from the decibel summation in the $\mathrm{IL}_{\max }$ result because the 18 inch single system had a slightly higher average insertion loss at the $400 \mathrm{~Hz}$ band. The $4 \mathrm{~dB}$ difference in means in this narrow range is of practical importance only if that frequency range is prominent in the source to be controlled.

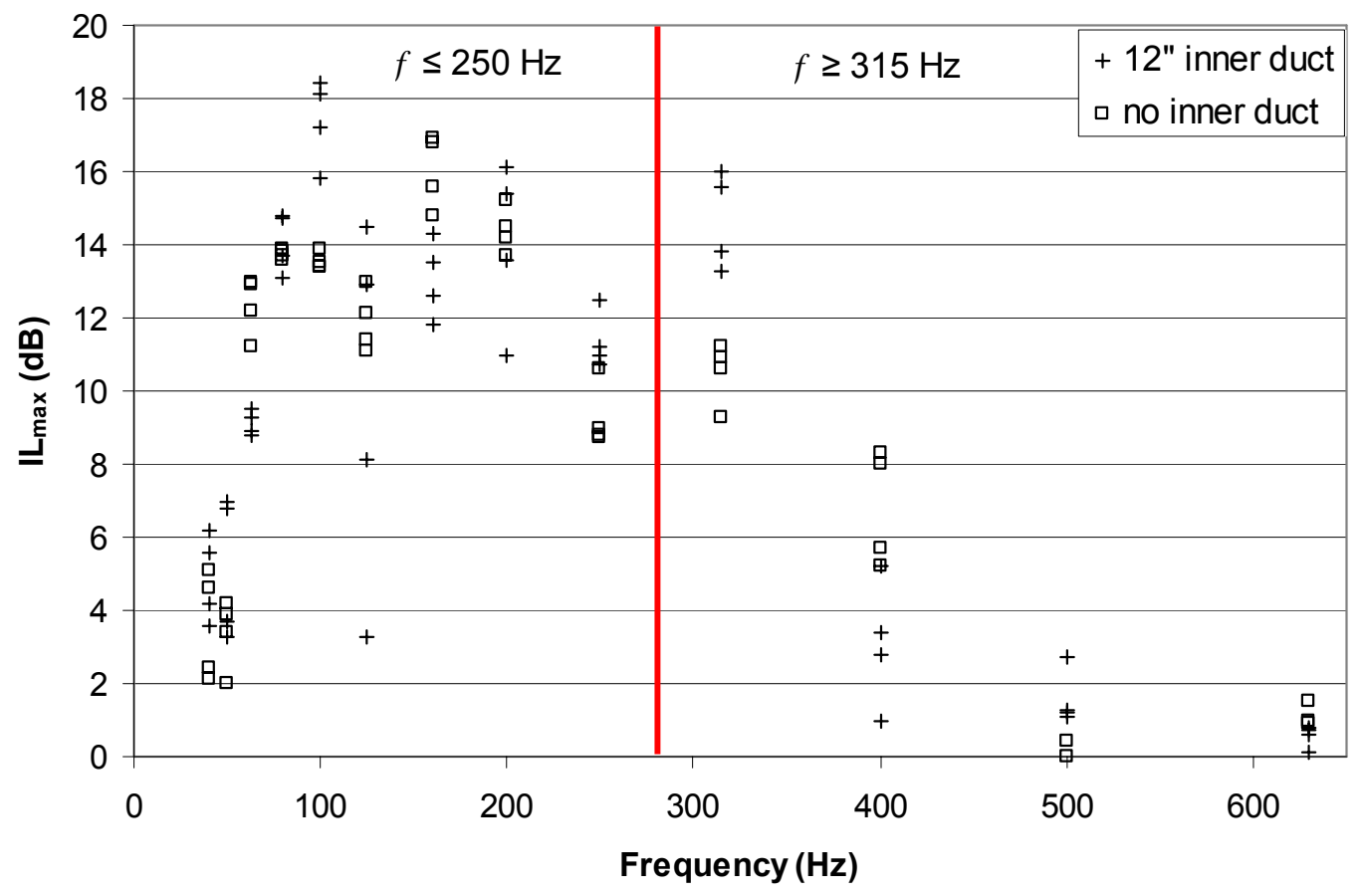

Figure 26. Study IIIa Results, ANC insertion loss by $1 / 3$ octave bands (Dual 12 inch full hardware system vs.

18 inch single system) 


\section{Study IIIa Conclusion}

The dual system achieved $2 \mathrm{~dB}$ better ANC insertion loss over the 18 inch single system on average. While that difference is significant, it is not highly substantial unless the individual $315 \mathrm{~Hz}$ third octave band is considered. This design may still be a viable option for some noise control strategies, depending on the frequency spectrum of the noise to be controlled. The second stage of the simultaneous dual-duct study (IIIb) was intended to increase the attractiveness of the strategy by reducing the hardware costs of the dual-duct system.

\section{Study IIIb: Simultaneous Dual-duct Operation with Reduced Hardware}

While Study IIIa confirmed the efficacy of the simultaneously-operated dual-duct system (using another round duct for the cross-sectional partitioning), it may be useful to reduce the hardware of the system components to decrease the cost of the intervention. As described in the unique apparatus section of this chapter, several hardware reduction schemes were attempted, but only one provided the ANC stability needed to conduct comparative experiments. The only reduced hardware option for the dual-duct system was to use the reference microphone inside the 12 inch diameter inner duct as the reference signal for both duct systems. Each duct (18 inch outer and 12 inch inner ducts) had separate ANC controller channels and separate control speaker signals and error microphones. Other than the single reference signal, the two systems were independent, but operating simultaneously.

\section{Study IIIb Model and Study Design}

Study IIIb was designed to test the hypothesis that there was no difference in $\mathrm{IL}_{\max }$ between the 18 inch ANC system alone and the dual ANC system with reduced hardware. The statistical model for this simple comparative experiment was:

$$
\mathrm{IL}_{i j}=\mu_{i}+\varepsilon_{i j}
$$

\section{Where:}

$\mathrm{IL}_{i j}=$ insertion loss in decibels $(\mathrm{dB})$

$\mu_{i}=$ average insertion loss at the $i^{\text {th }}$ factor level, $i=1,2, \ldots, a$

$\varepsilon_{i j}=$ random error $, j=1,2, \ldots, n$ 
This model was used to test the following hypothesis on the comparison of the two treatments:

$$
\begin{aligned}
& \mathrm{H}_{0}: \mu_{1}=\mu_{2} \\
& \mathrm{H}_{1}: \mu_{1} \neq \mu_{2}
\end{aligned}
$$

Stated non-mathematically, the hypothesis was:

$\mathrm{H}_{0}$ : No difference between the 18 inch duct system alone and the dual duct system operated simultaneously with reduced hardware

$\mathrm{H}_{1}$ : There is a difference

Power calculations indicated that, given the average variability in the preliminary tests $(s=1.72 \mathrm{~dB})$ and the desired detectable difference $(\delta=2.0 \mathrm{~dB})$, three replicates $(\mathrm{n}=3)$ were required to compare the means with $a=2$ treatment groups (single vs. dual with reduced hardware) with sufficient power $(\beta \leq 0.20)$ (Montgomery, 2001). The six runs were randomized to prevent any bias from order or time.

\section{Study IIIb Results}

Differing from previous results, significant differences were found for both the higher and the lower frequency range. 


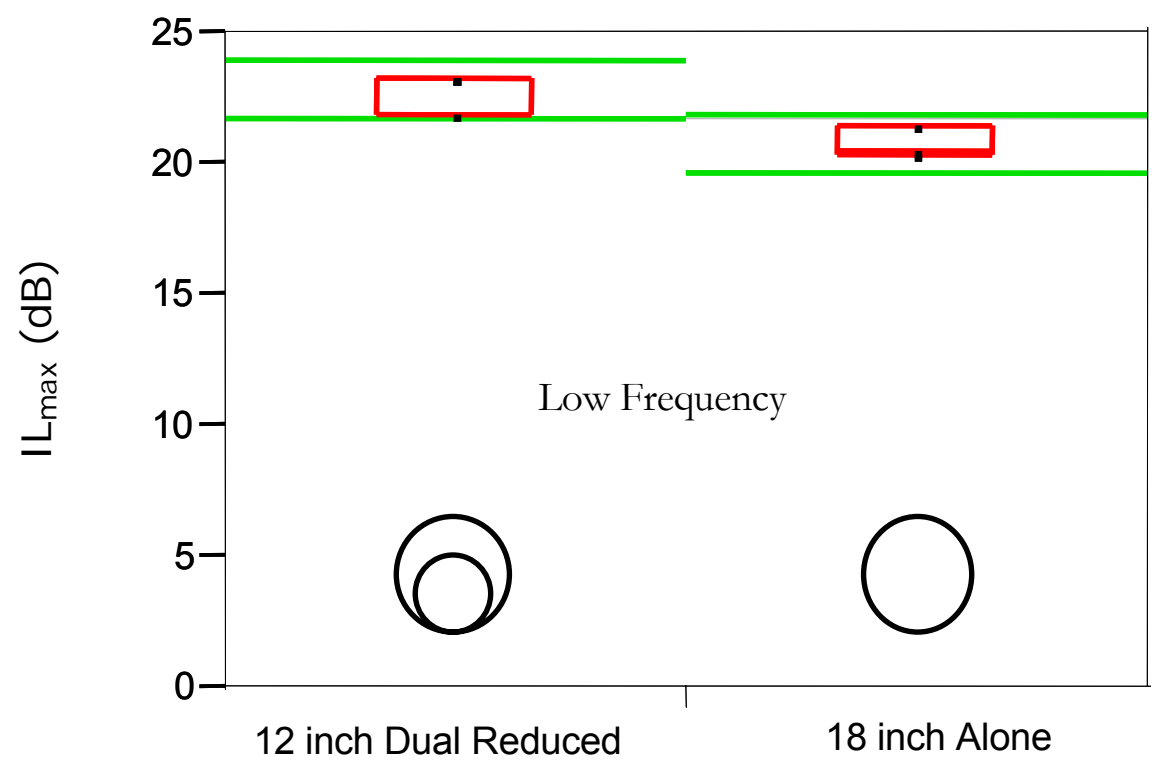

Treatment

Figure 27. Study IIIb Results, Low frequency comparison of $\mathrm{IL}_{\max }$ by treatment (Dual 12 inch reduced hardware system vs. 18 inch single system)

Low Frequency: The results for the low frequency $\mathrm{IL}_{\max }$ comparison between the reduced hardware dual system and the single 18 inch system are displayed in Figure 27. The means appear different, but the variances appear similar. An F-test on the equality of variances indicated that the variances were not significantly different $(\mathrm{p}=0.3848)$. An equal variance $t-$ test indicated that the two treatment groups were significantly different $(\mathrm{p}=0.0146)$. The graph of the data supported that result. Although the variances are not very different, the $\mathrm{IL}_{\max }$ values for the two groups do not overlap. At low frequency, the dual reduced system achieved $2 \mathrm{~dB}$ more $\mathrm{ANC}$ insertion loss on average. 


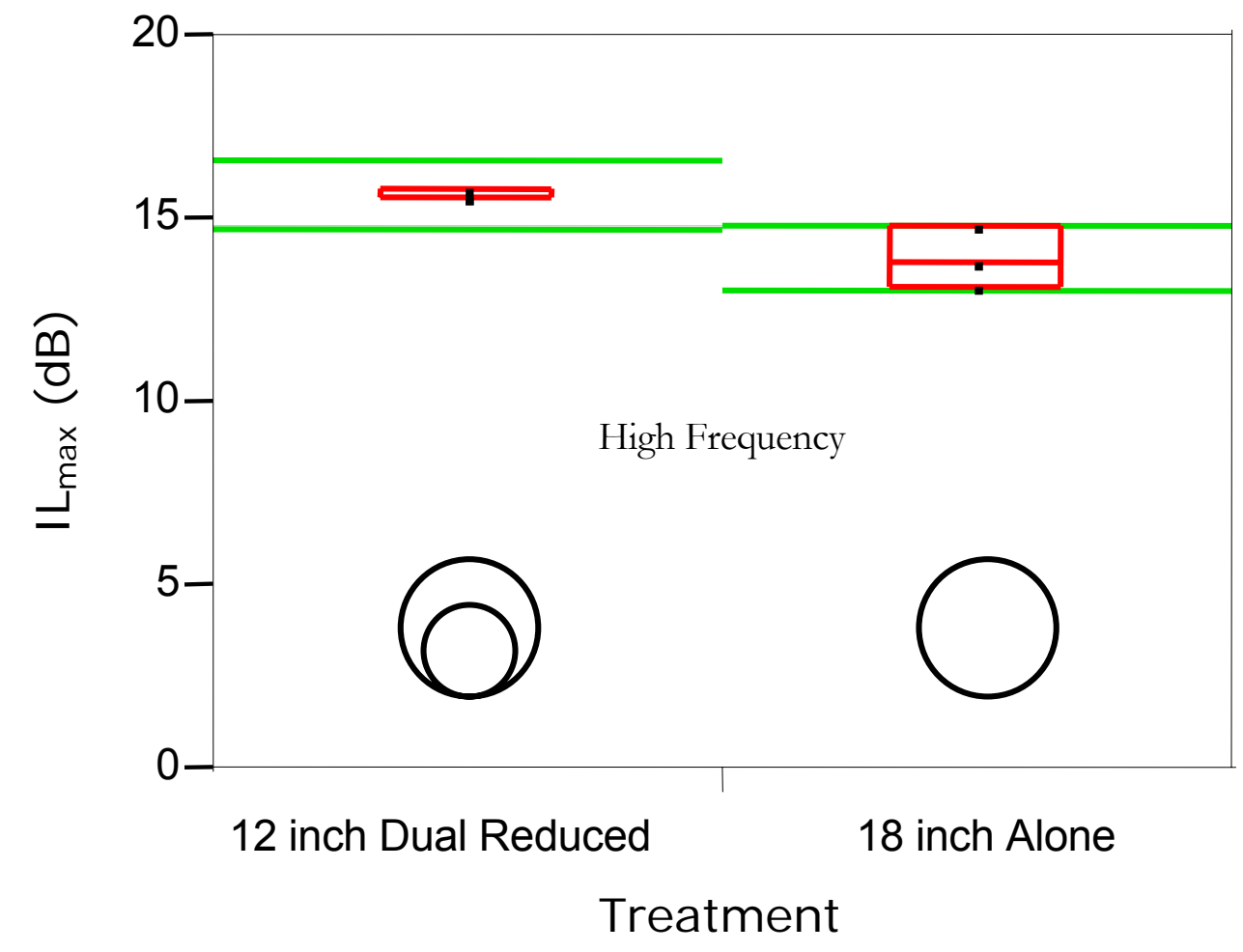

Figure 28. Study IIIb Results, High frequency
comparison of $\mathrm{IL}_{\max }$ by treatment (Dual 12 inch
reduced hardware system vs. 18 inch single system)

High Frequency: The results for the high frequency $\mathrm{IL}_{\max }$ comparison between the reduced hardware dual system and the single 18 inch system are displayed in Figure 28. The variances and the means of the data appear different. An F-test on the equality of variances indicated that the variances were significantly different $(\mathrm{p}=0.0257)$. An unequal variance $t$-test indicated that the two treatment groups were significantly different $(\mathrm{p}=0.0333)$. The graph of the data support that result, since the variances are very different but the $\mathrm{IL}_{\max }$ values for the two groups do not overlap. At high frequency, the dual system achieved $1.7 \mathrm{~dB}$ more ANC insertion loss on average.

\section{Study IIIb Discussion}

The dual system with reduced hardware achieved 1.7 to $2 \mathrm{~dB}$ better ANC insertion loss over the 18 inch single system on average. While that difference is significant, it is not at 
all substantial. Further investigation of the $1 / 3$ octave band insertion loss values (Figure 29) revealed that there was not the substantial difference between the two treatment groups for high frequency third octave bands that there was for the full hardware dual system in Study IIIa. The dual system data points were denoted by "+" signs, and the 18 inch single system data points were denoted by open squares. The vertical line in the center of the figure marks the division between low and high frequency for the experiments. The mean difference between the groups at the $315 \mathrm{~Hz}$ band is $2 \mathrm{~dB}$. In effect, the summary high and low frequency $\mathrm{IL}_{\max }$ values used in the comparison did not seem to obscure the underlying data. Although the difference in $\mathrm{IL}_{\max }$ for high and low frequency between the two treatments was significant, it was not substantial, even at individual $1 / 3$ octave bands.

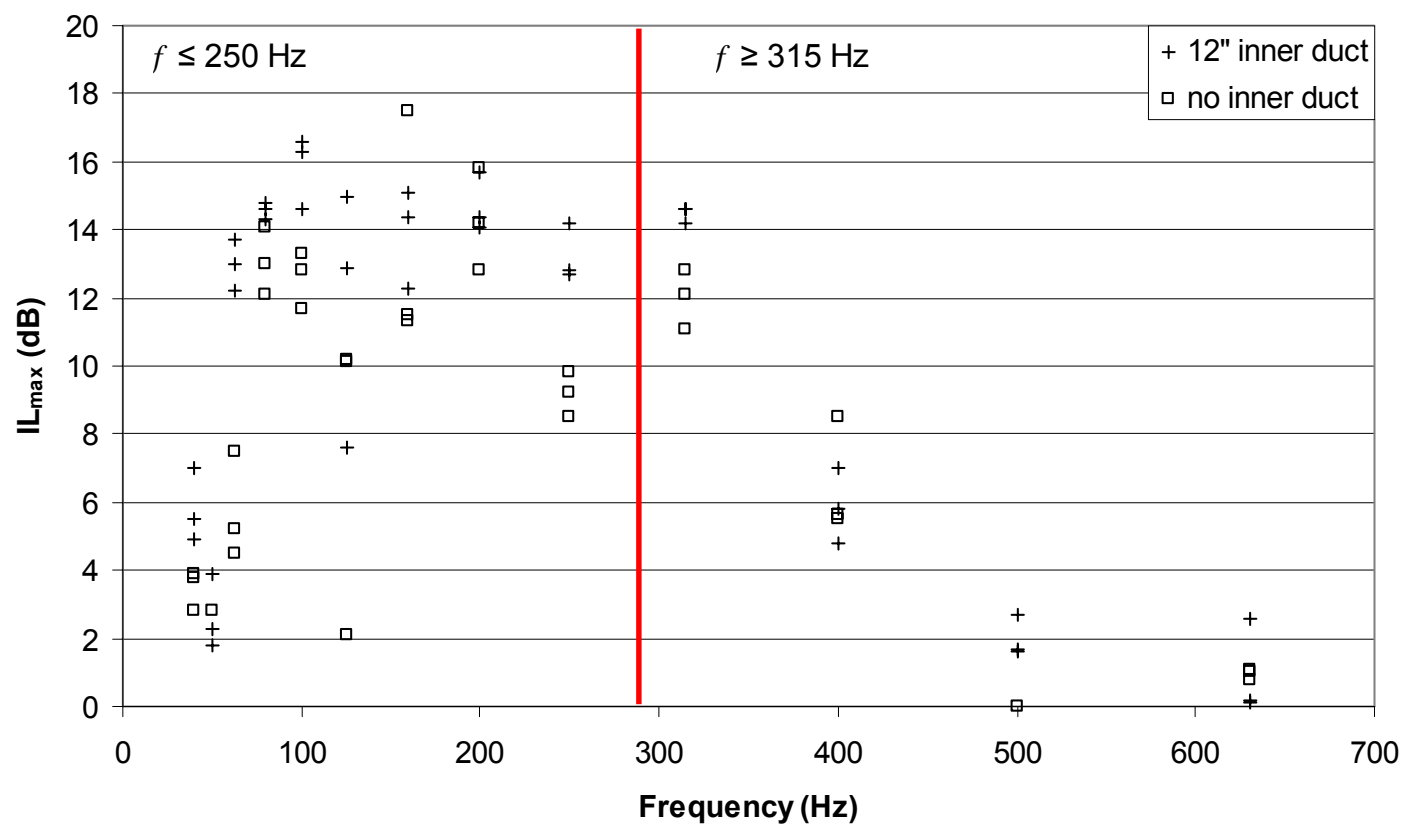

Figure 29. Study IIIb Results, ANC insertion loss by $1 / 3$ octave bands (Dual 12 inch reduced hardware system vs. 18 inch single system) 


\section{Study IIIb Conclusion}

The dual system with reduced hardware was significantly better, but not substantially better, than the 18 inch single system on average for both low and high frequency ranges. This design may still be a viable option for some noise control strategies, but only if the needed additional insertion loss were very small. The results indicated that a reduced hardware dualduct cross-sectional partitioning system could increase the high and low frequency ANC insertion loss on a large 18 inch outer duct. It is also important to keep in mind that the average ANC insertion loss for the reduced hardware dual duct system was $15.7 \mathrm{~dB}$ for high frequency and $22.8 \mathrm{~dB}$ for low frequency. Such insertion loss values are substantial with regards to noise control. 


\section{CHAPTER 5: STUDY IV - CROSS-SHAPED SPLIT'TER}

Partitioning with an inner duct was a marginal success. However, it is possible that dividing an 18 inch duct into quadrants would be more successful since the maximum free dimension would be much less. The fourth study was designed to test the ANC insertion loss in the 18 inch duct using the cross-shaped partition compared to ANC within the 18 inch outer duct alone.

\section{Study IV Unique Apparatus}

Study IV used the previously described 18 inch diameter outer duct, with a $24 \mathrm{ft}$ long cross-shaped plywood splitter inserted into the 18 inch duct. The 18 inch diameter duct was modified in that the control speakers at the tee area were mounted directly on the side wall for Study IV. Four control speakers were mounted at the 18 inch diameter tee at $21 \mathrm{ft}$ from the source speaker. Several preliminary tests kept all four quadrants live with separate ANC channels devoted to the individual quadrants. Although the cross-splitter was caulked at its center to reduce noise cross-contamination between quadrants, the ANC system was too unstable to have all four channels operating, most likely due to mutual interference. Even though the quadrants should have similar shape and noise traveling down their lengths, the single weighting system of the ANC controller could not adequately control the four individual quadrants. Therefore, the study was restricted to compare a single quadrant, with the other three quadrants blocked off, vs. the 18 inch diameter duct alone, as in Figure 30. The other three quadrants were blocked with a dense rubber sheet across the face sealed with duct tape, and acoustic foam stuffed inside the duct. 


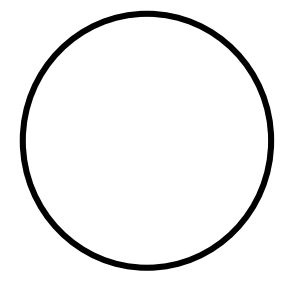

18 inch Duct Alone

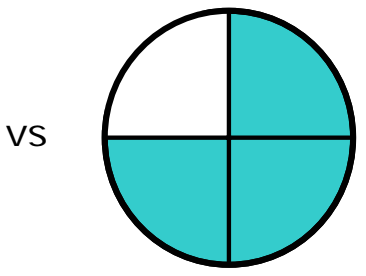

Single Quadrant

Figure 30. Study IV Apparatus, End view of comparison treatments

Since not all quadrants had "live" ANC systems in place, an external result microphone would not represent the two treatments. Instead, the comparisons used the error microphone signal, which was mounted at the same position for both treatments, $23 \mathrm{ft}$ along the duct.

\section{Study IV Model and Study Design}

Study IV was designed to test the hypothesis that there was no difference in $\mathrm{IL}_{\max }$ between the 18 inch ANC system alone and the single quadrant ANC system. The statistical model for this simple comparative experiment was:

$$
\mathrm{IL}_{i j}=\mu_{i}+\varepsilon_{i j}
$$

Where:

$\mathrm{IL}_{i j}=$ insertion loss in decibels $(\mathrm{dB})$

$\mu_{i}=$ average insertion loss at the $i^{\text {th }}$ factor level, $i=1,2, \ldots, a$

$\varepsilon_{i j}=$ random error $j=1,2, \ldots, n$

This model was used to test the following hypothesis on the comparison of the two treatments:

$$
\begin{aligned}
& \mathrm{H}_{0}: \mu_{1}=\mu_{2} \\
& \mathrm{H}_{1}: \mu_{1} \neq \mu_{2}
\end{aligned}
$$


Stated non-mathematically, the hypothesis was:

$\mathrm{H}_{0}$ : No difference between the 18 inch duct system alone and the single quadrant system

$\mathrm{H}_{1}$ : There is a difference

Power calculations indicated that, given the average variability in the preliminary tests $(s=0.81 \mathrm{~dB})$ and the desired detectable difference $(\delta=3 \mathrm{~dB})$, three replicates $(\mathrm{n}=3)$ were required to compare the means with $a=2$ treatment groups (18 inch vs. single quadrant) with sufficient power $(\beta \leq 0.20)$ (Montgomery, 2001). The six runs were randomized to prevent any bias from order or time.

\section{Study IV Results}

For this study, significant differences were found for both the higher and the lower frequency ranges. However, the partition was counter-productive for the low frequency range. 


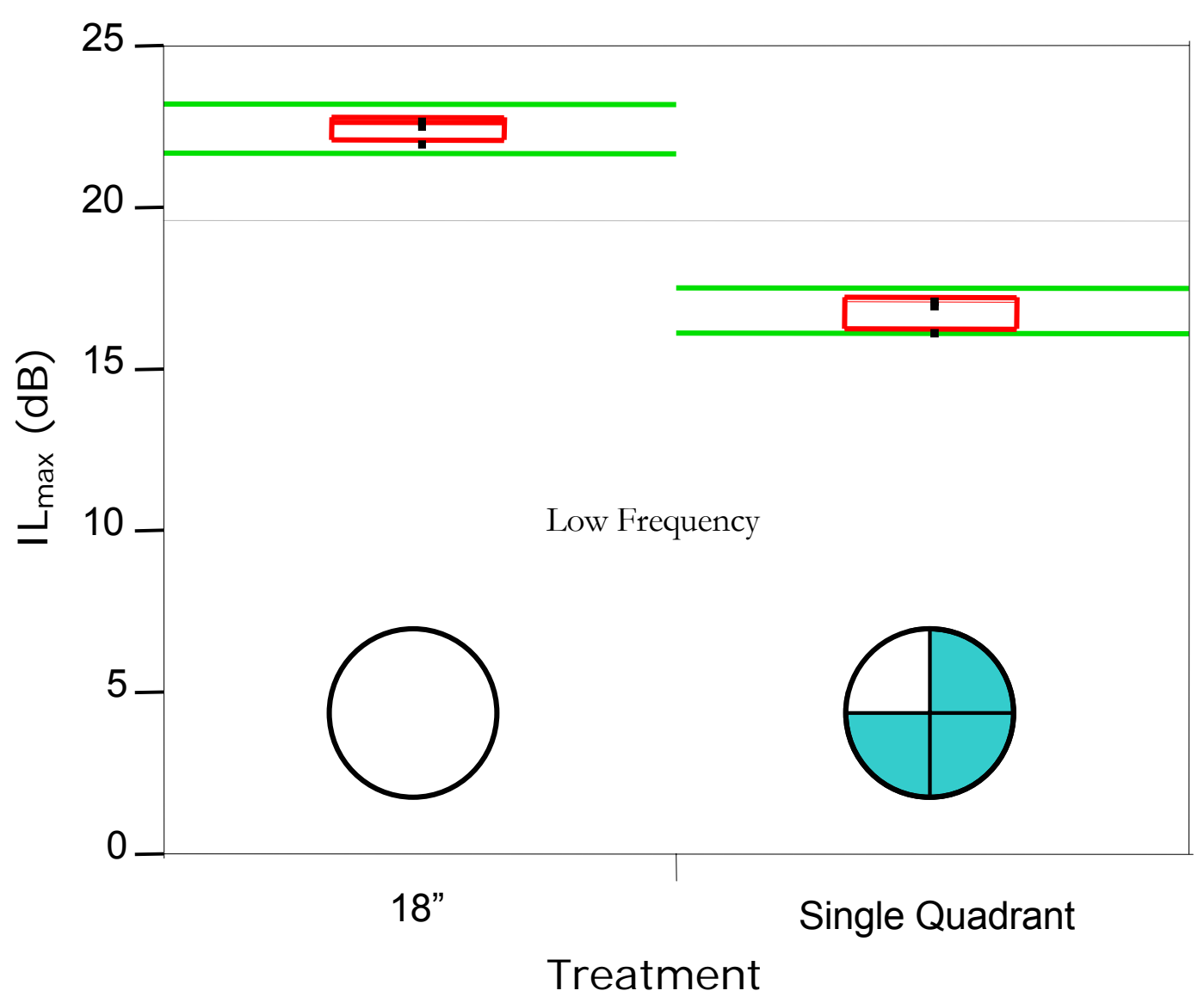

Figure 31. Study IV Results, Low frequency comparison of $\mathrm{IL}_{\max }$ by treatment (Single quadrant system vs. 18 inch duct system)

Low Frequency: The results for the low frequency $\mathrm{IL}_{\max }$ comparison between the single quadrant system and the 18 inch diameter duct system are displayed in Figure 31. The variances of the two groups did not appear different, but the means were very different. An Ftest on the equality of variances indicated that the variances were not significantly different $(\mathrm{p}=0.3055)$. An equal variance $\mathrm{t}$-test indicated that the two treatment groups were significantly different $(\mathrm{p}<0.0001)$. The graph of the data supported that result; the variances were not very different, and the $\mathrm{IL}_{\max }$ values for the two groups did not overlap. The single quadrant low frequency $\mathrm{IL}_{\max }$ values were $5.6 \mathrm{~dB}$ lower than the 18 inch diameter duct $\mathrm{ANC}$ system alone. The partition was counter-productive for the low frequency range. 


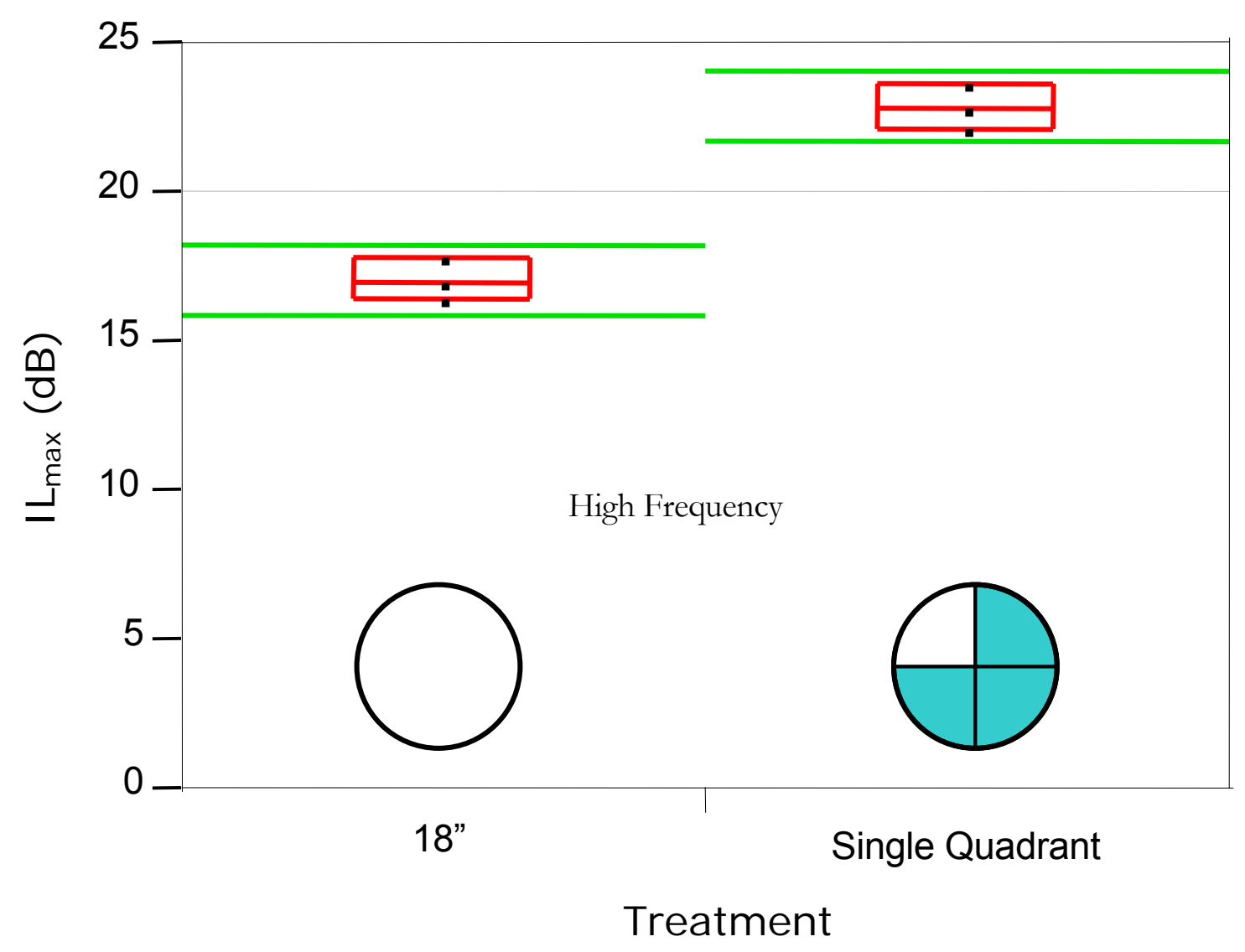

Figure 32. Study IV Results, High frequency comparison of $\mathrm{IL}_{\max }$ by treatment (Single quadrant system vs. 18 inch duct system)

High Frequency: The results for the high frequency $\mathrm{IL}_{\max }$ comparison between the single quadrant system and the 18 inch diameter duct system are displayed in Figure 32. The variances did not appear different, but the means did. An F-test on the equality of variances indicated that the variances were not significantly different $(\mathrm{p}=0.4905)$. An equal variance $t-$ test indicated that the two treatment groups were significantly different $(\mathrm{p}=0.0003)$. The graph of the data supported that result; the variances did not appear very different, and the $\mathrm{IL}_{\max }$ values for the two groups did not overlap. The single quadrant low frequency $\mathrm{IL}_{\max }$ values were $5.8 \mathrm{~dB}$ higher than the 18 inch diameter duct $\mathrm{ANC}$ system alone, a substantial improvement. 


\section{Study IV Discussion}

The single quadrant system achieved $5.8 \mathrm{~dB}$ higher ANC insertion loss over the 18 inch diameter system on average at high frequency, but $5.6 \mathrm{~dB}$ lower ANC insertion loss at low frequency. The difference (in both directions) is both significant and substantial. The $1 / 3$ octave band insertion loss values were plotted in Figure 33. The single quadrant system data points were denoted by "+" signs, and the 18 inch diameter duct system data points were denoted by open squares. The vertical line in the center of the figure marks the division between low and high frequency for the experiments. The mean difference between the groups at the $630 \mathrm{~Hz}$ band is $15.5 \mathrm{~dB}(17.8 \mathrm{~dB}$ for the single quadrant vs. $2.3 \mathrm{~dB}$ for the 18 inch duct system). Although some low frequency ANC insertion loss would be sacrificed by the cross-shaped splitter, the increase in high frequency ANC insertion loss would be quite substantial. Further, the high frequency ANC insertion loss for the single quadrant treatment extended out to $1000 \mathrm{~Hz}(8.1 \mathrm{~dB})$, which would help fill the frequency gap between passive and active noise control. 


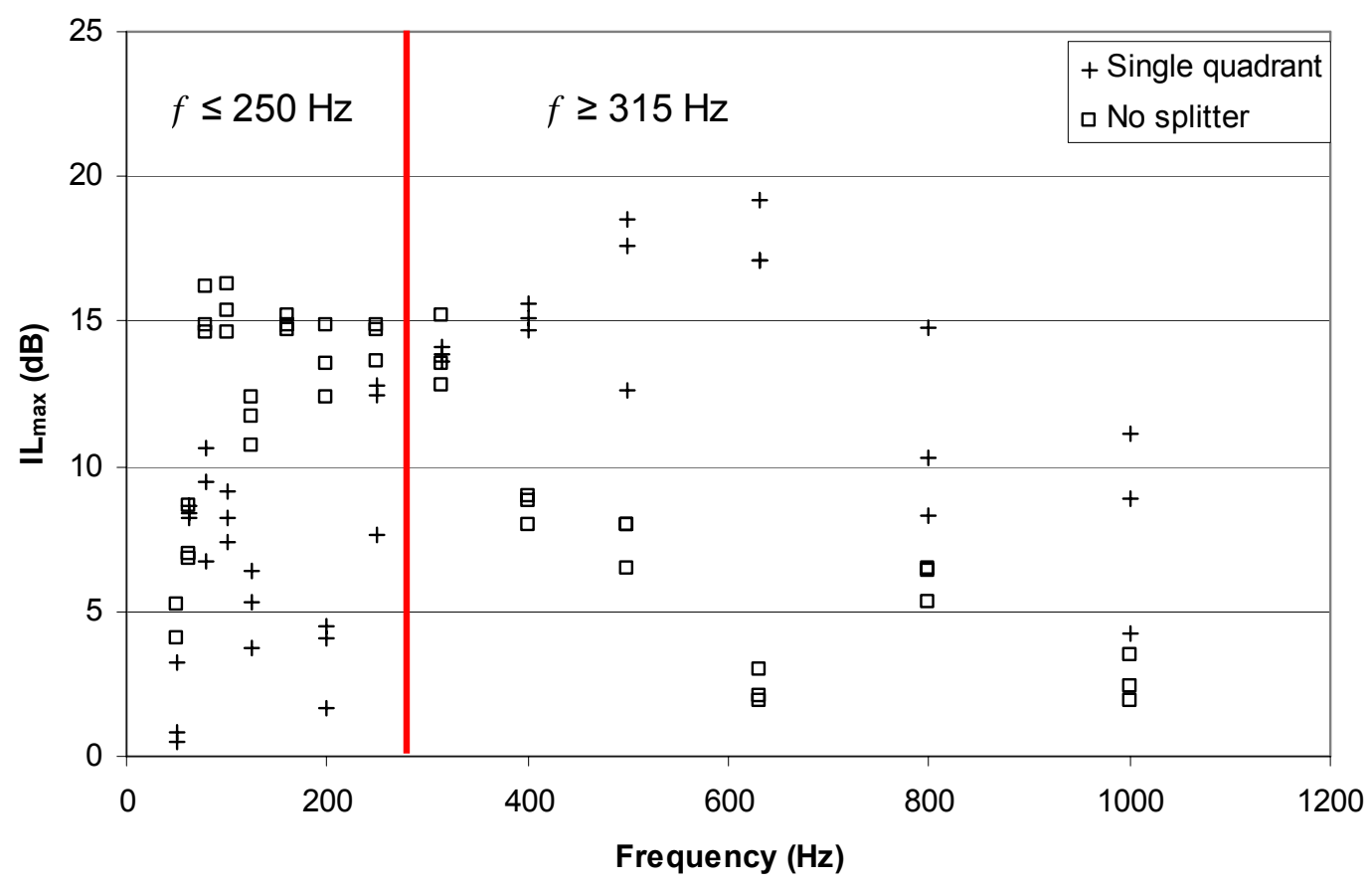

Figure 33. Study IV Results, ANC insertion loss by $1 / 3$ octave bands (Single quadrant system vs. 18 inch duct system)

\section{Study IV Conclusion}

While the ANC controller was not capable of having all four quadrants active at once, the single quadrant experiment of Study IV was very interesting. The average ANC insertion loss for the single quadrant system at $630 \mathrm{~Hz}$ was $17.8 \mathrm{~dB}$. If all four quadrants could be operated with a more advanced ANC controller, perhaps a cross-shaped cross-sectional partitioning of a large round duct would be the best design to extend active control of noise into the higher frequency regions. However, the loss of low frequency control would have to be considered.

The lower $\mathrm{IL}_{\max }$ at the low frequency regions for the single quadrant design may well have to do with the error microphone positioning. Less than $5 \mathrm{~dB}$ of insertion loss was achieved in the single quadrant at the $200 \mathrm{~Hz} 1 / 3$ octave band. The error microphone position relative to the duct and the control speaker may have been such that the ANC was 
less effective for low frequency, longer wavelength range. This same problem may be less important for the higher frequency, shorter wavelength range. This could explain some of the Study IV results. 


\section{DISCUSSION}

The p-values and summary results from all of the studies are displayed in Table 8.

Table 8. p-values and summary results from all studies to describe independent variables

\begin{tabular}{|c|c|c|c|c|c|}
\hline \multirow[b]{2}{*}{ Study } & \multirow[b]{2}{*}{ Variable } & \multirow[b]{2}{*}{$\mathbf{H}_{0}$} & \multirow[b]{2}{*}{ Test } & \multicolumn{2}{|c|}{ p-values and $\mathrm{IL}_{\max }$ difference } \\
\hline & & & & Low Frequency & High Frequency \\
\hline \multirow[t]{2}{*}{$\mathrm{Ia}$} & Rectangular & No effect of & 1-way & $p=0.3348$ & $\mathrm{p}=0.0220$ \\
\hline & dimension & horizontal dimension & ANOVA & (no effect) & $(16.2-14 \mathrm{~dB})$ \\
\hline \multirow[t]{3}{*}{$\mathrm{Ib}$} & Round & No effect of diameter & 1-way & $\mathrm{p}=0.4328$ & $\mathrm{p}=0.0024$ \\
\hline & diameter & & ANOVA & (no effect) & $(9.5 \mathrm{~dB})$ \\
\hline & & No effect of inner & & Diameter: $\mathrm{p}=0.1906$ & Diameter: $\mathrm{p}=0.4353$ \\
\hline \multirow{2}{*}{ IIa } & Inner duct & No effect of inner & 2-way & Position: $\mathrm{p}=0.0799$ & Position: $\mathrm{p}=0.1811$ \\
\hline & position & diameter, interaction & ANOVA & $\begin{array}{c}\text { Dia x Pos: } \mathrm{p}=0.1788^{*} \\
\text { (no effect) }\end{array}$ & $\begin{array}{c}\text { Dia x Pos: } \mathrm{p}=0.5283^{*} \\
\text { (no effect) }\end{array}$ \\
\hline \multirow[t]{2}{*}{$\mathrm{IIb}$} & Inner duct & No effect of inner & 1-way & $\mathrm{p}=0.0157$ & $\mathrm{p}=0.0020$ \\
\hline & diameter & duct diameter & ANOVA & (no effect) & $(3.7-4.4 \mathrm{~dB})$ \\
\hline \multirow[t]{2}{*}{ IIIa } & Simultaneous & No difference & & & \\
\hline & operation & $\begin{array}{l}\text { between } 18 \text { " duct } \\
\text { alone and dual-duct } \\
\text { simultaneously }\end{array}$ & t-test & $\begin{array}{l}\mathrm{p}=0.3749 \\
\text { (no effect) }\end{array}$ & $\begin{array}{c}\mathrm{p}=0.0178 \\
(2 \mathrm{~dB})\end{array}$ \\
\hline \multirow[t]{2}{*}{$\mathrm{IIIb}$} & Hardware & No difference & & & \\
\hline & combination & $\begin{array}{l}\text { between } 18 \text { " duct } \\
\text { alone and dual-duct } \\
\text { with single reference } \\
\text { microphone }\end{array}$ & t-test & $\begin{array}{c}\mathrm{p}=0.0146 \\
(2 \mathrm{~dB})\end{array}$ & $\begin{array}{l}\mathrm{p}=0.0333 \\
(1.8 \mathrm{~dB})\end{array}$ \\
\hline IV & $\begin{array}{l}\text { Cross-shaped } \\
\text { splitter }\end{array}$ & $\begin{array}{l}\text { No difference } \\
\text { between } 18 \text { " duct } \\
\text { alone and single } \\
\text { quadrant area }\end{array}$ & t-test & $\begin{array}{l}\mathrm{p}<0.0001 \\
(-5.6 \mathrm{~dB})\end{array}$ & $\begin{array}{l}\mathrm{p}=0.0003 \\
(5.8 \mathrm{~dB})\end{array}$ \\
\hline
\end{tabular}

*Equality of variances assumption may have been violated for two-way ANOVA for interaction p-value

For Study I, the change in duct dimensions did not improve the $\mathrm{IL}_{\max }$ values at low frequencies, but did at high frequencies. This was as expected given the equations (1 and 3) that describe the cut-on for higher order mode (and conversely, the plane wave) regions of the frequency spectrum for a given cross sectional area. The rectangular duct study (Ia) indicated up to a $16.2 \mathrm{~dB}$ increase in high frequency $\mathrm{IL}_{\max }$ by reducing the cross-sectional width. The round duct study $(\mathrm{Ib})$ indicated up to $9.5 \mathrm{~dB}$ increase in high frequency $\mathrm{IL}_{\max }$ by reducing duct diameter, confirming speculations by practitioners.

Studies II and III investigated the cross-sectional partitioning method of inserting a smaller round duct inside a larger round duct. Study IIa indicated that the inner duct could be 
placed at either the center of the larger duct, or tangent to one wall with the same results. The tangent position was chosen for ease of implementation. Study IIb showed that the inner duct diameter of a dual-duct system had an effect on both high and low frequency ANC insertion loss. However, follow-up multiple comparison tests showed that the several inner duct diameter treatments were not different from the large duct alone at low frequency. At high frequency, the 12 inch and 16 inch diameter inner duct treatments were significantly better than the 18 inch duct alone, with associated increase in $\mathrm{IL}_{\max }$ of 3.7 and $4.4 \mathrm{~dB}$, respectively.

Study III was designed to actually operate the dual-duct system simultaneously and compare it to the 18 inch duct ANC system alone. Study IIIa used two separate ANC systems with complete hardware (speakers and microphones) vs. 18 inch diameter duct ANC system alone. There was no difference between the two systems at low frequency, but there was a modest $2 \mathrm{~dB}$ increase in $\mathrm{IL}_{\max }$ for the dual-duct system at high frequency. Study IIIb used a reduced hardware configuration with a single reference microphone for the dual duct system vs. the 18 inch diameter duct ANC system alone. There was a significant but modest increase in $\mathrm{IL}_{\max }$ using the reduced hardware dual-duct system for both low $(2 \mathrm{~dB})$ and high $(1.8 \mathrm{~dB})$ frequency.

Finally, Study IV explored the cross-shaped splitter for cross-sectional partitioning. The $\mathrm{IL}_{\max }$ of the single pie-shaped quadrant system was significantly different from the 18 inch diameter duct ANC system alone, but with mixed results. At low frequency, the splitter degraded performance by $5.6 \mathrm{~dB}$ but improved performance by $5.8 \mathrm{~dB}$ at high frequency. Also, the single quadrant system resulted in ANC insertion loss of $17.8 \mathrm{~dB}$ at the $630 \mathrm{~Hz} 1 / 3$ octave band.

All of the studies indicated that active control of random broadband noise in ducts can be extended to higher frequencies by using either smaller duct dimensions (Study I), or crosssectional partitioning (Studies II, III, and IV). The most impressive high frequency partitioning results came from the cross-shaped splitter (Study IV), but there was a trade-off of low frequency ANC insertion loss.

The application of this research to industrial noise control problems would be most useful for environmental noise from exhaust stack situations. One concern would be the increase in pressure requirements to the exhaust fan. For instance, if an 18 inch diameter duct were to be replaced with smaller ducts of equal total cross-sectional area (see Figure 3), the 
number of ducts would increase quickly. Table 9 lists the duct diameters used in Study Ib to increase high frequency ANC insertion loss, with the number of ducts of that size needed to equal the same cross-sectional area of a single 18 inch diameter duct. The increase in fan pressure from twenty 4 inch diameter ducts would be large (about $\left(\mathrm{D}_{1} / \mathrm{D}_{2}\right)^{1.22}=\left(18 " / 4^{\prime \prime}\right)^{1.22}=$ 6.26" w.g. for each duct) (Guffey and Hickey, 1983). This is not to mention the increase in cost simply to purchase and install 20 ducts. Further, the ANC hardware costs would become considerable.

Table 9. Number of ducts needed to equal the crosssectional area of an 18 inch diameter duct

\begin{tabular}{cc}
$\begin{array}{c}\text { Duct diameter } \\
\text { Studied (in) }\end{array}$ & $\begin{array}{c}\text { \# ducts needed } \\
\text { for 18" area }\end{array}$ \\
\hline $4 "$ & 20 \\
$6 "$ & 9 \\
$8 "$ & 5 \\
$12 "$ & 2 \\
\hline
\end{tabular}

Therefore, the more modest gains of the cross-sectional partitioning methods may be attractive if the noise control problem could be solved with the ANC insertion loss levels reported in this research. It should be noted that ANC actually was highly effective in every test except when it was unstable. The modest differences between ANC in the 18 inch duct alone compared to the partitioning interventions were due to the fact that the $\mathrm{ANC}$ on the 18 inch duct worked well in the first place. The 18 inch duct ANC system typically achieved 14 $\mathrm{dB}$ of insertion loss at higher frequencies. The partitioning treatments achieved 16 to $23 \mathrm{~dB}$ ANC insertion loss. At lower frequencies, both the 18 inch system and the partitioning systems achieved over $20 \mathrm{~dB}$ of ANC insertion loss (except the cross-splitter). 


\section{CONCLUSION}

The research presented here indicated that active control of random broadband noise in ducts can be extended to higher frequencies by using either smaller duct dimensions (Study I), or cross-sectional partitioning (Studies II, III, and IV). The most impressive high frequency partitioning results came from the cross-shaped splitter (Study IV), but there was a trade-off of low frequency ANC insertion loss.

Further research in this vein would be useful on the cross-shaped splitter method of partitioning. While losing some low-frequency control, the impressive insertion loss in the range of 8.1 to $17.8 \mathrm{~dB}$ from 315 to $1000 \mathrm{~Hz}$ may make that method more attractive for some

specific industrial applications. Also, it would be useful to extend the diameter size study to 24 to 48 inches. One of the limitations of this research was that having an 18 inch duct did not seriously degrade the ANC performance. It would be better to start with a large duct that were so large that no ANC insertion loss could be achieved, then attempt partitioning strategies.

Active noise control has long been an area of interest for acousticians and noise control engineers. The hardware limitations and need for expertise in implementation have limited the industrial applications of ANC technology. One application to which ANC is particularly well-suited is noise control on exhaust stacks. ANC works well to reduce the low frequency "rumble" that can travel great distances and annoy neighboring communities. However, for broadband noise sources, even a combination of active and passive controls may fall short of complete broadband noise control. This research indicated that the use of either smaller ducts, or cross-sectional partitioning, can extend the frequency range of control of ANC methods to higher frequencies. By providing up to $17 \mathrm{~dB}$ of insertion loss at $630 \mathrm{~Hz}$, ANC may become more viable as an option for industrial noise control issues. 


\section{BIBLIOGRAPHY}

Beranek, L.L. (Ed.) (1960) Noise Reduction. McGraw-Hill Book Co., Inc., New York.

Bies, D.A., and C.H. Hansen. (2003) Engineering Noise Control: Theory and Practice, $3^{\text {rd }}$ Ed. Spon Press, New York.

Boudreau, A., A.L. L'Esperance, M. Bouchard, and B. Paillard. (2000) Actuators positioning for multichannel active control system in circular ducts. Applied Acoustics, 59 (2000), 323-335.

Brown, M.B., and A.B. Forsythe. (1974) Robust tests for the equality of variances. Journal of the American Statistical Association, 69 (346), 364-367.

Brown, M.B., and A.B. Forsythe. (1974a) The small sample behavior of some statistics which test the equality of several means. Technometrics, 16 (1), 129-132.

Chen, G., H. Wang, K. Chen, and K. Muto. (2005) A preprocessing method for multichannel feedforward active noise control. Acoustical Science and Technology, 26 (3), 292-295.

Cullum, D.J.W. (1949) The Practical Application of Acoustic Principles. E.\&F.N. Spon, Ltd., London.

Driscoll D.P., and L.H. Royster. (2000) Noise Control Engineering. In The Noise Manual, $5^{\text {th }}$ Ed. AIHA Press, Fairfax, VA: Pp. 279-378.

Egana, J.M., J. Diaz, and J. Vinolas. (2003) Active control of low-frequency broadband air-conditioning duct noise. Noise Control Engineering Journal, 51 (5), 292-299.

Eghtesadi, K., W.K.W. Hong, and H.G. Leventhall. (1986) Energy conservation by active noise attenuation in ducts. Noise Control Engineering Journal, 27, 90-94.

Eriksson, L.J. (1980) Higher order mode effects in circular ducts and expansion chambers. Journal of the Acoustical Society of America, 68(2), 545-550.

Eriksson, L.J., and M.C. Allie. (1988) A practical system for active attenuation in ducts. Sound and Vibration, February, 30-34.

Eriksson, L.J., M.C. Allie, R.H. Hoops, and J.V. Warner. (1989) Higher order mode cancellation in ducts using active noise control. Proceedings of Internoise '89, Newport Beach: 495-500.

Gordon, R.T., and W.D. Vining. (1992) Active noise control: A review of the field. American Industrial Hygiene Association Journal, 53 (11), 721-725.

Guffey, S.E., and J.L.S. Hickey. (1983) Equations for redesign of existing ventilation systems. American Industrial Hygiene Association Journal, 44 (11), 819-827. 
Gulyas, K., G. Pinte, F. Augusztinovicz, W. Desmet, and P. Sas. (2002) Active noise control in agricultural machines. Proceedings of International Conference of Noise and Vibration Engineering (ISMA) 2002, Vol I, Leuven, Belgium, Sep, pp. 11-22.

Hansen, C.H. (2001) Understanding Active Noise Cancellation. Spon Press, New York.

Kim, S., and Y. Park. (1999) Active control of multi-tonal noise with reference generator based on on-line frequency estimation. Journal of Sound and Vibration, 227 (3), 647-666.

Kino, G.S. (1987) Acoustic Waves: Devices, Imaging, and Analog Signal Processing. Prentice-Hall, Inc., Englewood Cliffs, New Jersey.

Kuo, S.M., and J. Tsai. (1993) Residual noise shaping technique for active noise control systems. Journal of the Acoustical Society of America, 95 (3), 1665-1668.

LaFontaine, R.F., and I.C. Shephard. (1991) Active control of plane wave noise in ducts. Acoustics Australia, 19 (3), 79-81.

Liu, S., and K.Y. Fung. (2002) Robust active control of broadband noise in finite ducts. Journal of the Acoustical Society of America, 111 (6), 2727-2734.

Mazanikov, A.A., V.V. Tyutekin, and A.T. Ukolov. (1977) An active system for the suppression of sound fields in a multimode waveguide. Akust. Zh., 23, 486-487. (English translation: Soviet Physics Acoustics. 23, 276-277).

Montgomery, D.C. (2001) Design and Analysis of Experiments, $5^{\text {th }}$ Ed. John Wiley and Sons, Inc., New York.

Norton, M.P., and D.G. Karczub. (2003) Fundamentals of Noise and Vibration Analysis for Engineers, $2^{\text {nd }} \mathrm{Ed}$. Cambridge University Press, Cambridge.

Okamoto, Y., H. Boden, and M. Abom. (1994) Active noise control in ducts via side-branch resonators. Journal of the Acoustical Society of America, 96 (3), 1533-1538.

Patel, D.S., K. Witte, C. Zuckerman, L. Murray-Johnson, V. Orrego, A.M. Maxfield, S. Meadows-Hogan, J. Tisdale, and E.D. Thimons. (2001) Understanding barriers to preventive health actions for occupational noise-induced hearing loss. Journal of Health Communication, 6, 155-168.

Pelton, H.K., S. Wise, and W.S. Sims. (1994) Active HVAC noise control systems provide acoustical comfort. Sound and Vibration, July, 14-18.

Poole, J.H.B., and H.G. Leventhall. (1976) An experimental study of Swinbank's method of active attenuation of sound in ducts. Journal of Sound and Vibration, 49 (2), 257-266.

Royster, L.H., and J.D. Royster [2000]. Education and Motivation, in The Noise Manual, $5^{\text {th }}$ Ed. E.H. Berger, L.H. Royster, J.D. Royster, D.P. Driscoll, and M. Layne, eds. AIHA Press: Fairfax, VA. 
Slagley, J.M., and S.E. Guffey (2006) Active noise control of stageloader noise in longwall mining. 2005 Transactions of the Society for Mining, Metallurgy, and Exploration, Inc., 318, 154-160.

Sommerfeldt, S.D., and T.O. Samuels. (2001) Incorporation of loudness measures in active noise control. Journal of the Acoustical Society of America, 109 (2), 591-599.

Snyder, S.D., and C.H. Hansen. (1989) Active noise control in ducts: Some physical insights. Journal of the Acoustical Society of America, 86 (1), 184-194.

Snyder, S.D. (2001) Active Control - a bigger microprocessor is not always enough. Noise Control Engineering Journal, 49 (1), 21-29.

Snyder, S.D., and N. Tanaka. (1993) To absorb or not to absorb: Control source power output in active noise control systems. Journal of the Acoustical Society of America, 94 (1), 185-195.

Swinbanks, M.A. (1973) The active control of sound propagation in long ducts. Journal of Sound and Vibration, 27 (3), 411-436.

Tanaka, M., Y. Yamada, and M. Shirotori. (1992) Boundary element method applied to simulation of active noise control in ducts. Japanese Society of Mechanical Engineers International Journal, Series III, 35 (3), 387-392.

Walker, B. (2001) Sensitivity issues in active control of circular duct modes using axially-spaced actuator arrays. Noise Control Engineering Journal, 49 (1), 6-20.

Welch, B.L. (1951) On the comparison of several mean values: An alternative approach. Biometrika, 38 (3/4) (Dec., 1951), 330-336.

Wu, Z., V.K. Varadan, and V.V. Varadan. (1996) Time-domain analysis and synthesis of active noise control systems in ducts. Journal of the Acoustical Society of America, 101 (3), 1502-1511.

Yuan, J. (2003) Improving robustness of active noise control in ducts. Journal of the Acoustical Society of America, 114 (1), 210-217.

Zander, A.C., and C.H. Hansen. (1992) Active control of higher order acoustic modes in ducts. Journal of the Acoustical Society of America, 92 (1), 244-257.

Zhou, J., and T. Shi. (1991) On the study of the active attenuation of noise in an L-formed duct. Applied Acoustics, 34, 181-191.

Zimmer, B.J., S.P. Lipshitz, K.A. Morris, J. Vanderkooy, and E.E. Obasi. (2003) An improved acoustic model for active noise control in a duct. Transactions of the ASME, 125, 382-395. 